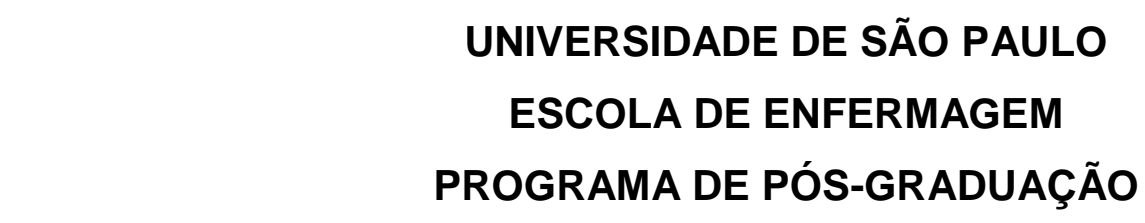

MESTRADO PROFISSIONAL EM ENFERMAGEM NA ATENÇÃO PRIMÁRIA EM SAÚDE NO SISTEMA ÚNICO DE SAÚDE

VANDERLÉA APARECIDA SILVA GONZAGA

BARREIRAS ORGANIZACIONAIS PARA DISPONIBILIZAÇÃO DO DISPOSITIVO INTRAUTERINO NOS SERVIÇOS DE ATENÇÃO BÁSICA À SAÚDE (MACRORREGIÃO SUL DE MINAS GERAIS) 



\title{
BARREIRAS ORGANIZACIONAIS PARA DISPONIBILIZAÇÃO DO DISPOSITIVO INTRAUTERINO NOS SERVIÇOS DE ATENÇÃO BÁSICA À SAÚDE (MACRORREGIÃO SUL DE MINAS GERAIS)
}

\begin{abstract}
Dissertação apresentada ao Programa de Pós-Graduação Mestrado Profissional em Enfermagem na Atenção Primária em Saúde no Sistema Único de Saúde, da Escola de Enfermagem da Universidade de São Paulo, para obtenção do Título de Mestre em Ciências da Saúde.
\end{abstract}

Área de Concentração: Cuidado em Atenção Primária em Saúde

Orientadora: Prof. ${ }^{\text {a }}$ Dr. ${ }^{\text {a }}$ Ana Luiza Vilela Borges

\section{São Paulo}


AUTORIZO A REPRODUÇÃO TOTAL OU PARCIAL DESTE TRABALHO, POR QUALQUER MEIO CONVENCIONAL OU ELETRÔNICO, PARA FINS DE ESTUDO E PESQUISA, DESDE QUE CITADA A FONTE.

Assinatura: Data

Catalogação na Publicação (CIP)

Biblioteca "Wanda de Aguiar Horta"

Escola de Enfermagem da Universidade de São Paulo

Gonzaga, Vanderléa Aparecida Silva

Barreiras organizacionais para disponibilização do dispositivo intrauterino nos Serviços de Atenção Básica à Saúde (Macrorregião Sul de Minas Gerais) / Vanderléa Aparecida Silva / São Paulo; 2016.

$151 \mathrm{p.}$

Dissertação (Mestrado) - Escola de Enfermagem da Universidade de São Paulo.

Orientadora: Profa. Dra. Ana Luiza Vilela Borges

1. Dispositivos intrauterinos. 2. Planejamento familiar. 3. Saúde reprodutiva. I. Título. 
Nome: Vanderléa Aparecida Silva Gonzaga

Título: Barreiras Organizacionais para Disponibilização do Dispositivo Intrauterino nos Serviços de Atenção Básica à Saúde (Macrorregião Sul de Minas Gerais)

Dissertação apresentada ao Programa de Pós-Graduação, Mestrado Profissional em Enfermagem na Atenção Primária em Saúde no Sistema Único de Saúde, da Escola de Enfermagem da Universidade de São Paulo, para obtenção do título de Mestre em Ciências da Saúde.

Aprovado em:

\section{Banca Examinadora}

Prof. Dr. Instituição:

Julgamento: Assinatura:

Prof. Dr. Instituição:

Julgamento: Assinatura:

Prof. Dr. Instituição:

Julgamento: Assinatura: 



\section{DEDICATÓRIA}

A Deus.

Ao meu esposo Edson e a minha filha Gabriela. 



\section{AGRADECIMENTOS}

A Deus que, por seu imenso amor e misericórdia, permitiu a realização de mais um sonho, me orientando e me protegendo em todos os momentos.

A minha orientadora, Ana Luiza, que aceitou me orientar e que com seu profundo conhecimento e paciência direcionou todos meus passos durante a pesquisa. Querida Ana, muito obrigada pela oportunidade de tê-la como orientadora, por tantos ensinamentos e principalmente por ter acreditado e não ter desistido de mim. Sintome honrada por ter desenvolvido esta pesquisa sob sua orientação.

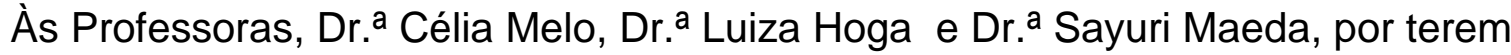
aceitado, cordialmente, o convite para participar da banca de qualificação e pelas grandes contribuições para o projeto.

A todos os docentes e profissionais da Escola de Enfermagem da Universidade de São Paulo (USP) por terem contribuído para minha formação como Mestre e como

pessoa.

Ao meu esposo Edson e a minha filha Gabriela por terem me incentivado e apoiado em todos os momentos. Meus amores, muito obrigada por respeitarem a minha escolha e por caminharem comigo. Ter vocês ao meu lado me fez sentir mais forte e capaz. Muito obrigada por todo amor, carinho e cuidado. 

À memória da minha mãe e do meu pai, e a todos os meus familiares e amigos.

Aos meus queridos amigos da pós-graduação, que dividiram comigo os prazeres e os desprazeres desse período, e que tanto me ajudaram e me incentivaram: Aline, Vânia, Evelim, Alexandre, Selma, Douglas e Ana Carolina.

Agradeço também às amigas da Pós-Graduação (Mestrado e Doutorado) em Enfermagem, que tanto me ajudaram: Christiane, Osmara, Natália e Karina.

Aos profissionais de saúde dos municípios do Sul de Minas, que apesar de sobrecarregados de trabalho, gentilmente aceitaram participar da pesquisa.

Aos Superintendentes Regionais de Saúde e funcionários das Regionais de Saúde do Sul de Minas, que atenciosamente responderam às minhas solicitações.

Aos Secretários de Saúde dos municípios participantes da pesquisa, por terem atendido as minhas solicitações e por terem autorizado a coleta de dados nesses municípios.

A todos que não foram citados, mas que, de alguma forma contribuíram para a realização desta pesquisa. Muito obrigada! 

Talvez não tenha conseguido fazer o melhor, mas lutei para que o melhor fosse feito. Não sou o que deveria ser, mas graças a Deus, não sou o que era antes (Marthin Luther King). 

Gonzaga VAS. Barreiras organizacionais para disponibilização do dispositivo intrauterino nos serviços de Atenção Básica à Saúde (macrorregião Sul de Minas Gerais) [dissertação]. São Paulo: Escola de Enfermagem, Universidade de São Paulo; 2016.

\section{RESUMO}

Embora o dispositivo intrauterino (DIU) seja pouco usado no Brasil, ele é o método contraceptivo reversível mais usado no mundo. Trata-se de um método seguro, altamente eficaz e com resultados positivos na saúde das populações. Por meio da prevenção de gestações não planejadas, atua na redução da morbidade e mortalidade materna, mortalidade infantil e abortos inseguros. Pesquisas recentes, contudo, mostram que o acesso ao DIU nos serviços de Atenção Básica à Saúde nem sempre é facilitado, sendo permeado por barreiras organizacionais que contribuem para sua subutilização. Tais barreiras podem restringir o pleno exercício dos direitos sexuais e reprodutivos das mulheres brasileiras. Objetivo: Identificar barreiras organizacionais para disponibilização do DIU nos serviços de Atenção Básica à Saúde e elaborar, como produto desta dissertação, uma síntese destas barreiras, destinada aos gestores de saúde, com suas implicações e recomendações. Método: Estudo quantitativo, descritivo. A coleta de dados foi realizada por meio do preenchimento de um instrumento estruturado, online, pelos 79 profissionais responsáveis pela área técnica de Saúde da Mulher. O cenário do estudo foi a macrorregião Sul de Minas Gerais. A análise dos dados foi realizada por meio do software Stata, versão 14.0, e descrita por meio de número absoluto e proporções. Resultados: A maioria dos municípios possui protocolo de atenção à saúde da mulher $(55,7 \%)$. Destes, $77,3 \%$ elaboraram seu próprio protocolo, mas $29,6 \%$ não treinaram a equipe de saúde para usá-lo. Dentre todos os municípios participantes, 15,2\% não disponibilizam DIU, sendo que alguns também não referenciam a mulher para outros serviços $(8,3 \%)$. Dentre aqueles que disponibilizam o DIU, a grande maioria não possui protocolo específico (68,7\%); uma parcela não adota a gravidez como condição impossibilitante da inserção do DIU $(10,5 \%)$ e, por outro lado, adotam condições menos relevantes como infecção vaginal (80,6\%). Como critério para acesso ao DIU, $86,5 \%$ referiram prescrição médica, $71,6 \%$ realização de exames, 44,6\% idade acima de 18 anos e $24,4 \%$ participação em grupos. Como exames necessários, foi citado o Papanicolaou $(94,7 \%)$, teste de gravidez (63,2\%) e exame de sangue $(29,8 \%)$. Quanto ao local de disponibilização, 83,7\% não o disponibilizam nas Unidades Básicas de Saúde. Como profissional que insere o DIU, 97,0\% referiram médico e nenhum citou o enfermeiro. Quanto aos grupos de planejamento reprodutivo, 43,0\% dos municípios não os realizam. Por fim, $86,1 \%$ dos trabalhadores reportaram não haver dificuldades para obtenção do DIU. Conclusão: Foram identificadas barreiras organizacionais que dizem respeito ao uso de protocolos, também barreiras relacionadas à disponibilização e inserção do DIU, e barreiras relativas aos grupos de planejamento reprodutivo.

PALAVRAS-CHAVE: Dispositivo intrauterino; Planejamento familiar; Saúde sexual e reprodutiva; Atenção primária à saúde. 

Gonzaga VAS. Organizational barriers to providing the intrauterine device in Primary Health Attention services (macro-region in the southern of Minas Gerais) [dissertation]. São Paulo (SP), Brasil: Escola de Enfermagem, Universidade de São Paulo; 2016.

\section{ABSTRACT}

Introduction: Although the intrauterine device (IUD) is little used in Brazil, it is the most used reversible contraceptive method in the world. It is about a safe method, highly effective and with positive results in the health of populations. By means of preventing unplanned pregnancies, it works to reduce maternal morbidity and mortality, infant mortality and unsafe abortions. Recent research, however, show that access to IUD in Primary Health Attention services is not always facilitated, being permeated by organizational barriers that contribute to their underutilization. Such barriers may restrict the full exercise of sexual and reproductive rights of Brazilian women. Objective: To identify organizational barriers for providing IUD in the Primary Health Attention services and elaborate, as a product of this dissertation, a summary of these barriers, which is intended for health managers, with their implications and recommendations. Method: Qualitative, descriptive study. Data collection was performed by completing, online, a structured instrument, by 79 professionals responsible for the technical field of Women's Health. The study setting was the macroregion in the southern of Minas Gerais. Data analysis was performed using Stata software, version 14.0, and described by absolute number and proportions. Results: Most municipalities have attention protocol to women's health (55.7\%). Of these, $77.3 \%$ developed its own protocol, but $29.6 \%$ did not train health staff to use it. Among all participating municipalities, $15.2 \%$ do not offer IUD, and some did not refer women to other services (8.3\%). Among those, which provide the IUD, the vast majority do not have specific protocol (68.7\%); a portion does not adopt pregnancy as an impeditive condition of insertion of the IUD (10.5\%) and, on the other hand, adopt less relevant conditions such as vaginal infection (80.6\%). As a criterion for accessing the IUD, $86.5 \%$ reported prescription, $71.6 \%$ exams, $44.6 \%$ aged over 18 years old and $24.4 \%$ participation in groups. As required exams, it was quoted the Pap smear (94.7\%), pregnancy test $(63,2 \%)$ and blood tests $(29,8 \%)$. As a place of availability, $83.7 \%$ do not provide in the Basic Health Units. As a professional to insert the IUD, $97.0 \%$ reported the doctor and none cited the nurse. Municipalities do not realize reproductive planning group at $43.0 \%$. Finally, $86.1 \%$ of workers reported not having difficulties in obtaining the IUD. Conclusion: Organizational barriers were identified concerning the use of protocols, also barriers related to the availability and IUD insertion, and barriers related to the reproductive planning groups.

KEYWORDS: Intrauterine device; Family planning; Sexual and reproductive health; Primary Health Attention. 



\section{LISTA DE ILUSTRAÇÕES}

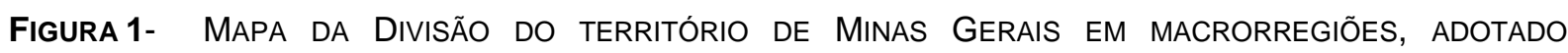
OFICIALMENTE PELO GOVERNO ESTADUAL (MG, 2015).

Figura 2 - MAPA dA divisão administrativa de saúde dA MAcrorregião Sul de Minas GERAIS.

Figura 3 - Diagrama de protocolo de ATEnÇÃo À SaÚde da Mulher. Macrorregião SUl de Minas GERAIS, 2016. 66

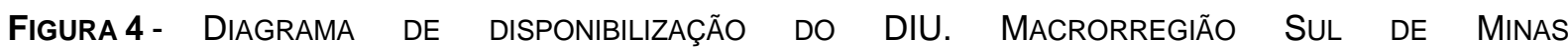
GERAIS, 2016. 67

FIGURA 5 - CRITÉRIOS ESTABELECIDOS PELOS SERVIÇOS DE SAÚDE PARA DISPONIBILIZAÇÃO DO DIU, DENTRE OS MUNICÍPIOS QUE O DISPONIBILIZAM. MACRORREGIÃo SUL DE MINAS GERAIS, 2016 68

FIGURA 6 - TIPOS DE EXAMES NECESSÁRIOS PARA DISPONIBILIZAÇÃO DO DIU, DENTRE OS MUNICÍPIOS QUE DECLARARAM REALIZAÇÃo dE EXAMES COMO CRITÉRIO. MACRORREGIÃo SUL dE MINAS GERAIS, 2016. 69

Figura 7 - FormAS dE AGENDAMENTO DE CONSULTA, CASO A MULHER TENHA INTERESSE EM USAR O DIU, DENTRE OS CRITÉRIOS DOS MUNICÍPIOS. MACRORREGIÃO SUL DE MINAS GERAIS, 2016. 69

FIGURA 8 - LOCAIS DE DISPONIBILIZAÇÃO DO DIU, DENTRE OS MUNICÍPIOS QUE O DISPONIBILIZAM. MACRORREGIÃo SUL dE MINAS GERAIS, 2016. 70

Figura 9 - MunicíPIOS QUE REALIzAM GRUPOS EDUCATIVOS DE PLANEJAMENTO REPROdUtivo. MACRORREGIÃo SUL DE MINAS GERAIS, 2016. 72

QUADRO 1 - SÍNTESE DAS BARREIRAS ORGANIZACIONAIS PARA DISPONIBILIZAÇÃO DO DIU IDENTIFICADAS NOS Serviços de Atenção Básica À Saúde em Municípios da Macrorregião Sul de Minas GeraIS. MACRORREGIÃo SUL de Minas GeRAIS, 2016. 



\section{LISTA DE TABELAS}

TABELA 1 - MunicíPIOS QUE AUtORIZARAM A COLETA DE DADOS, SEGUNDO AS SRS. MACRORREGIÃO SUL DE MINAS GERAIS, 2016.

Tabela 2 - Características das SuperintendÊnCias Regionais de Saúde. MacrorRegião Sul dE MinAS GERAIS, 2016.

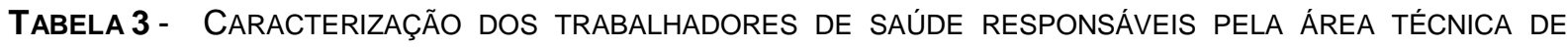

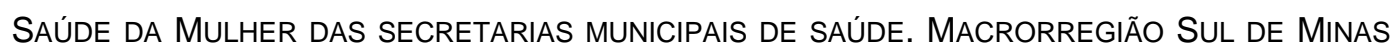
GERAIS, 2016.

TABELA 4 - CONSIDERAÇÕES dE TRABALHADORES de SAÚdE RESPONSÁVEIS PELA ÁREA TÉCNICA DE SAÚdE DA MULHER QUE REPORTARAM HAVER DIFICULDADES OU FACILIDADES PARA AS MULHERES OBTEREM O DIU. MACRORREGIÃo SUL DE MINAS GERAIS, 2016. 65

TABELA 5 - ROTINAS PARA INSERÇÃO DO DIU, SEGUNDO A EXISTÊNCIA DE PROTOCOLO DE DISPONIBILIZAÇÃO DO DIU dO MUNICÍPIO. MACRORREGIÃo SUL DE MINAS GERAIS, 2016.

TABELA 6 - CONDIÇÕES QUE PODEM IMPOSSIBILITAR A INSERÇÃO DO DIU, SEGUNDO PROTOCOLO DE DISPONIBILIZAÇÃO DO DIU. MACRORREGIÃO SUL DE MINAS GERAIS, 2016

TABela 7 - Organização dos grupos educativos de planejamento reprodutivo. Macrorregião SUL DE MINAS GERAIS, 2016.

TABELA 8 - DISPONIBILIZAÇÃO DE OUTROS MÉTODOS CONTRACEPTIVOS, SEGUNDO DISPONIBILIZAÇÃO DO DIU. MACRORREGIÃO SUL DE MINAS GERAIS, 2016.

TABELA 9 - LocAIS DE DISPONIBILIZAÇÃO DE OUTROS MÉTOdOS CONTRACEPTIVOS, SEGUNDO DISPONIBILIZAÇÃO DO DIU. MACRORREGIÃO SUL DE MINAS GERAIS, 2016. 75 



\section{LISTA DE SIGLAS}

ACS - $\quad$ Agente Comunitário de Saúde

AIDS - $\quad$ Síndrome da Imunodeficiência Adquirida

CIPD - $\quad$ Conferência Internacional sobre População e Desenvolvimento

CIR - Comissão Intergestores Regional

DIP - Doença Inflamatória Pélvica

DIU - Dispositivo Intrauterino

DST - $\quad$ Doença Sexualmente Transmissível

ESF - $\quad$ Estratégia Saúde da Família

FENSG - Faculdade de Enfermagem Nossa Senhora das Graças

HIV - $\quad$ Acquired Immunodeficiency Syndrome

LNG - Levonorgestrel

MS - $\quad$ Ministério da Saúde

OMS - $\quad$ Organização Mundial da Saúde

ONU - $\quad$ Organização das Nações Unidas

PACS - $\quad$ Programa de Agentes Comunitários de Saúde

PAISM - $\quad$ Programa de Assistência Integral à Saúde da Mulher

PMI - $\quad$ Programa Materno Infantil

PNDS - Pesquisa Nacional de Demografia e Saúde

PSF - $\quad$ Programa de Saúde da Família

SRS - $\quad$ Superintendência Regional de Saúde

SUS - $\quad$ Sistema Único de Saúde

TCLE - $\quad$ Termo de Consentimento Livre e Esclarecido

UFMG - Universidade Federal de Minas Gerais

UPE - $\quad$ Universidade de Pernambuco

USG - Ultrassonografia

USP - $\quad$ Universidade de São Paulo 



\section{SUMÁRIO}

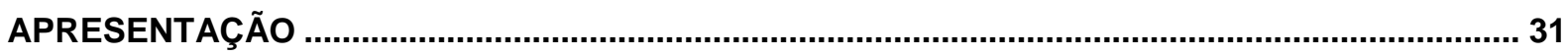

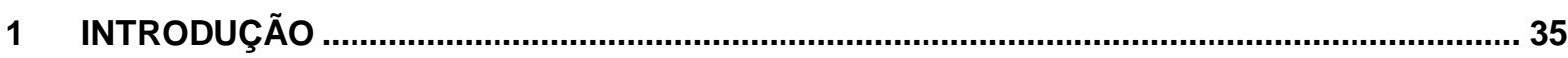

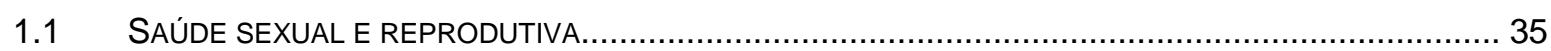

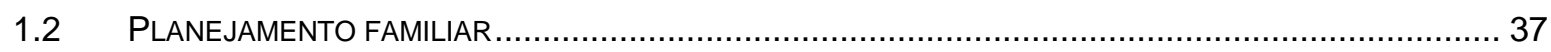

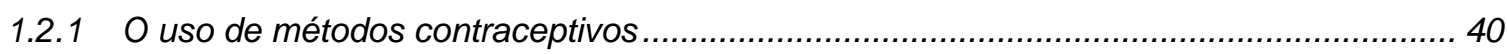

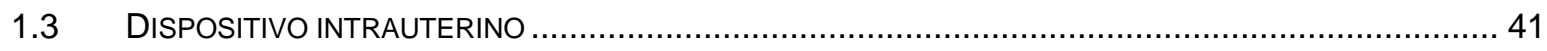

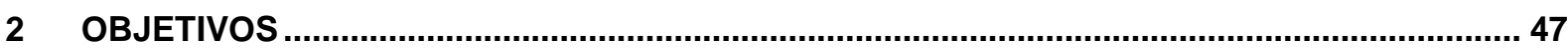

3 MÉTODO

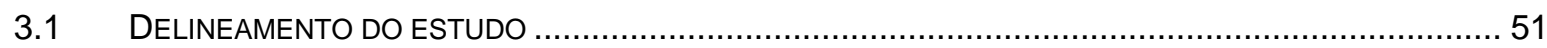

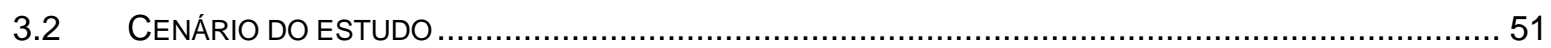

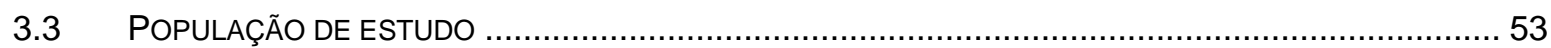

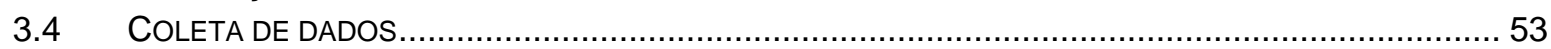

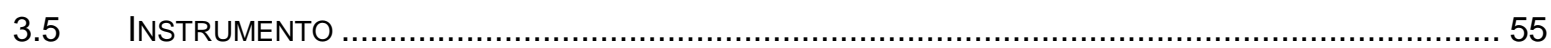

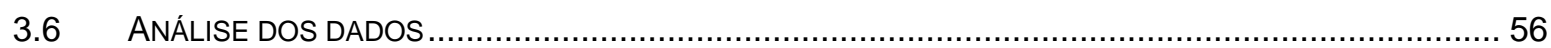

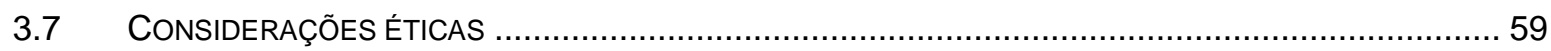

4 RESULTADOS

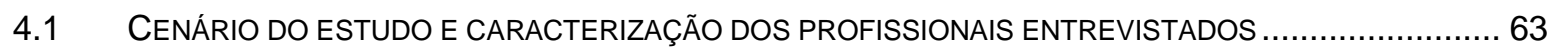

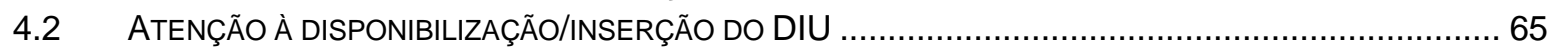

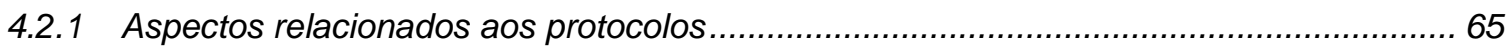

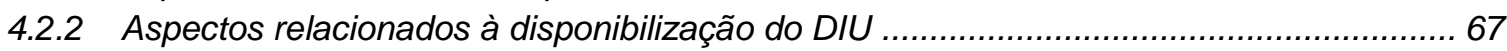

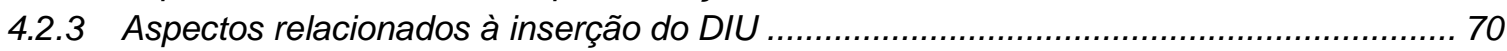

4.2.4 Aspectos relacionados aos grupos educativos de planejamento reprodutivo .................. 72

4.2.5 Aspectos relacionados à disponibilização de outros métodos contraceptivos ................. 74

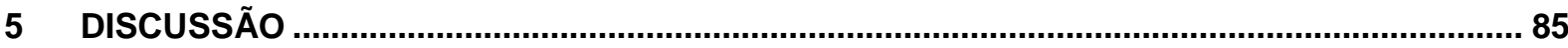

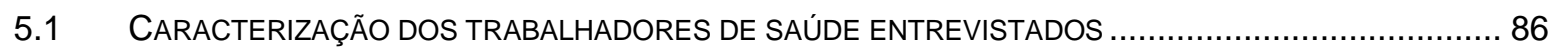

5.2 BARREIRAS ORGANIZACIONAIS QUE DIZEM RESPEITO AO USO DE PROTOCOLOS .......................... 86

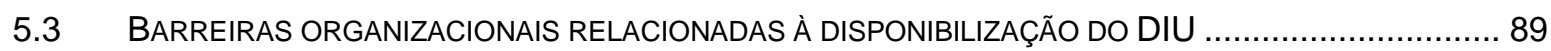

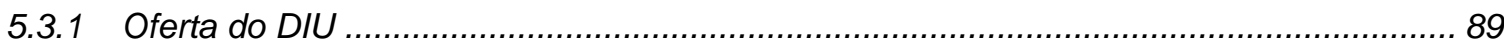

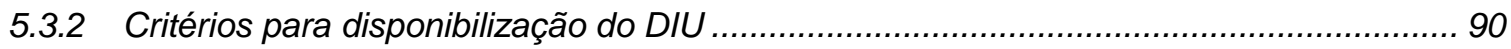

5.4 BARREIRAS ORGANIZACIONAIS ASSOCIADAS À INSERÇÃO DO DIU …...................................... 93

5.5 BARREIRAS ORGANIZACIONAIS RELATIVAS AOS GRUPOS DE PLANEJAMENTO REPRODUTIVO.......... 95

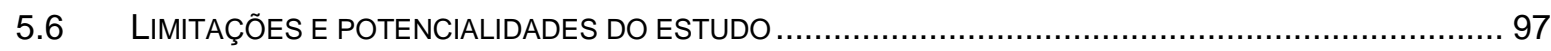

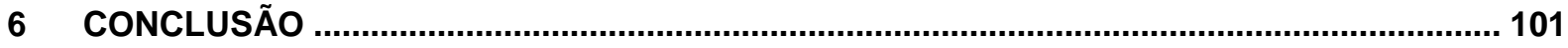

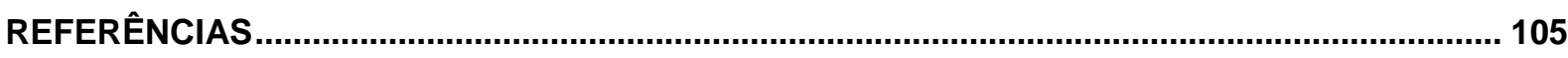

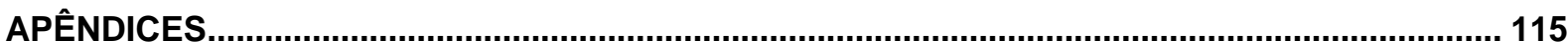

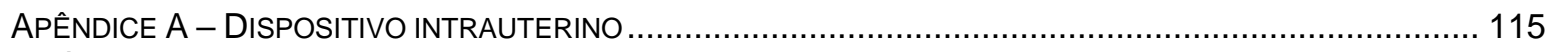

APÊNDICE B - CARACTERIZAÇÃO DA MACRORREGIÃO SUL DE MINAS GERAIS …............................. 118

APÊNDICE C- SUPERINTENDÊNCIAS REGIONAIS DE SAÚDE (SRS) DA MACRORREGIÃO SUL DE MINAS

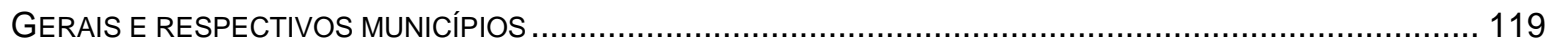

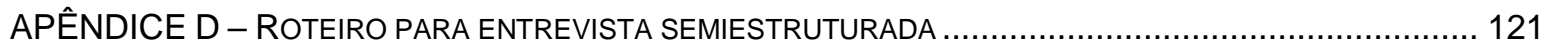

APÊNDICE E - CARTA DE SOLICITAÇÃO DE AUTORIZAÇÃO ENVIADA ÀS SUPERINTENDÊNCIAS REGIONAIS DE

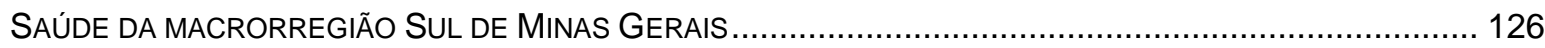



APÊNDICE F - CARTA DE SOLICITAÇÃO DE AUTORIZAÇÃO ENVIADA AOS GESTORES DE SAÚDE DOS MUNICÍPIOS DA MACRORREGIÃO SUL DE MINAS GERAIS...

APÊNDICE G - TERMO DE CONSENTIMENTO LIVRE E ESCLARECIDO ............................................. 128

ANEXOS

ANEXO 1- Parecer Consubstanciado do Comitê de Ética em Pesquisa da Escola de

ENFERMAGEM DA UNIVERSIDADE DE SÃO PAULO

ANEXO 2 - CRITÉRIOS CLíNICOS DE ELEGIBILIDADE PARA USO DE DISPOSITIVO INTRAUTERINO COM

COBRE (BRASIL, 2002) ....

ANEXO 3 - CRITÉRIOS CLÍNICOS DE ELEGIBILIDADE PARA USO DE DISPOSITIVO INTRAUTERINO COM

LEVONORGESTREL (BRASIL, 2002).

ANEXO 4 - CRITÉRIOS MÉdICOS DE ELEGIBILIDADE PARA USO DE DIU COM COBRE DA ORGANIZAÇÃO

MUNDIAL DA SAÚDE (OMS, 2007).......

ANEXO 5 - CRITÉRIOS MÉDICOS DE ELEGIBILIDADE PARA USO DE DIU COM LEVONORGESTREL DA

ORGANIZAÇÃO MUNDIAL DA SAÚDE (OMS, 2007)

ANEXO 6 - LISTA DE VERIFICAÇÃO DE GRAVIDEZ DA ORGANIZAÇÃO MUNDIAL DA SAÚDE

(OMS, 2007) 

APRESENTAÇÃO 



\section{APRESENTAÇÃO}

Nos 26 anos de trajetória profissional como enfermeira, tive a oportunidade de trabalhar, basicamente, na área da saúde coletiva. Em 1994, fui selecionada para o então Programa de Saúde da Família (PSF) de Camaragibe (PE). Na época, o programa estava começando no Brasil como proposta de reorganização do modelo vigente de assistência. Fazer parte deste processo, que objetivava mudanças para a consolidação do nosso Sistema Único de Saúde (SUS), era motivo de grande orgulho para mim. Considero essa experiência muito significativa para minha carreira, assemelhando-se a uma grande escola de saúde coletiva. Nesse período, me especializei em Saúde Pública pela Faculdade de Enfermagem Nossa Senhora das Graças (FENSG) da Universidade de Pernambuco (UPE).

Em 1998, fui morar no município de Belo Horizonte (MG), para acompanhar meu esposo, que havia sido transferido. Lá, não tive dificuldades para me inserir no mercado de trabalho, pois o PSF, em muitos municípios da região, estava sendo estruturado. Comecei, por conta disso, uma nova história profissional, também muito motivadora, em Ibirité (MG), município da região metropolitana de $\mathrm{BH}$, onde pude atuar como coordenadora municipal do PSF e do PACS (Programa de Agentes Comunitários de Saúde). Nessa fase, fiz especialização em Saúde da Família, pela Universidade Federal de Minas Gerais (UFMG), no programa de pós-graduação Veredas de Minas.

Em 2001, interessei-me por uma proposta de trabalho em Brumadinho (MG), visto que aquele município apresentava, por meio de seus gestores, vontade política para uma efetiva transformação do modelo assistencial vigente. Integrei-me à equipe e tive a oportunidade de trabalhar no PSF da zona rural, ampliando meus conhecimentos na área.

Em 2002, mudei-me para Guaratinguetá (SP) e, em 2003, fui aprovada no processo seletivo para a Estratégia Saúde da Família (ESF) de Itajubá (MG), minha cidade natal, próxima à Guaratinguetá. Iniciei minhas atividades em 2004, em uma comunidade com muitas necessidades de saúde, bastante pobre e violenta. Lá, a experiência também foi muito rica, principalmente pela oportunidade de conviver com alunos de graduação de uma escola de enfermagem da cidade, que estagiavam na Unidade de Saúde da Família, na qual eu atuava. Em 2006, fui convidada para 
participar de um processo seletivo daquela escola, para o cargo de professor. Comecei, então, um novo desafio: a docência, que me motivou para o mestrado. Atualmente, sou aluna do curso de Mestrado Profissional em Enfermagem na Atenção Primária em Saúde no Sistema Único de Saúde, da Escola de Enfermagem da Universidade de São Paulo (USP).

A experiência na ESF me ajudou a elencar diversos problemas que poderiam ser objeto de pesquisa científica, porém ao ser vinculada à Profa. Ana Luíza Vilela Borges fui atraída pelas questões do Planejamento Familiar, dos Métodos Contraceptivos e, mais especificamente, pelo Dispositivo Intrauterino (DIU). No decorrer da minha prática profissional, me deparei, com frequência, com situações em que as pessoas desejavam evitar a gravidez, porém não usavam qualquer método contraceptivo ou, quando usavam, era de forma incorreta, não era o método de sua preferência ou o mais adequado para si, o que poderia resultar, muitas vezes, em gravidez indesejada, não planejada, abortos, morte materna e outras gravidades. Tal situação pode ser justificada pelas barreiras organizacionais e individuais para acesso ao método contraceptivo pela população.

Assim, pareceu-me importante identificar quais são as barreiras organizacionais encontradas pelas mulheres para acesso ao DIU nos serviços de Atenção Básica à Saúde. Considero que a disponibilização oportuna de métodos contraceptivos, especialmente do DIU, e seu adequado aconselhamento são ações imprescindíveis para a garantia do exercício dos direitos sexuais e reprodutivos dos indivíduos no país. 
1 INTRODUÇÃO 



\section{INTRODUÇÃO}

Este estudo toma como objeto o processo de disponibilização do dispositivo intrauterino (DIU) na Atenção Básica à Saúde dos municípios da macrorregião Sul de Minas Gerais, vislumbrado na perspectiva do quadro teórico da Saúde Sexual e Reprodutiva.

\subsection{SAÚDE SEXUAL E REPRODUTIVA}

No final da segunda metade do século $X X$, a realização de importantes conferências mundiais sobre população, desenvolvimento e mulher contribuiu para o reconhecimento e a promoção dos direitos individuais, especialmente da mulher, em todo o mundo. Dentre elas, destacam-se a Conferência Internacional sobre População e Desenvolvimento (CIPD), mais conhecida como Conferência do Cairo, realizada em setembro de 1994, e a IV Conferência Mundial sobre a Mulher, que aconteceu na cidade de Pequim, em 1995 (Corrêa, Alves, Jannuzzi, 2006).

A partir dessas conferências, os direitos sexuais e reprodutivos passaram a ser reconhecidos como direitos humanos, mudando a forma como o mundo entendia e lidava com as questões populacionais. Até então, as iniciativas para erradicação da pobreza e das desigualdades sociais eram direcionadas, entre outras, para o controle do crescimento da população, sem qualquer tipo de consideração da necessidade de um pleno desenvolvimento humano, no qual a promoção dos níveis de saúde e dos direitos reprodutivos, da igualdade de gênero e do bem-estar social é o foco (ONU, 1994).

Na Conferência do Cairo, princípios foram acordados entre os países visando assegurar, por meio de metas, os direitos humanos. Dentre estes, destacam-se os direitos sexuais e reprodutivos que constam no $8^{\circ}$ princípio:

Toda pessoa tem direito ao gozo do mais alto padrão possível de saúde física e mental. Os estados devem tomar todas as devidas providências para assegurar, na base da igualdade de homens e mulheres, o acesso universal aos serviços de assistência médica, inclusive os relacionados com saúde reprodutiva, que inclui planejamento familiar e saúde sexual. Programas de assistência à saúde reprodutiva devem prestar a mais ampla variedade de serviços sem qualquer forma de coerção. Todo casal e indivíduo têm o direito básico de decidir livre e responsavelmente sobre o número e o espaçamento 
de seus filhos e ter informação, educação e meios de o fazer (ONU, 1994, p. 43).

$\mathrm{Na}$ Conferência de Pequim, análises sobre os avanços das conferências anteriores e sobre os obstáculos a serem enfrentados pelas mulheres para exercerem seus direitos possibilitaram a elaboração de um conjunto de objetivos estratégicos que serviriam como guia para os governos na formulação de políticas e na implementação de programas com a mesma finalidade: assegurar os direitos humanos (ONU, 1995).

De acordo com o Ministério da Saúde (MS) (Brasil, 2009), os direitos humanos são direitos fundamentais e essenciais da pessoa humana, determinantes para a qualidade de vida dos indivíduos. Como parte destes direitos, estão os direitos sexuais e reprodutivos, com as seguintes definições:

Direitos Reprodutivos: Direito das pessoas de decidirem, de forma livre e responsável, se querem ou não ter filhos, quantos filhos desejam ter e em que momento de suas vidas. Direito a informações, meios, métodos e técnicas para ter ou não ter filhos. Direito de exercer a sexualidade e a reprodução livre de discriminação, imposição e violência (Brasil, 2009, p. 4).

\begin{abstract}
Direitos sexuais: Direito de viver e expressar livremente a sexualidade sem violência, discriminações e imposições e com respeito pleno pelo corpo do(a) parceiro(a).Direito de escolher o(a) parceiro(a) sexual. Direito de viver plenamente a sexualidade sem medo, vergonha, culpa e falsas crenças. Direito de viver a sexualidade independentemente de estado civil, idade ou condição física. Direito de escolher se quer ou não quer ter relação sexual. Direito de expressar livremente sua orientação sexual: heterossexualidade, homossexualidade, bissexualidade, entre outras. Direito de ter relação sexual independente da reprodução. Direito ao sexo seguro para prevenção da gravidez indesejada e de DST/HIV/AIDS. Direito a serviços de saúde que garantam privacidade, sigilo e atendimento de qualidade e sem discriminação. Direito à informação e à educação sexual e reprodutiva (Brasil, 2009, p. 4).
\end{abstract}

De acordo com a CIPD e a Conferência de Pequim, o conceito de saúde reprodutiva não se baseia apenas na ausência de doenças ou enfermidades relacionadas aos aspectos reprodutivos, suas funções e processos, mas em um estado de completo bem-estar físico, mental e social, incluindo a saúde sexual satisfatória e sem riscos, além da capacidade e liberdade de procriação (ONU, 1994, 1995).

A saúde sexual apresenta-se como a habilidade dos indivíduos para usufruir e expressar sua sexualidade sem constrangimento. Sua definição é ambivalente, podendo ser vista como uma questão subordinada à reprodução ou como uma 
questão independente, sem ligação com a concepção e a contracepção (Corrêa, Alves, Jannuzzi, 2006; Carvalho, Lemos, Cerqueira, 2010).

Segundo o Programa de Ação do Cairo, todos os países devem dedicar-se à atenção à saúde sexual e reprodutiva dos indivíduos, tornando acessíveis atividades como aconselhamento, informação, educação e comunicação sobre sexualidade, reprodução humana e paternidade responsável; serviços de planejamento familiar, de assistência pré-natal, de parto seguro e de assistência pós-natal. O Programa inclui, também, a prevenção e o devido tratamento da esterilidade, do aborto e de suas sequelas, assim como o tratamento de infecções do aparelho reprodutivo (ONU, 1994).

Passados mais de 20 anos da realização dessas conferências, são observados inegáveis avanços nos indicadores de saúde sexual e reprodutiva no Brasil. No entanto, algumas lacunas persistem, como a elevada taxa de mortalidade materna, da ordem de 63,7 óbitos por 100.000 nascidos vivos (Painel de Monitoramento da Mortalidade Materna, 2015); a realização de inúmeros abortamentos inseguros (Brasil, 2011); a persistente desigualdade entre homens e mulheres nas relações sociais, de trabalho e pessoais; as dificuldades no acesso aos meios para o planejamento da fecundidade, dentre outros, apontando para a deficiência da promoção e da proteção dos direitos sexuais e reprodutivos (ONU, 1994; Dias, Spindola, 2007; Casarin, Siqueira, 2010; Brasil, 2010, 2011; Morse et al., 2011; Painel de Monitoramento da Mortalidade Materna, 2015).

Especificamente no que se refere ao planejamento da fecundidade, é plenamente reconhecido o direito inalienável do indivíduo e do casal de ter acesso ao planejamento familiar, às orientações para a escolha do método contraceptivo pretendido, bem como ao método que melhor se adapte as suas condições atuais de saúde, por meio de estratégias individuais e coletivas (Brasil, 2002; Andrade, Silva, 2009; Casarin, Siqueira, 2010; Figueiredo, Castro Filho, Kalckmann, 2014).

\subsection{PLANEJAMENTO FAMILIAR}

O planejamento familiar é direito básico de cidadania previsto na Constituição Federal de 1988. Este programa de saúde tem como principais objetivos assegurar às mulheres, aos homens e ao casal o direito de decidir se desejam ou não ter filhos, o número e o momento que pretendem tê-los; contribuir para a redução da gravidez 
indesejada, da morbidade e da mortalidade materna e infantil resultantes de abortamento inseguro ou de gestação de alto risco; além de promover a amamentação (ONU, 1994; Brasil, 2002; Andrade, Silva, 2009; Casarin, Siqueira, 2010).

De acordo com Cleland et al. (2012), a contribuição do planejamento familiar para a saúde e o desenvolvimento social é inquestionável, tendo em vista que o programa possibilita 0 atendimento das necessidades contraceptivas, podendo evitar mortes maternas e melhorar os resultados perinatais e a sobrevivência da criança. Os autores mencionam que o aumento do uso de contraceptivos nos países em desenvolvimento reduziu o número de mortes maternas em $40 \%$, ao longo dos últimos 20 anos, apenas por reduzir o número de gravidezes não desejadas e impedir gestações de alto risco. Além disto, a escolha reprodutiva pode libertar as mulheres de um ciclo incessante de gravidez, amamentação e cuidados infantis, representando enorme passo no sentido de maior igualdade de gênero.

Porém, nem sempre o acesso ao planejamento familiar foi priorizado. A partir dos anos 1970, as políticas de saúde da mulher evoluíram, passando de uma abordagem da mulher como simples reprodutora até as políticas atuais que preconizam a integralidade como princípio da assistência. Neste contexto, em 1974, foi criado o Programa Materno Infantil (PMI), cujo enfoque priorizava a gestação, o parto, o puerpério, a criança e o adolescente (Coelho, Lucena, Silva, 2000; Demarqui, Gouvêa, 2009). Em 1983, baseado na pressão dos movimentos feministas, que reivindicavam o atendimento de outras necessidades da população feminina, além das necessidades reprodutivas, surgiu o Programa de Assistência Integral à Saúde da Mulher (PAISM), que contemplava a assistência à mulher de forma integral, inclusive abordando os assuntos da sexualidade e da reprodução (Andrade, Silva, 2009).

O PAISM tornou explícito que o planejamento familiar deveria ser implementado em todo país, com a oferta dos métodos contraceptivos, orientações e acompanhamento de seu uso, mediante ações de atendimento integral. Este programa é considerado um marco histórico, pois, além de propor a atenção que vai adiante do ciclo gravídico-puerperal, possui amplo significado social, uma vez que provocou debates bastante importantes naquele momento, principalmente sobre a autonomia das mulheres nas questões reprodutivas (Osis, 1998; Coelho, Lucena, Silva, 2000; Demarqui, Gouvêa, 2009; Costa, 2009; Figueiredo, Castro Filho, Kalckmann, 2014). 
Em 1996, foi sancionada a Lei 9.263/96 sobre o planejamento familiar, que o estabelece como direito de todo cidadão e obriga todas as instâncias gestoras do SUS, em todos os seus níveis, a garantir assistência à concepção e à contracepção, dentro da visão de atendimento global e integral à saúde. Nesta lei, em seu art. $2^{\circ}, 0$ planejamento familiar é entendido como conjunto de ações de regulação da fecundidade, que garanta direitos iguais de constituição, limitação ou aumento da prole pela mulher, pelo homem ou pelo casal (Brasil, 1996).

O Programa de Planejamento Familiar prevê que a atuação dos profissionais em anticoncepção deve estar pautada no art. 226, parágrafo 7, da Constituição Federal, no princípio da paternidade responsável e no direito de livre escolha dos indivíduos e/ou casais (Brasil, 2002), cuja competência profissional deve contemplar conhecimentos técnicos, científicos e culturais atualizados, além de habilidade para orientar, informar, comunicar e decidir, junto ao indivíduo, pela escolha do método contraceptivo a ser utilizado, direcionados ao atendimento e ao acolhimento das necessidades de saúde sexual e reprodutiva (Nicolau et al., 2011).

Apesar dos avanços possibilitados pelo PAISM e pela ampliação da cobertura da Atenção Básica - que é o nível de atenção em que muitas das ações do PAISM e, mais especificamente, de planejamento familiar, devem ocorrer - o que se observa em relação às práticas contraceptivas é o descolamento do que preconiza a legislação sobre planejamento familiar. Estudos têm evidenciado, na verdade, um cenário incongruente, com oferta insuficiente de insumos contraceptivos; existência de lacunas nas ações educativas no planejamento familiar e ausência desta atividade em ESF de diversas regiões do país, além de ações realizadas em horários de trabalho dos interessados; a realização de orientações que não resultam em mudança de comportamento do usuário frente à prática da atividade sexual segura; falta de profissionais capacitados para aconselhamento contraceptivo; e falta de definição de fluxos e protocolos para atender as necessidades sexuais e reprodutivas dos indivíduos, garantindo o exercício dos seus direitos (Brasil, 2002; Dias, Spindola, 2007; Heilborn et al., 2009; Andrade, Silva, 2009; Wartcow, 2010; Nicolau et al., 2011; Figueiredo, Castro Filho, Kalckmann, 2014).

Para a plena efetivação da atenção em planejamento familiar, no Brasil, é fundamental assegurar aos indivíduos o direito de escolha do método contraceptivo a ser utilizado, mediante conhecimento sobre todos os métodos e acesso universal, 
simples e rápido a eles (Andrade, Silva, 2009; Figueiredo, Castro Filho, Kalckmann, 2014).

\subsubsection{O uso de métodos contraceptivos}

Segundo o relatório The World's Women and Girls (Population Reference Bureau, 2011), 62\% das mulheres unidas, no mundo, utilizam algum método contraceptivo, sendo que, nos países mais desenvolvidos, a taxa é de $71 \%$ e, nos menos desenvolvidos, 60\%. A Pesquisa Nacional de Demografia e Saúde (PNDS), de 2006, mostrou que aproximadamente $80 \%$ das mulheres brasileiras unidas usavam algum tipo de método contraceptivo. Porém, apesar desse alto percentual, dentre os nascimentos ocorridos no país nos cinco anos anteriores à PNDS (2006), 45,8\% totalizaram gravidezes que ocorreram em momentos diferentes do que era desejado pelas mulheres (Brasil, 2006).

Dados da PNDS (de 1996 e 2006), quando comparados, mostram que houve desconcentração do tipo de métodos contraceptivos utilizados pelas mulheres unidas de 15 a 49 anos de idade no Brasil. Eles evidenciam diminuição importante do percentual da laqueadura tubária, de 40,1\% (1996) para 29,1\% (2006), e aumento do percentual do uso da pílula, de 20,7\% (1996) para 24,7\% (2006). As Pesquisas também revelam aumento da participação dos homens na contracepção, por meio do preservativo masculino. Evidencia-se, ainda, aumento significativo no uso dos métodos contraceptivos de longa duração, como o dispositivo intrauterino (DIU) e os injetáveis. No entanto, no que concerne ao DIU, seu percentual de uso ainda é baixo no país, sendo relatado por apenas 1,5\% das mulheres (Brasil, 2006; Caetano 2010).

Embora seu uso seja pouco frequente no Brasil, o DIU é o método contraceptivo reversível mais usado no mundo (Kaneshiro, Aeby, 2010; Cleland et al., 2012), porém ainda permanece subutilizado na América do Norte, Sul da Ásia, Oceania e África subsaariana (Muller, 2004; Holanda et al., 2013; Wu, Pickle, 2013).Trata-se de um método seguro, altamente eficaz e com resultados positivos na saúde das populações, pois atua na redução da morbidade e da mortalidade materna, da mortalidade infantil e dos abortos inseguros (Bergin et al., 2012; Bahamondes et al., 2014).

Pesquisas recentes mostram, contudo, que o acesso ao DIU nem sempre é facilitado, sendo, inúmeras vezes, permeado por barreiras, tanto de ordem organizacional, quanto de ordem individual. As barreiras organizacionais são 
instituídas na organização dos serviços e nos critérios para disponibilização estabelecidos por eles, como a oferta insuficiente e descontínua do método, o condicionamento à participação em grupos educativos para o seu acesso, o conhecimento inadequado de profissionais de saúde sobre o método, a falta de profissionais habilitados para a sua inserção, a atribuição exclusiva da tarefa de inserção do DIU ao profissional médico e a ausência de protocolos com fluxos simplificados para sua inserção (Hayashi, Nogueira, 2007; Heilborn et al., 2009; Secura et. al., 2010; Nicolau et al., 2011; Bergin, 2012).

Por sua vez, as barreiras individuais ao uso do DIU são aquelas estabelecidas pelo usuário propriamente dito, como o baixo nível de conhecimento sobre o método; os mitos e os tabus que cercam o método, como a crença na possibilidade de provocar câncer, de ser abortivo e de ser pouco eficaz; o receio dos efeitos colaterais, como o aumento do fluxo menstrual, tanto em número de dias como em volume; e a crença de que não é apropriado para as mulheres nulíparas, jovens ou solteiras (Brasil, 2002; Moura, Silva, 2004; Carvalho, Schor, 2005; Brasil, 2006; Dias, Spindola, 2007; Andrade, Silva, 2009; Casarin, Siqueira, 2010; Secura et. al., 2010; Nicolau et al., 2011; Kittur et al., 2011; Bergin, 2012).

Tais barreiras são frequentemente vivenciadas nos serviços de Atenção Básica à Saúde no Brasil (Heilborn et al., 2009), dificultando o acesso ao DIU e contribuindo para a baixa frequência de seu uso. Por constituir-se em entrave ao acesso ao DIU, entre mulheres que querem usá-lo ou que poderiam usá-lo e se beneficiar de sua alta eficácia, esse conjunto de barreiras pode ser considerado uma restrição ao pleno exercício dos direitos sexuais e reprodutivos das mulheres brasileiras (Heilborn et al., 2009).

\subsection{DISPOSITIVO INTRAUTERINO}

O DIU é uma pequena estrutura sólida, de plástico flexível, com a forma da letra $\mathrm{T}$, que deve ser posicionado na cavidade endometrial, por um profissional de saúde devidamente treinado, com o objetivo de evitar a gravidez. O dispositivo atua provocando uma reação inflamatória uterina, desencadeando alterações bioquímicas que interferem no trânsito dos espermatozoides no aparelho genital feminino, além de alterarem os óvulos e espermatozoides impedindo a fecundação. Sua inserção pode 
ocorrer a qualquer momento durante o ciclo menstrual, desde que se tenha a certeza de que a mulher não esteja grávida, não existam sinais de infecções e não tenha malformação uterina. No Brasil estão disponíveis atualmente dispositivos com cobre (TCu 380A e multiload Cu 375) ou com levonorgestrel (LNG) (Curitiba, 2005; OMS, 2007; Penna, Brito, 2015) (Apêndice A - Detalhes técnicos sobre o método DIU).

De acordo com a Federação Brasileira das Associações de Ginecologia e Obstetrícia (Poli et al., 2009), os critérios e as condições clínicas para a inserção do DIU são:

a) a mulher deve estar saudável, sendo essencial exame ginecológico normal e colpocitologia oncótica dentro da normalidade;

b) ausência de vaginites, de cervicites infecciosas, de doença inflamatória pélvica (DIP) aguda ou crônica, de malformações uterinas, de tumores pélvicos ou câncer genital;

c) ausência de cardiopatias, de doenças hematológicas, especialmente as hemorrágicas, de deficiências imunológicas;

d) a mulher não deve estar grávida.

No entanto, a Organização Mundial da Saúde (OMS) (2007) propõe protocolo mais simplificado, em que as mulheres podem começar a utilizar o DIU, mediante uso dos Critérios Médicos de Elegibilidade (Anexo 3), que ajudam a verificar se há sinais de problemas que poderiam excluir a possibilidade de colocação de um DIU. Se a resposta a todas as questões for "não", então a mulher poderá colocar um DIU, não sendo necessários testes para Doença Sexualmente Transmissível (DST), testes de detecção do HIV, quaisquer exames de sangue ou outros testes laboratoriais de rotina, testes preventivos para câncer cervical ou exame das mamas.

Para a OMS (2007), a maioria das mulheres pode usar DIU com segurança e eficácia, incluindo mulheres que tenham ou não tido filhos; não sejam casadas; de qualquer idade, inclusive adolescentes e mulheres acima de 40 anos; que tenham passado por aborto espontâneo ou induzido, sem evidência de infecção; estejam amamentando; executem trabalhos físicos pesados; tenham tido gravidez ectópica; tenham tido DIP; tenham infecções vaginais; tenham anemia; estejam infectadas com o HIV ou estejam em terapia antirretroviral e bem de saúde.

Quanto ao protocolo adotado pelo MS (Brasil, 2002), nele é proposto o uso de Critérios Clínicos de Elegibilidade para uso de DIU (Anexo 2 e 3), cujas condições clínicas que podem impossibilitar a inserção do DIU são apresentadas por categorias 
tais como: Categoria 1: condições clínicas onde o DIU pode ser usado sem restrições; Categoria 2: condições clínicas onde o DIU pode ser usado com restrições; Categoria 3: condições clínicas onde o DIU é o método de última escolha. Os riscos possíveis e comprovados superam os benefícios do DIU, sendo necessário acompanhamento rigoroso; e Categoria 4: o DIU não deve ser usado.

Na mesma direção do MS (2002) e da OMS (2007), Bergin (2012) menciona que os serviços de saúde deveriam utilizar protocolos de visita única, para evitar que a mulher necessite comparecer ao serviço mais de uma vez para colocar o DIU. Para este autor, protocolos que exigem duas ou mais visitas ao serviço para a obtenção do método podem ser onerosos e representar uma oportunidade perdida. Secura et al. (2010) também mencionaram sobre a importância da utilização de protocolos mais simplificados, pois encontraram associação entre a possibilidade de inserção do DIU no mesmo dia da consulta e o aumento da opção por usá-lo.

No Brasil, o DIU é um método disponível, conhecido e demandado pelas mulheres, porém, quando elas optam por esse método, encontram barreiras, o que as leva a desistir do DIU e optar pela pílula ou pela esterilização cirúrgica (Heilborn et al., 2009). Para Figueiredo, Castro Filho e Kalckmann (2014), a disponibilidade e o acesso ao DIU necessitam ser aperfeiçoados, tendo em vista que não é disponibilizado e nem inserido em todas as unidades de saúde (UBS e ESF). Na verdade, somente 63,2\% das UBS pesquisadas no município de São Paulo realizavam a inserção do DIU; $31,4 \%$ encaminhavam para outros serviços; e 4,7\% não inseriam e nem encaminhavam. $\mathrm{O}$ acesso parece ser ainda mais restrito em ESF, pois os médicos generalistas nem sempre são capacitados para realizar tal procedimento.

Segundo MS (2002), OMS (2007) e Poli et al. (2009), a inserção do DIU requer um profissional de saúde devidamente habilitado e treinado, mas não há especificação em relação à formação desse profissional. Para Polus et al. (2015), a inserção de DIU pode ser executada, com o mesmo nível de habilidade, por enfermeiros e obstetrizes. Isso sugere que a mudança ou a ampliação da competência legal do enfermeiro neste caso, para a disponibilização/inserção do DIU - pode ser uma intervenção eficaz e segura para aumentar o acesso aos métodos contraceptivos (WHO, 2012). Essa competência já foi reconhecida pelo Conselho Federal de Enfermagem (COFEN), no 
PARECER 17/2010/COFEN/CTLN 1 : "o enfermeiro está apto a realizar consulta clínica e a prescrever e inserir o DIU, como ações intraconsulta”, e pela Câmara Técnica do Conselho Regional de Enfermagem de São Paulo, por meio da orientação fundamentada 060/2016 (COREN/SP, 2016).

De acordo com Figueiredo, Castro Filho e Kalckmann (2014), dispor do método contraceptivo no serviço de saúde não significa necessariamente que o indivíduo tenha acesso universal, simples e rápido a ele. Para esses autores, é necessário analisar os fluxos e os critérios estabelecidos pelos serviços, com vistas a verificar se neles existem elementos que possam se constituir como barreiras para a sua utilização. Diante do exposto, observa-se que há evidências de que os fluxos e a organização dos serviços de atenção à saúde sexual e reprodutiva no Brasil são falhos, pois apresentam barreiras organizacionais na disponibilização do DIU, contribuindo para a baixa frequência de seu uso. Nesse sentido, nossa pergunta de pesquisa é a seguinte: quais são as barreiras organizacionais para disponibilização do DIU nos serviços de Atenção Básica à Saúde?

1O Parecer17/2010/COFEN/CTLN trata-se de uma solicitação do Ministério da Saúde ao COFEN para análise e emissão de parecer sobre a "viabilidade dos Enfermeiros realizarem procedimentos com Medicamentos e Insumos para Planejamento Familiar Reprodutivo". A consulta solicita esclarecimentos acerca da viabilidade técnica, em consonância com a Lei do Exercício Profissional, de os enfermeiros, que atuam nos serviços públicos de saúde, inserir DIU, com o objetivo de ampliar a oferta deste método às usuárias do SUS. A consulta do Ministério da Saúde pode ter sido originada pelo fato de o texto do Manual Técnico "Assistência em Planejamento Familiar" (4a Edição, 2002), elaborado pelo Ministério da Saúde / Secretaria de Política de Saúde / Área Técnica de Saúde da Mulher, se referir, de modo abrangente, à possibilidade de profissionais de saúde realizar tal procedimento.

http://www.cofen.gov.br/parecer-n-172010-cofen-ctln_6148.html 



\section{OBJETIVOS}

Identificar barreiras organizacionais para disponibilização do DIU nos serviços de Atenção Básica à Saúde

Elaborar uma síntese das barreiras organizacionais identificadas, destinada aos gestores de saúde, como produto desta dissertação, com as respectivas implicações e recomendações. 

3 MÉTODO 



\section{MÉTODO}

\subsection{DELINEAMENTO DO ESTUDO}

Para ser coerente com as características do objeto de estudo e com o objetivo proposto, foi realizado um estudo quantitativo, de natureza descritiva (Gil, 2008).

\subsection{CENÁRIO DO ESTUDO}

O estudo foi conduzido nas coordenadorias da área técnica de Saúde da Mulher das Secretarias de Saúde dos municípios das Superintendências Regionais de Saúde (SRS) da macrorregião Sul de Minas Gerais. A escolha por esta macrorregião devese ao fato de a pesquisadora ser natural do Sul de Minas Gerais e desejar colaborar, por meio da pesquisa, com os serviços de saúde da referida área, na árdua tarefa de oferecer atendimento de qualidade e promover a saúde das pessoas.

O estado de Minas Gerais adota um sistema de regionalização da saúde desde a década de 1960, cujo objetivo inicial era criar pontos descentralizados de supervisão dos serviços de atenção primária. A partir da Constituição de 1988, foram introduzidos novos métodos de gestão, levando à reestruturação dos serviços assistenciais. A Secretaria Estadual de Saúde passou a empregar um plano de regionalização, de acordo com níveis crescentes de complexidade tecnológica, objetivando orientar a estruturação em redes de atendimento. A regionalização passou, assim, a ser uma importante ferramenta na estruturação dos serviços de saúde no estado, tendo em vista que ela define bases geográficas e populacionais, importantes para a alocação de recursos. Desde sua implantação, a regionalização da saúde no estado passou por diversas alterações (Silva, Ramires, 2010). Atualmente, o estado de Minas Gerais é dividido em treze macrorregiões (853 municípios), conforme mapa apresentado na Figura 1. 
Figura 1- Mapa da Divisão do território de Minas Gerais em macrorregiões, adotado oficialmente pelo governo estadual (MG, 2015).

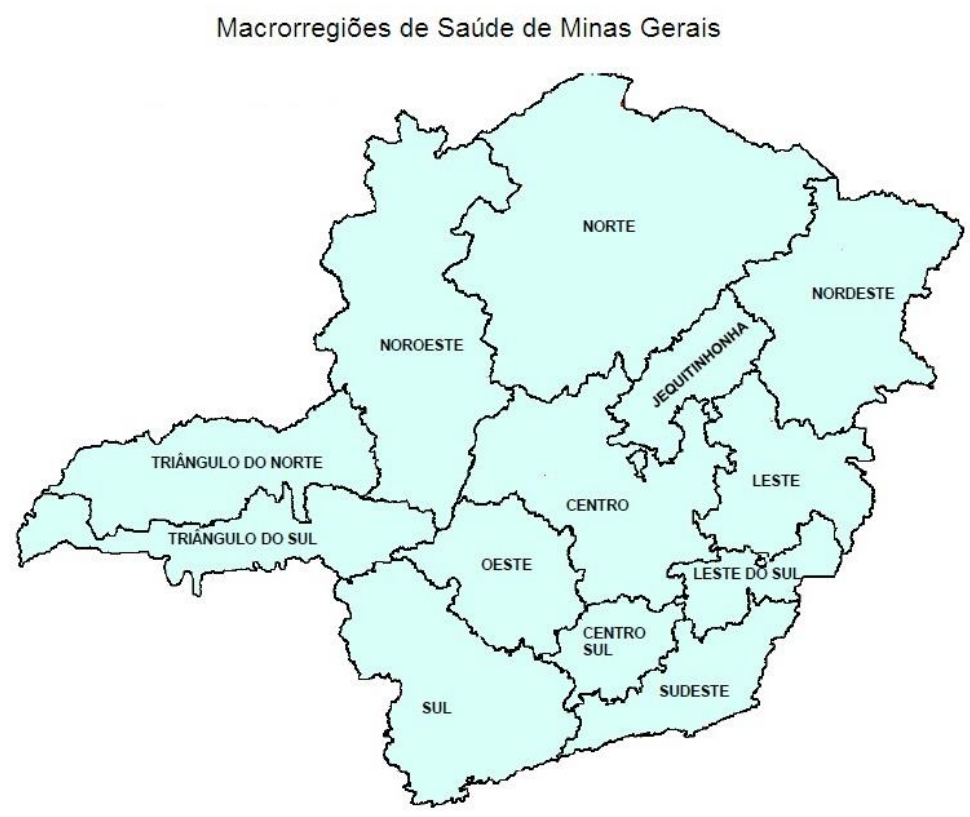

Fonte: www.saude.mg.gov.br

A macrorregião Sul, que é o cenário deste estudo, tem extensão territorial de 53.766,3 Km² (Minas Gerais, 2014) e população estimada de 2.641.132 habitantes, sendo 710.673 mulheres em idade fértil (15 a 49 anos) (DATASUS, 2012). Esta macrorregião faz fronteira com as macrorregiões Sudeste, Centro Sul, Oeste, Triângulo do Sul e com os estados de São Paulo e Rio de Janeiro. A caracterização da macrorregião Sul é apresentada no Apêndice B. Esta macrorregião possui quatro SRS: Alfenas, Passos, Pouso Alegre e Varginha, que atendem a 152 municípios (Figura 2). A relação das SRS e dos seus respectivos municípios é mostrada no Apêndice C.

Dentre todos os municípios da macrorregião, 12 são considerados microrregiões responsáveis pelo segundo nível de complexidade. As microrregiões são: Alfenas/Machado, Guaxupé, Itajubá, Lavras, Passos/Piumhi, Poços de Caldas, Pouso Alegre, São Lourenço, São Sebastião do Paraíso, Três Corações, Três Pontas e Varginha. 
Figura 2 - Mapa da divisão administrativa de saúde da Macrorregião Sul de Minas Gerais.

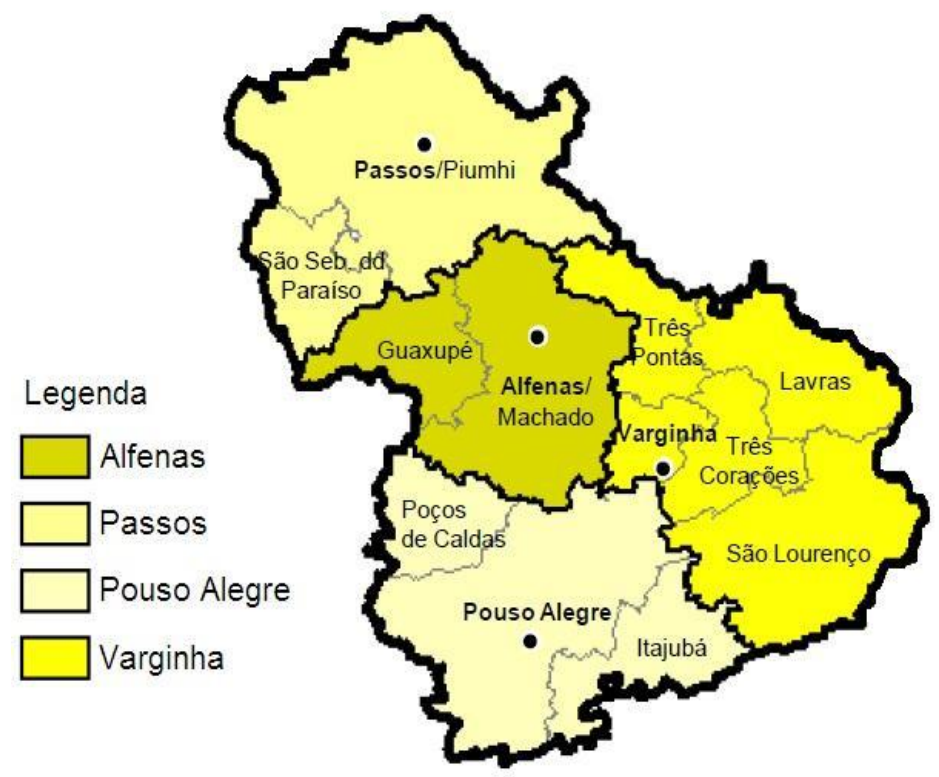

Fonte: Adaptado de www.saude.mg.gov.br

\subsection{POPULAÇÃO DE ESTUDO}

O estudo foi desenvolvido com os trabalhadores responsáveis pela área técnica de saúde da mulher das secretarias de saúde dos municípios das SRS da macrorregião Sul de Minas Gerais, eleitos pelo critério de serem os responsáveis (ou que sabiam responder) pelas práticas de disponibilização do DIU no município.

\subsection{COLETA DE DADOS}

Antes da coleta de dados propriamente dita, foi solicitado, por ofício, aos Superintendentes Regionais de Saúde das quatro regionais, autorização para realização da pesquisa (Apêndice E). Somente a SRS de Alfenas solicitou apresentação do projeto de pesquisa pessoalmente, que foi devidamente realizada no dia 27 de agosto de 2015, na reunião da Comissão Intergestores Regional (CIR) de Alfenas. Apesar de as respostas dos superintendentes terem sido positivas, foi requerido que a pesquisadora também fizesse contato com os gestores de saúde de cada município, para que os mesmos tomassem conhecimento sobre a pesquisa e concedessem a autorização. 
Tal requerimento foi atendido pela pesquisadora, que encaminhou ofícios de solicitação de autorização para coleta de dados a todos os gestores de saúde dos municípios da macrorregião (Apêndice F). Conforme apresentado na Tabela 1, do total de municípios $(n=153), 86$ deles autorizaram a coleta de dados, o equivalente a $56,2 \%$. No entanto, 64 municípios não responderam ao ofício $(41,8 \%)$ e 3 negaram a solicitação (2,0\%), alegando reestruturação do serviço e não disponibilização do DIU. Dentre os que autorizaram ( $n=86$ ), $82,5 \%$ o fizeram por e-mail e $17,5 \%$ autorizaram por telefone.

Tabela 1 - Municípios que autorizaram a coleta de dados, segundo as SRS. Macrorregião Sul de Minas Gerais, 2016.

\begin{tabular}{|c|c|c|c|c|c|c|c|c|c|c|c|}
\hline \multirow[b]{3}{*}{ SRS } & \multirow{3}{*}{$\begin{array}{c}\text { № de } \\
\text { municípios }\end{array}$} & \multicolumn{6}{|c|}{ Solicitação autorizada } & \multirow{2}{*}{\multicolumn{2}{|c|}{$\begin{array}{c}\text { Solicitação } \\
\text { negada }\end{array}$}} & \multirow{2}{*}{\multicolumn{2}{|c|}{$\begin{array}{l}\text { Solicitação } \\
\text { não } \\
\text { respondida }\end{array}$}} \\
\hline & & \multicolumn{2}{|c|}{ e-mail } & \multicolumn{2}{|c|}{ Telefone } & \multicolumn{2}{|c|}{ Total } & & & & \\
\hline & & $\mathbf{n}$ & $\%$ & $\mathbf{n}$ & $\%$ & $\mathbf{n}$ & $\%$ & $\mathbf{n}$ & $\%$ & $\mathbf{n}$ & $\%$ \\
\hline Alfenas & 26 & 15 & 100,0 & - & - & 15 & 57,7 & - & - & 10 & 38,5 \\
\hline Passos & 24 & 09 & 75,0 & 03 & 25,0 & 12 & 50,0 & - & - & 12 & 50,0 \\
\hline Pouso Alegre & 53 & 21 & 65,6 & 11 & 34,4 & 32 & 60,4 & 02 & 3,8 & 19 & 35,8 \\
\hline Varginha & 50 & 26 & 96,3 & 01 & 3,7 & 27 & 54,0 & 01 & 2,0 & 22 & 44,0 \\
\hline Total & 153 & 71 & 82,5 & 15 & 17,5 & 86 & 56,2 & 03 & 2,0 & 64 & 41,8 \\
\hline
\end{tabular}

De posse das autorizações, a pesquisadora entrou em contato por telefone com os trabalhadores de cada município e esclareceu sobre o estudo. Além disto, também solicitou o endereço eletrônico de cada trabalhador (e sua autorização) para o envio do questionário a ser respondido.

Dentre os municípios que autorizaram a pesquisa $(n=86)$, foram obtidas 80 respostas, o que corresponde a $93 \%$ do total de autorizações. Porém, uma resposta foi excluída, pois foram recebidas duas respostas do Município de Pouso Alto. Neste caso, foi considerada a resposta do coordenador da área técnica de Saúde da Mulher do município, totalizando 79 respostas.

A coleta de dados foi realizada de março a maio de 2016, por meio de instrumento autopreenchível, desenvolvido pela própria pesquisadora, e enviado juntamente com o Termo de Consentimento Livre e Esclarecido (TCLE) aos participantes do estudo por e-mail. Seu preenchimento ocorreu logo depois do aceite do TCLE pelos participantes, online. 


\subsection{INSTRUMENTO}

O instrumento utilizado para coleta de dados foi desenvolvido pela própria pesquisadora, no período de setembro 2015 a fevereiro de 2016 (Apêndice D). Para sua elaboração, foi utilizado o aplicativo Forms do Google, tendo como base os documentos: "Assistência em Planejamento Familiar - Manual Técnico" (Brasil, 2002), "Selected Practice For Contraceptive Use" (WHO, 2004), "Planejamento Familiar - um Manual Global para Profissionais de Saúde" (OMS, 2007) e WHO Recommendations - Optimizing health worker roles to improve access to key maternal and newborn health interventions through task Shifting (WHO, 2012).

Após elaboração, foi realizado o pré-teste, que aconteceu em março de 2016 e contou com a participação de alunos do Programa de Mestrado Profissional em Enfermagem na Atenção Primária em Saúde, Mestrado e Doutorado em Enfermagem da Escola de Enfermagem da Universidade de São Paulo.

O instrumento consistiu de cinco blocos de informação:

Bloco 1: refere-se às características das SRS, como:

- Nome;

- Número de municípios;

- Número total de unidades de saúde;

Bloco 2: refere-se ao perfil do profissional responsável pela área técnica de saúde da mulher, ou seja, o participante da pesquisa, como:

- Profissão;

- Sexo;

- Idade;

- Grau de escolaridade;

- Tipo de especialização;

- Tempo de atuação no cargo. 
Bloco 3: refere-se às atividades de atenção à saúde da mulher, como:

- Utilização e elaboração de protocolos;

- Treinamento e capacitação dos profissionais de saúde para aplicação do protocolo;

- Disponibilização do DIU;

- Critérios para disponibilização do DIU;

- Condições para inserção do DIU;

- Disponibilização de outros métodos contraceptivos;

- Local para aquisição do DIU e outros contraceptivos;

- Profissional que insere o DIU.

Bloco 4: refere-se às atividades educativas, como:

- Operacionalização de grupos educativos de planejamento familiar.

Bloco 5: refere-se às considerações dos respondentes a respeito da existência de dificuldades e facilidades para as mulheres obterem o DIU.

\subsection{ANÁLISE DOS DADOS}

O banco de dados foi originado a partir do Google forms, com todas as variáveis em formato string. $O$ banco foi convertido em códigos numéricos e lançado no programa Excel, no período de junho a julho de 2016. A análise estatística foi realizada por meio do software Stata, versão 14.0, e descrita por meio de número absoluto e proporções. A análise foi realizada em 3 etapas:

\section{Etapa 1 - Caracterização do cenário do estudo e dos profissionais entrevistados:}

Realizou-se a análise das características das SRS segundo:

- Número total de municípios por SRS;

- Número médio de unidades públicas de saúde por município;

- Número e proporção de municípios participantes da pesquisa. 
Quanto à caracterização dos profissionais entrevistados, a análise se deu por meio das seguintes variáveis:

- Idade (anos completos);

- Sexo (masculino ou feminino);

- Grau de escolaridade (ensino médio, superior, especialização, mestrado e doutorado);

- Tipo de especialização, incluindo mestrado e doutorado, na área de Atenção à Saúde da Mulher (não ou sim);

- Profissão (médico, enfermeiro, psicólogo, assistente social, odontólogo e outro);

- Tempo de atuação no cargo (menos de 1 ano, de 1 a 5 anos, de 6 a 10 anos, e mais de 10 anos).

\section{Etapa 2 - Caracterização da Atenção à Disponibilização/Inserção do DIU:}

A análise dos dados nesta etapa caracterizou a Atenção à Disponibilização/Inserção do DIU. Para tanto, se utilizaram as seguintes variáveis:

Variáveis relacionadas ao Protocolo de Atenção à Saúde da Mulher:

- Existência de protocolo para atendimento da mulher (não ou sim);

- Elaboração do protocolo (não ou sim);

- Existência de protocolo específico para disponibilização do DIU;

- Treinamento dos profissionais de saúde para aplicação do protocolo (não ou sim).

Variáveis relacionadas à disponibilização/inserção do DIU:

- Disponibilização do DIU (não ou sim);

- Existência de protocolo específico para disponibilização do DIU (não ou sim);

- Condições que podem impossibilitar a inserção do DIU (anemia, HIV, infecção vaginal, aborto espontâneo ou induzido recente, história anterior de DIP, gravidez, história anterior de gravidez ectópica, estar amamentando, diabetes, hipertensão, execução de trabalho físico pesado e outro);

- Profissional que insere o DIU (médico ginecologista/obstetra, médico generalista, enfermeiro obstetra, enfermeiro generalista e outro);

- Agendamento para inserção do DIU (não ou sim); 
- Tempo médio esperado pela mulher, entre o dia da consulta ou o dia que ela comunica seu interesse em usar o DIU até a sua inserção (menos de 1 semana, entre 1 e 4 semanas ou mais de 1 mês);

- Encaminhamento da mulher, no caso de o município não disponibilizar o DIU (não encaminha, encaminha para outro município ou outro);

- Local para aquisição do DIU (UBS/ESF, ambulatório de especialidade, farmácia central, hospital, setor de saúde da mulher, secretaria de saúde, outro município e outro);

- Critérios necessários para a mulher ter acesso ao DIU (não há critérios, ter prescrição somente do ginecologista, ter prescrição somente de médico, ter prescrição somente de enfermeiro, com prescrição de ginecologista, médico ou enfermeiro, realizar exames, ser casada, ter idade acima de 18 anos, participar previamente de grupo educativo ou outro);

- Tipos de exames necessários para ter acesso ao DIU (preventivo para câncer cervical, exame de mamas, de sangue, teste HIV, teste de gravidez e outro);

- Agendamento de consultas (agendada somente por iniciativa da mulher, agendada somente por encaminhamento do agente comunitário de saúde, agendada somente por encaminhamento de outro profissional, agendada por iniciativa da mulher ou por encaminhamento do agente comunitário de saúde ou por encaminhamento de outro profissional e outro).

Variáveis relacionadas à disponibilização de outros métodos contraceptivos:

- Disponibilização de outros métodos contraceptivos (pílula oral, preservativo masculino, preservativo feminino, injetável, pílula de emergência, diafragma, laqueadura tubária, vasectomia e outro);

- Local para aquisição de outros métodos contraceptivos (UBS/ESF, ambulatório de especialidade, farmácia central, hospital, setor de saúde da mulher, secretaria de saúde, outro município e outro).

Variáveis relacionadas aos grupos educativos de planejamento reprodutivo:

- Realização de grupos de planejamento reprodutivo (não ou sim, algumas unidades ou sim, todas as unidades); 
- Coordenação do grupo de planejamento reprodutivo (médico, enfermeiro, auxiliar de enfermagem, agente comunitário de saúde, assistente social, odontólogo, psicólogo ou outro);

- Participantes do grupo de planejamento reprodutivo (mulheres e homens em geral de todas as idades, apenas mulheres de todas as idades, apenas mulheres exceto as adolescentes, apenas adolescentes ou outro);

- Inscrição para participar do grupo de planejamento reprodutivo (iniciativa das pessoas, encaminhamento do agente comunitário de saúde, encaminhamento por algum outro profissional de saúde, todas as alternativas anteriores ou outro);

- Local de realização do grupo de planejamento reprodutivo (UBS/ESF, espaços na comunidade - garagens, quadras, espaços da comunidade - escolas, associações e igrejas, fora da comunidade e outro);

- Período do dia que são realizados os grupos de planejamento reprodutivo (somente no período da manhã, somente no período da tarde, somente no período da noite, sempre manhã, tarde e noite, horários variados ou outro);

- Frequência de realização dos grupos de planejamento reprodutivo (1 vez por semana, 1 vez por mês, 2 vezes por mês, esporádica ou outro).

\section{Etapa 3 - Considerações dos respondentes:}

Esta etapa considerou as seguintes variáveis para analisar os dados:

Varáveis relacionadas às considerações dos respondentes:

- Existência de dificuldades para as mulheres obterem o DIU (não ou sim);

- Existência de facilidades para as mulheres obterem o DIU (não ou sim).

\subsection{CONSIDERAÇÕES ÉTICAS}

O projeto foi submetido e aprovado pelo Comitê de Ética em Pesquisa da Escola de Enfermagem da Universidade de São Paulo (Número do Parecer: 1.212.779), assim como foi solicitada autorização às SRS e às secretarias de saúde dos municípios da macrorregião Sul de Minas Gerais para realização deste estudo (Anexo 1, Apêndice $E$, Apêndice $F$, respectivamente). 
Em observância às determinações da Resolução 466/12, do Conselho Nacional de Saúde, que regulamenta a ética em pesquisa envolvendo seres humanos no Brasil, foi respeitada a confiabilidade e o sigilo sobre as informações obtidas nesta pesquisa, bem como a garantia da liberdade do participante de retirar-se da pesquisa a qualquer momento, sem prejuízo, punição ou atitude preconceituosa.

A adesão e a participação dos profissionais foram de livre iniciativa. Os profissionais foram convidados a participar do estudo por meio do TCLE, que apresentou o objetivo do estudo e foi enviado via e-mail. A inclusão dos participantes na pesquisa foi mediante aceite do TCLE (Apêndice $G$ ).

Os resultados da pesquisa ficarão disponíveis para consulta pública após defesa da dissertação e serão apresentados aos participantes do estudo. 
4 RESULTADOS 



\section{RESULTADOS}

\subsection{CENÁRIO DO ESTUDO E CARACTERIZAÇÃO DOS PROFISSIONAIS ENTREVISTADOS}

As características das Superintendências Regionais de Saúde (SRS), segundo número total de municípios, número médio de unidades públicas de saúde por município e número e proporção de municípios participantes da pesquisa, estão apresentadas na Tabela 2.

O maior número de municípios participantes foi da SRS Pouso Alegre $(n=29)$, ao passo que a SRS Passos teve apenas 11 municípios. No entanto, a proporção dos municípios participantes dentre todos os municípios da SRS foi semelhante, ao redor de $50 \%$. A média de unidades de saúde por município também foi similar dentre as SRS.

Tabela 2 - Características das Superintendências Regionais de Saúde. Macrorregião Sul de Minas Gerais, 2016.

\begin{tabular}{|c|c|c|c|c|}
\hline SRS $^{\star}$ & $\begin{array}{l}\text { №. total de } \\
\text { municípios }\end{array}$ & $\begin{array}{c}\text { №. de } \\
\text { municípios } \\
\text { participantes }\end{array}$ & $\%$ & $\begin{array}{c}\text { №. médio de } \\
\text { unidades } \\
\text { públicas de } \\
\text { saúde/município }\end{array}$ \\
\hline Alfenas & 26 & 15 & 57,7 & 06 \\
\hline Pouso Alegre & 53 & 29 & 54,7 & 07 \\
\hline Varginha & 50 & 24 & 48,0 & 07 \\
\hline Passos & 24 & 11 & 45,8 & 08 \\
\hline TOTAL & 153 & 79 & 51,6 & - \\
\hline
\end{tabular}

*Superintendência Regional de Saúde

Nas SRS, foram entrevistados os trabalhadores responsáveis pela área técnica de Saúde da Mulher de cada município. Na Tabela 3, é apresentada a caracterização desses trabalhadores. Observou-se que mais da metade dos trabalhadores apresenta idade entre 24 e 34 anos, caracterizando-os como adultos jovens. Além disso, a maior parte foi composta por enfermeiros $(89,9 \%)$ e indivíduos do sexo feminino $(97,5 \%)$. Verificou-se, ainda, que a maioria apresentou tempo de atuação no cargo entre 1 e 5 
anos (59,5\%) e formação em nível de especialização $(62,0 \%)$. Dentre os trabalhadores com especialização, incluindo mestrado e doutorado $(n=52)$, apenas 26,9\% eram na área de Saúde da Mulher.

Tabela 3 - Caracterização dos trabalhadores de saúde responsáveis pela área técnica de Saúde da Mulher das secretarias municipais de saúde. Macrorregião Sul de Minas Gerais, 2016.

\begin{tabular}{|c|c|c|}
\hline Variáveis & $\mathbf{n}$ & $\%$ \\
\hline \multicolumn{3}{|l|}{ Idade } \\
\hline 24 a 34 anos & 40 & 50,6 \\
\hline 35 a 49 anos & 30 & 38,0 \\
\hline 50 anos e mais & 09 & 11,4 \\
\hline \multicolumn{3}{|l|}{ Sexo } \\
\hline Feminino & 77 & 97,5 \\
\hline Masculino & 02 & 2,5 \\
\hline \multicolumn{3}{|c|}{ Escolaridade } \\
\hline Superior & 27 & 34,2 \\
\hline Especialização & 49 & 62,0 \\
\hline Mestrado & 02 & 2,5 \\
\hline Doutorado & 01 & 1,3 \\
\hline \multicolumn{3}{|l|}{ Profissão } \\
\hline Enfermeiro & 71 & 89,9 \\
\hline Médico & 05 & 6,3 \\
\hline Farmacêutico & 02 & 2,5 \\
\hline Assistente Social & 01 & 1,3 \\
\hline \multicolumn{3}{|c|}{ Especialização na área de Saúde da Mulher* } \\
\hline Não & 38 & 73,1 \\
\hline Sim & 14 & 26,9 \\
\hline \multicolumn{3}{|c|}{ Tempo no Cargo } \\
\hline 1 a 5 anos & 47 & 59,5 \\
\hline 6 a 10 anos & 15 & 18,9 \\
\hline Mais de 10 anos & 10 & 12,7 \\
\hline Menos de 1 ano & 07 & 8,9 \\
\hline TOTAL & 79 & 100,0 \\
\hline
\end{tabular}

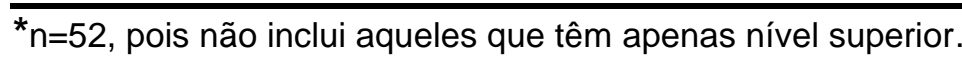

Os trabalhadores de saúde fizeram considerações sobre a existência de dificuldades e facilidades para as mulheres obterem o DIU, conforme apresentado na Tabela 4. A grande maioria deles reportou não haver dificuldades e haver facilidades 
para obtenção do DIU (86,1\%). Foi verificado que a taxa de municípios que reportaram dificuldades é maior nos municípios que não disponibilizam o DIU (66,6\%). O inverso acontece com relação às facilidades, ou seja, foi reportado mais facilidades entre os municípios que disponibilizam DIU (94,0\%).

Tabela 4 - Considerações de trabalhadores de saúde responsáveis pela área técnica de Saúde da Mulher que reportaram haver dificuldades ou facilidades para as mulheres obterem o DIU. Macrorregião Sul de Minas Gerais, 2016.

\begin{tabular}{|c|c|c|c|c|c|c|c|}
\hline \multirow{3}{*}{$\begin{array}{l}\text { Considerações dos respondentes sobre a } \\
\text { existência de dificuldades ou facilidades para } \\
\text { obtenção do DIU }\end{array}$} & \multicolumn{7}{|c|}{ O município disponibiliza DIU } \\
\hline & & \multicolumn{2}{|c|}{ Não } & \multicolumn{2}{|c|}{ Sim } & \multicolumn{2}{|c|}{ TOTAL } \\
\hline & & $\mathrm{n}$ & $\%$ & $\mathrm{n}$ & $\%$ & $\mathrm{n}$ & $\%$ \\
\hline \multirow{2}{*}{ Existem dificuldades } & Não & 04 & 33,4 & 64 & 95,5 & 68 & 86,1 \\
\hline & Sim & 08 & 66,6 & 03 & 4,5 & 11 & 13,9 \\
\hline \multirow{2}{*}{ Existem facilidades } & Não & 07 & 58,4 & 04 & 6,0 & 11 & 13,9 \\
\hline & Sim & 05 & 41,6 & 63 & 94,0 & 68 & 86,1 \\
\hline
\end{tabular}

\subsection{ATENÇÃO À DISPONIBILIZAÇÃO/INSERÇÃO DO DIU}

\subsubsection{Aspectos relacionados aos protocolos}

Considerando a importância dos protocolos para ordenar o acesso às ações e aos serviços de saúde, foi questionado, aos trabalhadores de saúde, se no município existe algum protocolo para atendimento da mulher. Na Figura 3, verifica-se que pouco mais da metade afirmou possuir algum tipo de protocolo (55,7\%). Dentre estes, foi observado que a maior parte elaborou seu próprio protocolo (77,3\%). Além disso, observou-se também que quase um terço dos municípios que possuem algum protocolo e um quarto dos municípios que elaboraram seu próprio protocolo não treinou a equipe de saúde para a utilização dos mesmos. Chama a atenção também o fato de que, dentre os municípios que não possuem protocolo para atendimento da mulher, 5,7\% possuem protocolo específico para disponibilização do DIU. 
Figura 3 - Diagrama de protocolo de atenção à Saúde da Mulher. Macrorregião Sul de Minas Gerais, 2016.

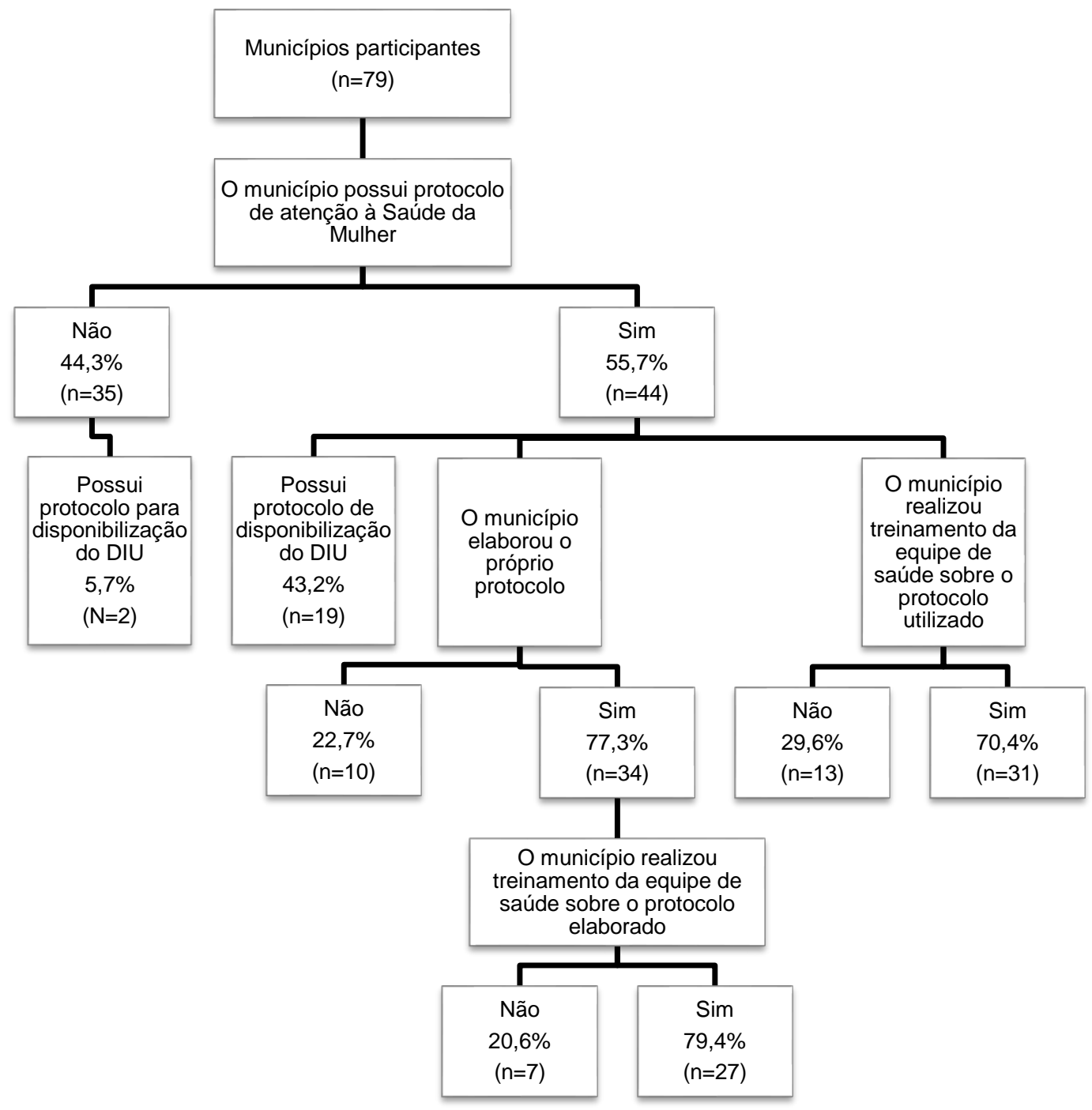

$\mathrm{Na}$ Figura 4, é apresentado o resultado sobre a disponibilização do DIU pelos serviços de saúde dos municípios. Verificou-se que a grande maioria dos municípios afirmou disponibilizá-lo (84,8\%). No caso dos municípios que não disponibilizam o DIU $(n=12)$, observou-se que a maioria encaminha ou referencia as mulheres para outro município (58,4\%). Também são significativas outras formas de encaminhamentos, como para rede particular, para especialista ou para o Centro Viva Vida (Programa de Redução da Mortalidade Infantil e Materna do Governo de Minas Gerais), que, somados, totalizam 33,3\%. Entretanto, alguns municípios, além de não disponibilizarem DIU, também não encaminham as mulheres que possuem interesse em usá-lo (8,3\%). 
Ademais, visando observar se os municípios que disponibilizam o DIU $(n=67)$ possuem algum protocolo que direcione a disponibilização do dispositivo, verificou-se (Figura 4) que a grande maioria não possui protocolo específico $(68,6 \%)$ (Figura 4).

Figura 4 - Diagrama de disponibilização do DIU. Macrorregião Sul de Minas Gerais, 2016.

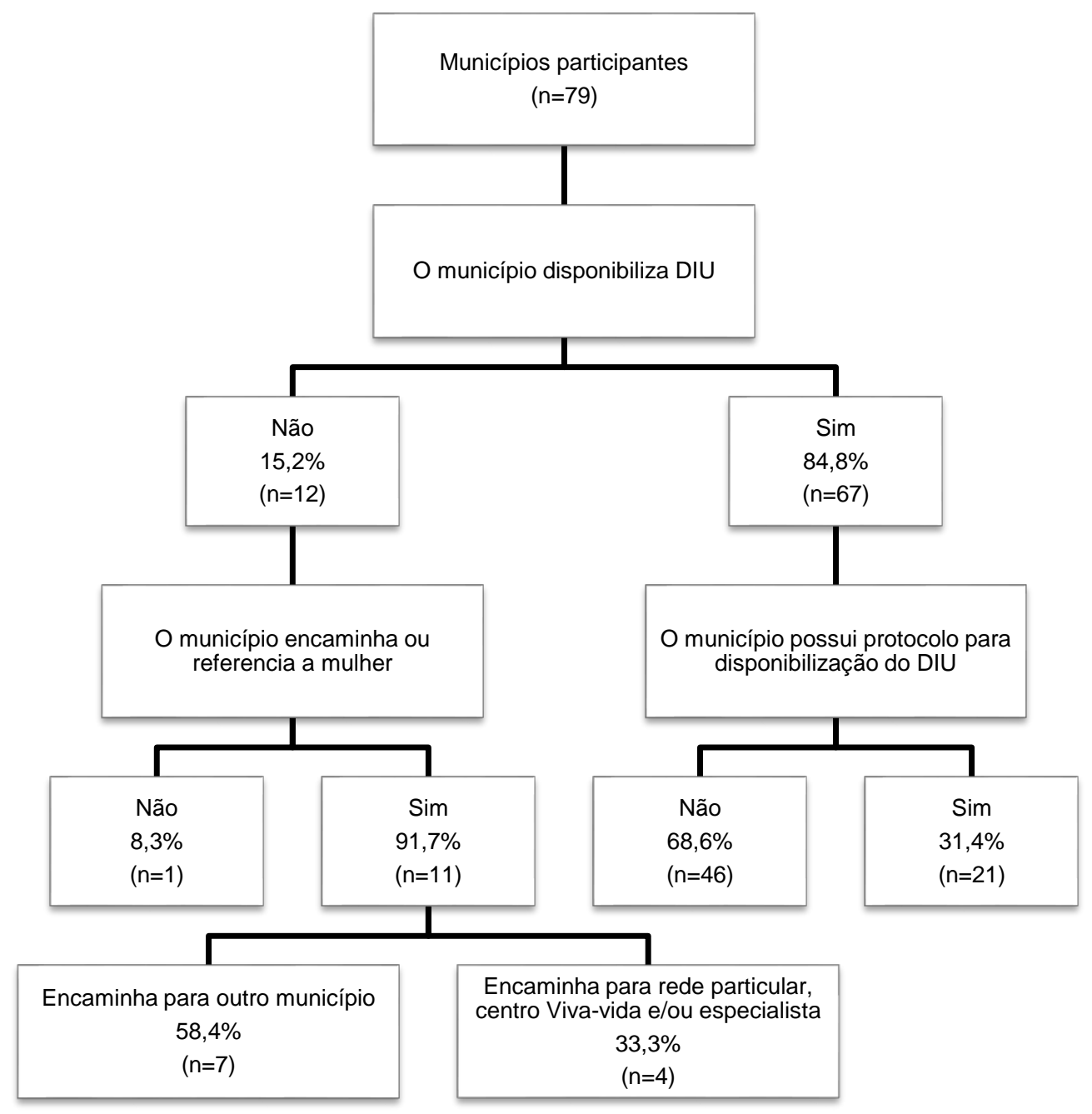

\subsubsection{Aspectos relacionados à disponibilização do DIU}

Os aspectos relacionados à disponibilização do DIU dizem respeito à oferta do método e aos critérios estabelecidos pelos serviços de saúde para disponibilizá-lo, como prescrição médica, realização de exames, idade mínima de 18 anos, participação em grupos educativos de planejamento reprodutivo e local centralizado para disponibilização do método.

Quanto aos critérios estabelecidos pelos serviços de saúde para disponibilização do DIU, verificou-se que, no geral, os municípios requerem prescrição médica 
(ginecologistas ou generalistas) $(86,5 \%)$ e realização de exames para disponibilizar o dispositivo (71,6\%). Além disso, foi possível notar que quase metade dos municípios não disponibiliza DIU para adolescentes (44,8\%). Em um quarto dos munícipios que disponibilizam, é necessário participar de grupo educativo para obter o DIU $(44,8 \%)$, conforme apresentado na Figura 5.

Figura 5 - Critérios estabelecidos pelos serviços de saúde para disponibilização do DIU, dentre os municípios que o disponibilizam. Macrorregião Sul de Minas Gerais, 2016

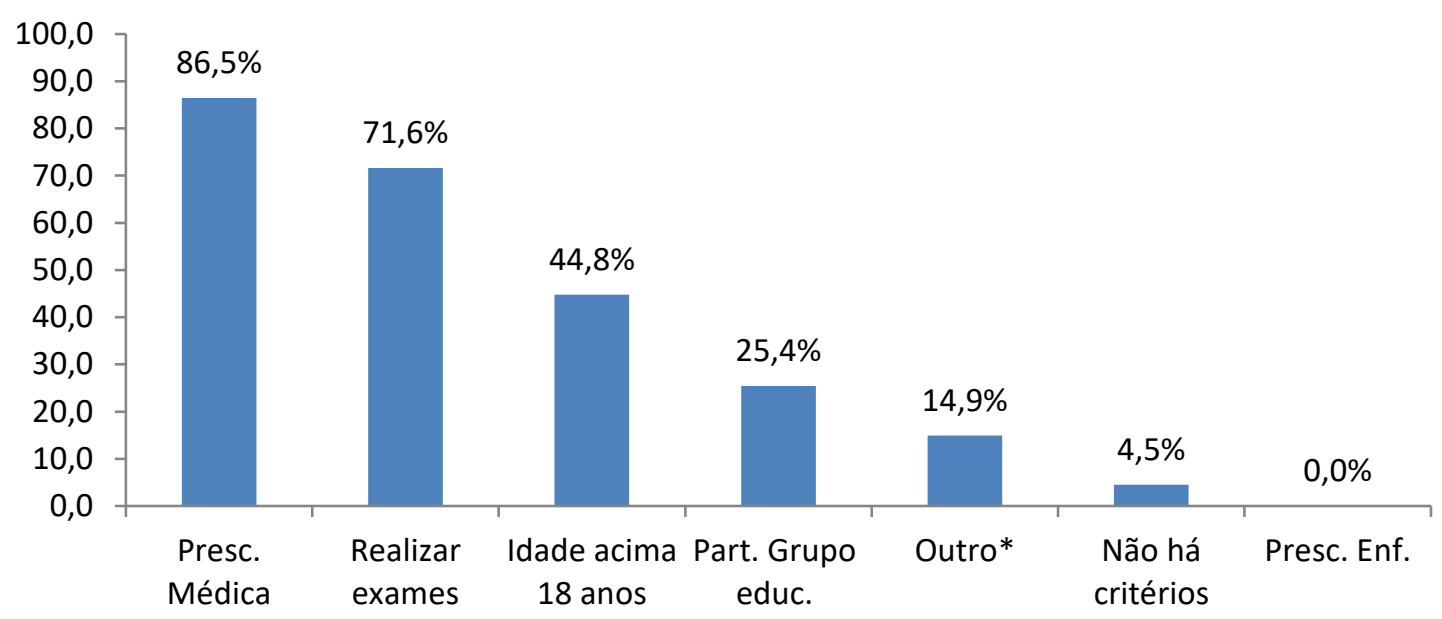

*Ser casada, ter ao menos um filho, estar menstruada, preventivo atual de seis meses.

Aos municípios que referiram a realização de exames como critério, foi questionado qual tipo de exame é necessário realizar para se ter acesso ao DIU. Houve respostas de tal questionamento $(n=48)$ oriundas de todos os municípios, porém, também de alguns municípios que não haviam referido realização de exames como critério $(n=9)$ - o que, somado, totalizou $n=57$. A Figura 6 apresenta os resultados obtidos. Dentre estes municípios, quase todos citaram o preventivo, mais da metade referiu teste de gravidez e um terço mencionou o exame de sangue como exames necessários. Além disso, os achados mostraram também que uma pequena parcela referiu necessidade de outros exames (14,9\%), dentre os quais a ultrassonografia transvaginal. 
Figura 6 - Tipos de exames necessários para disponibilização do DIU, dentre os municípios que declararam realização de exames como critério. Macrorregião Sul de Minas Gerais, 2016.

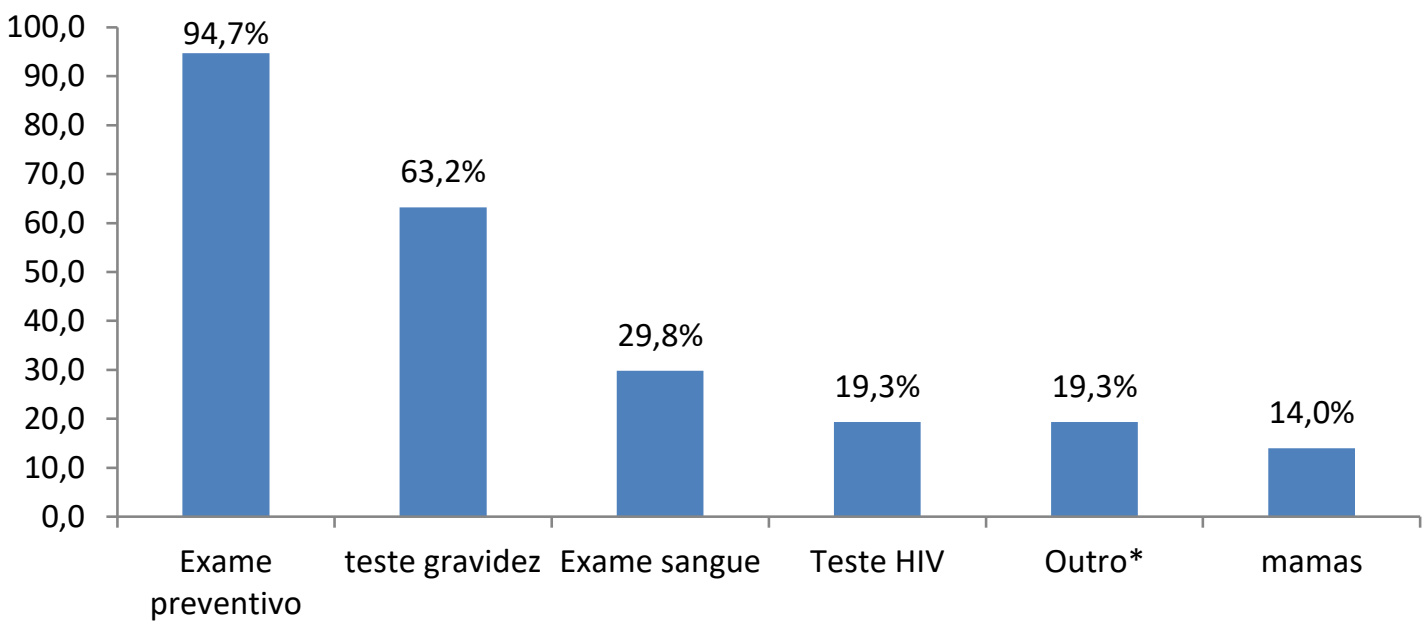

*Ultrassonografia transvaginal, avaliação ginecológica, avaliação pelo ginecologista, exame de urina tipo I, cultura vaginal.

A Figura 7 mostra os resultados quanto às formas de agendamento de consulta, caso ela seja necessária, quando a mulher tem interesse em usar o DIU. O estudo mostrou que, na grande maioria dos municípios, as consultas são agendadas tanto por iniciativa da mulher, como por encaminhamento do agente comunitário de saúde ou por encaminhamento de outro profissional de saúde $(77,2 \%)$. No entanto, foi verificado que, para uma parte dos municípios, o agendamento é realizado somente por iniciativa da mulher.

Figura 7 - Formas de agendamento de consulta, caso a mulher tenha interesse em usar o DIU, dentre os critérios dos municípios. Macrorregião Sul de Minas Gerais, 2016.

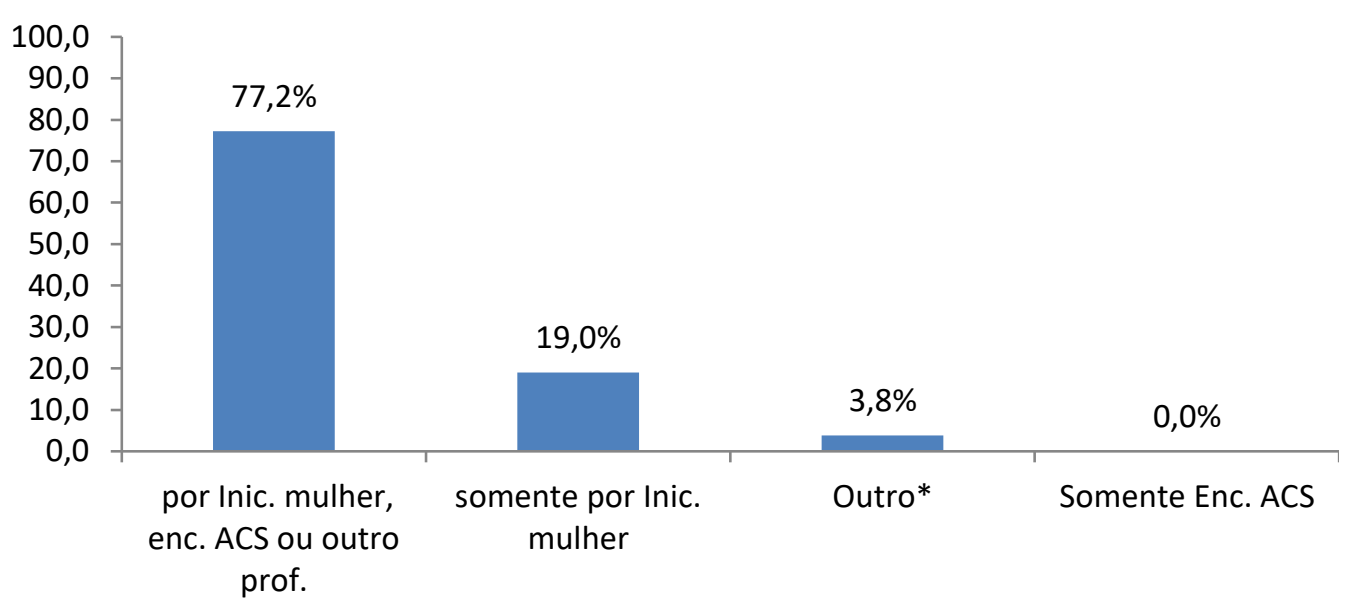

*Agendada pelo enfermeiro, agendada por médico ou enfermeiro da ESF, por encaminhamento de outro profissional. 
Em relação aos locais onde as mulheres podem adquirir o DIU, verificou-se que a grande maioria dos municípios referiu não disponibilizar o DIU nas UBS/ESF (79,2\%). Notou-se ainda que, alguns municípios citaram que a disponibilização do DIU acontece em locais de atenção secundária, como ambulatório de especialidade e hospital (Figura 8).

Figura 8 - Locais de disponibilização do DIU, dentre os municípios que o disponibilizam. Macrorregião Sul de Minas Gerais, 2016.

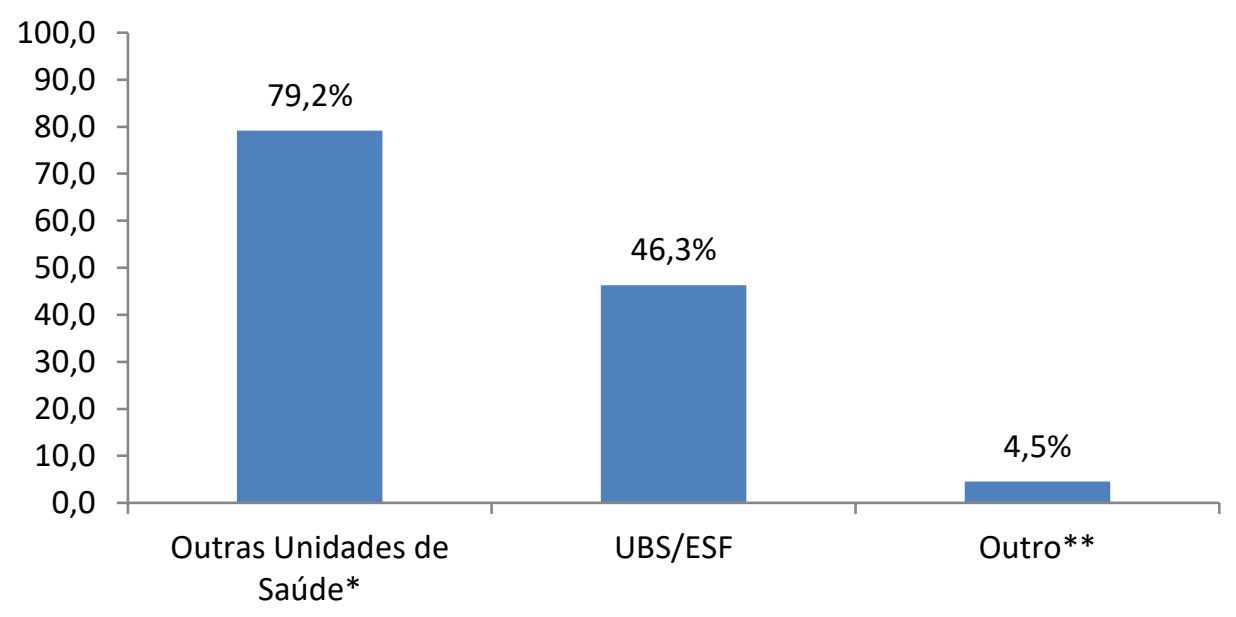

*Farmácia central, Setor Saúde da Mulher, Ambulatório de especialidades, Secretaria de Saúde e Hospital.

${ }^{* *}$ Casa de apoio à gestante e à puérpera, Centro Viva Vida.

\subsubsection{Aspectos relacionados à inserção do DIU}

Os resultados a seguir dizem respeito às rotinas que permeiam a inserção do DIU, como o tipo de profissional que insere o dispositivo e a necessidade de agendamento para sua inserção, assim como a adoção de determinadas condições clínicas da mulher - que podem impossibilitar o uso do DIU.

Observou-se que, em todos os municípios que disponibilizam o DIU, sua inserção é realizada pelo médico (ginecologista e obstetra 97,0\% e médico 3,0\%). Destaca-se, ainda, que nenhum município referenciou o enfermeiro como profissional que insere o DIU. Além disso, verificou-se também que quase todos os municípios têm como rotina o agendamento prévio para inserção do DIU (Tabela 5).

A Tabela 5 também mostra o tempo médio esperado pela mulher para ter o DIU inserido. Foi observado que as mulheres, na grande maioria dos municípios, esperam 
de uma a quatro semanas $(62,7 \%)$, mas, em quase um terço dos municípios, o tempo ultrapassa um mês $(28,4 \%)$.

Tabela 5 - Rotinas para inserção do DIU, segundo a existência de protocolo de disponibilização do DIU do município. Macrorregião Sul de Minas Gerais, 2016.

\begin{tabular}{|c|c|c|c|c|c|c|}
\hline \multirow{4}{*}{ Rotinas para inserção do DIU } & \multicolumn{6}{|c|}{ Existência de protocolo de disponibilização } \\
\hline & \multicolumn{4}{|c|}{ do DIU no Município } & \multicolumn{2}{|c|}{ Total } \\
\hline & \multicolumn{2}{|c|}{ Sim } & \multicolumn{2}{|c|}{ Não } & \multirow[b]{2}{*}{$\mathbf{n}$} & \multirow[b]{2}{*}{$\%$} \\
\hline & $\mathbf{n}$ & $\%$ & $\mathbf{n}$ & $\%$ & & \\
\hline \multicolumn{7}{|l|}{ Profissional que insere o DIU } \\
\hline Médico ginecologista e obstetra & 20 & 95,2 & 45 & 97,8 & 65 & 97,0 \\
\hline Médico generalista & 01 & 4,8 & 01 & 2,2 & 02 & 3,0 \\
\hline Enfermeiro & - & - & - & - & - & - \\
\hline \multicolumn{7}{|l|}{ Necessidade de agendamento } \\
\hline \multicolumn{7}{|l|}{ prévio para a inserção } \\
\hline Sim & 19 & 90,5 & 41 & 89,1 & 60 & 89,6 \\
\hline Não & 02 & 9,5 & 05 & 10,9 & 07 & 10,4 \\
\hline \multicolumn{7}{|l|}{ Tempo de espera para a inserção } \\
\hline 1 a 4 semanas & 18 & 85,7 & 24 & 52,2 & 42 & 62,7 \\
\hline Mais de 1 mês & 03 & 14,3 & 16 & 34,8 & 19 & 28,4 \\
\hline Menos de 1 semana & - & - & 06 & 13,0 & 06 & 8,9 \\
\hline
\end{tabular}

No que se refere às condições clínicas da mulher que podem impossibilitar a inserção do DIU, verificou-se que a maioria adota principalmente gravidez $(89,5 \%)$ e infecção vaginal $(80,6 \%)$ como condições impossibilitadoras, conforme apresentado na Tabela 6. Além disso, outras condições, como história anterior de DIP e aborto espontâneo ou induzido recente, também foram citadas por quase metade dos municípios (40,3\%). Do mesmo modo, foi observado que um terço dos municípios referiu anemia e história anterior de gravidez ectópica como condições que podem impossibilitar a inserção do DIU $(29,8 \%)$.

Na comparação entre as condições da mulher que podem impossibilitar a inserção do DIU, observou-se que os municípios que utilizam protocolo adotam mais condições do que os que não utilizam, com exceção das condições gravidez e HIV (Tabela 6). 
Tabela 6 - Condições que podem impossibilitar a inserção do DIU, segundo protocolo de disponibilização do DIU. Macrorregião Sul de Minas Gerais, 2016.

\begin{tabular}{|c|c|c|c|c|c|c|}
\hline \multirow{4}{*}{$\begin{array}{c}\text { Condições que podem } \\
\text { impossibilitar a inserção do DIU }\end{array}$} & \multicolumn{6}{|c|}{ Presença de protocolo de disponibilização } \\
\hline & \multicolumn{4}{|c|}{ do DIU no município } & \multicolumn{2}{|c|}{ Total } \\
\hline & \multicolumn{2}{|c|}{ Sim } & \multicolumn{2}{|c|}{ Não } & \multirow[b]{2}{*}{$\mathbf{n}$} & \multirow[b]{2}{*}{$\%$} \\
\hline & $\mathbf{n}$ & $\%$ & $\mathbf{n}$ & $\%$ & & \\
\hline Gravidez & 18 & 85,7 & 42 & 91,3 & 60 & 89,5 \\
\hline Infecção vaginal & 20 & 95,2 & 34 & 73,9 & 54 & 80,6 \\
\hline Aborto espontâneo ou induzido recente & 09 & 42,9 & 18 & 39,1 & 27 & 40,3 \\
\hline História anterior de DIP & 09 & 42,9 & 18 & 39,1 & 27 & 40,3 \\
\hline Anemia & 08 & 38,1 & 12 & 26,1 & 20 & 29.8 \\
\hline História anterior de gravidez ectópica & 10 & 47,6 & 10 & 21,7 & 20 & 29,8 \\
\hline HIV & 05 & 23,8 & 13 & 28,3 & 18 & 26,9 \\
\hline Outro* & 02 & 9,5 & 07 & 15,2 & 09 & 13,4 \\
\hline Estar amamentando & 01 & 4,8 & 02 & 4,4 & 03 & 4,5 \\
\hline Execução de trabalho físico pesado & 02 & 9,5 & 01 & 2,2 & 03 & 4,5 \\
\hline Diabetes & 02 & 9,5 & - & - & 02 & 3,0 \\
\hline Hipertensão & 02 & 9,5 & - & - & 02 & 3,0 \\
\hline
\end{tabular}

*Malformação uterina, fluxo sanguíneo excessivo, sangramento vaginal sem causa definida, tumores uterinos, múltiplos parceiros, colo do útero invertido, nuliparidade, espessamento endometrial, presença ou suspeita de câncer do colo do útero e contraindicação médica.

\subsubsection{Aspectos relacionados aos grupos educativos de planejamento reprodutivo}

Na Figura 9, é apresentada a proporção de municípios que referiram realizar grupos de planejamento reprodutivo nas unidades de saúde. Surpreendentemente, quase metade dos municípios afirmou não realizá-los (43,0\%).

Figura 9 - Municípios que realizam grupos educativos de planejamento reprodutivo. Macrorregião Sul de Minas Gerais, 2016.

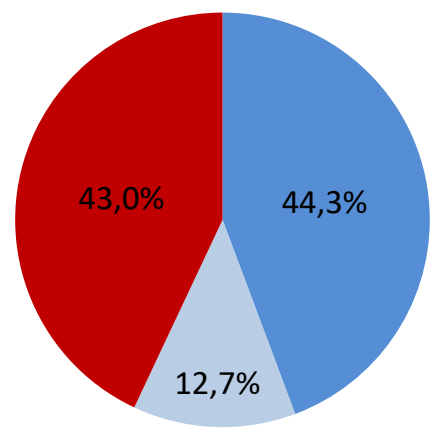

$$
\begin{aligned}
& \text { Sim, algumas unidades } \\
& \text { Sim, todas unidades } \\
& \text { Não }
\end{aligned}
$$


A Tabela 7 apresenta a caracterização dos grupos de planejamento reprodutivo dos municípios quanto a sua organização. Foi verificado que os enfermeiros se destacaram como coordenadores (84,4\%) e que nesses grupos existe maior ocorrência de mulheres de todas as idades como participantes (55,6\%). Os grupos são realizados preferencialmente nas UBS/ESF (88,9\%), em horários variados $(62,2 \%)$ e com frequência esporádica $(51,1 \%)$. Porém, em uma parcela de municípios, a realização dos grupos acontece somente no período da manhã ou somente no período da tarde.

Tabela 7 - Organização dos grupos educativos de planejamento reprodutivo. Macrorregião Sul de Minas Gerais, 2016.

(continua)

\begin{tabular}{|c|c|c|}
\hline Organização dos grupos & $\mathbf{n}$ & $\%$ \\
\hline \multicolumn{3}{|l|}{ Coordenação } \\
\hline Enfermeiro & 38 & 84,4 \\
\hline Médico & 04 & 8,9 \\
\hline Assistente social & 01 & 2,2 \\
\hline Psicólogo & 01 & 2,2 \\
\hline NASF* $^{*}$ & 01 & 2,2 \\
\hline \multicolumn{3}{|l|}{ Participantes } \\
\hline Apenas mulheres (todas as idades) & 25 & 55,6 \\
\hline Mulheres/ homens (todas as idades) & 17 & 37,8 \\
\hline Apenas mulheres (exceto adolescentes) & 02 & 4,4 \\
\hline Apenas adolescentes & 01 & 2,2 \\
\hline \multicolumn{3}{|l|}{ Inscrição } \\
\hline Iniciativa das pessoas, enc. ACS, enc. outro profissional de & 33 & 73,3 \\
\hline saúde. & 05 & 11,1 \\
\hline Iniciativa das pessoas & 03 & 6,7 \\
\hline Enc. por outro profissional de saúde & 02 & 4,4 \\
\hline \multicolumn{3}{|l|}{ Enc. pelo ACS } \\
\hline Outro** & 02 & 4,4 \\
\hline \multicolumn{3}{|l|}{ Local } \\
\hline UBS/ESF & 04 & 88,9 \\
\hline Outro*** & 04 & 8,9 \\
\hline Espaços da comunidade (escolas, associações e igrejas) & 01 & 2,2 \\
\hline
\end{tabular}




\begin{tabular}{|c|c|c|}
\hline Organização dos grupos & $\mathbf{n}$ & $\%$ \\
\hline Período & & \\
\hline Horários variados & 28 & 62,2 \\
\hline Somente manhã & 06 & 13,3 \\
\hline Somente tarde & 06 & 13,3 \\
\hline Outro**** & 03 & 6,7 \\
\hline Somente noite & 01 & 2,2 \\
\hline Manhã, tarde e noite & 01 & 2,2 \\
\hline Frequência & - & - \\
\hline Esporádica & 23 & 51,1 \\
\hline 1 a 2 vezes /semana & 05 & 11,0 \\
\hline 1 a 2 vezes / mês & 15 & 33,0 \\
\hline 2 a 4 vezes / ano & 02 & 4,4 \\
\hline
\end{tabular}

*Núcleo de Apoio à saúde da Família;

${ }^{* *}$ Convite e palestras;

*** Casa de apoio à gestante e puérpera, centro de atendimento à mulher e à criança, hospital local, não existe local específico;

${ }^{* * * *}$ Manhã e tarde.

\subsubsection{Aspectos relacionados à disponibilização de outros métodos contraceptivos}

Quanto à disponibilização de outros métodos contraceptivos, foi observado que praticamente todos os municípios mencionaram disponibilizar a pílula oral, o preservativo masculino e o método injetável. Os demais métodos apresentaram valores iguais ou inferiores a 50\%. A disponibilização de preservativo feminino se revelou muito superior nos municípios que disponibilizam DIU $(26,9 \%)$, em relação àqueles que não o disponibilizam (8,3\%). Chama a atenção que apenas um quarto dos municípios disponibiliza a pílula de emergência (26,7\%), taxa considerada baixa, se comparada com a disponibilização de outros métodos, independentemente da sua situação quanto à disponibilização do DIU (Tabela 8). 
Tabela 8 - Disponibilização de outros métodos contraceptivos, segundo disponibilização do DIU. Macrorregião Sul de Minas Gerais, 2016.

\begin{tabular}{|c|c|c|c|c|c|c|}
\hline \multirow{3}{*}{$\begin{array}{l}\text { Outros métodos } \\
\text { contraceptivos } \\
\text { disponibilizados }\end{array}$} & \multicolumn{4}{|c|}{ Município disponibiliza DIU } & \multirow{2}{*}{\multicolumn{2}{|c|}{ Total }} \\
\hline & \multicolumn{2}{|c|}{ Sim } & \multicolumn{2}{|c|}{ Não } & & \\
\hline & $\mathbf{n}$ & $\%$ & $\mathbf{n}$ & $\%$ & $\mathrm{n}$ & $\%$ \\
\hline Pílula oral & 66 & 98,5 & 12 & 100,0 & 78 & 98,7 \\
\hline $\begin{array}{l}\text { Preservativo } \\
\text { masculino }\end{array}$ & 67 & 100,0 & 11 & 91,7 & 78 & 98,7 \\
\hline Injetável & 62 & 92,5 & 11 & 91,7 & 73 & 92,4 \\
\hline Laqueadura tubária & 34 & 50,8 & 05 & 41,7 & 39 & 49,4 \\
\hline Vasectomia & 32 & 47,8 & 06 & 50,0 & 38 & 48,1 \\
\hline Pílula de emergência & 19 & 28,4 & 03 & 25,0 & 22 & 27,8 \\
\hline Preservativo feminino & 18 & 26,9 & 01 & 8,3 & 19 & 24,0 \\
\hline Outro* & 03 & 4,5 & - & - & 03 & 3,8 \\
\hline Diafragma & 01 & 1,5 & - & - & 01 & 1,3 \\
\hline
\end{tabular}

"Vasectomia apenas para pessoas com maior vulnerabilidade social e risco, vasectomia em campanhas ou via assistente social, orientações e métodos naturais.

A Tabela 9 apresenta os resultados quanto aos locais de disponibilização dos métodos contraceptivos, que se encontra concentrada na farmácia central $(75,9 \%)$ e nas UBS/ESF $(68,4 \%)$.

Tabela 9 - Locais de disponibilização de outros métodos contraceptivos, segundo disponibilização do DIU. Macrorregião Sul de Minas Gerais, 2016.

\begin{tabular}{|c|c|c|c|c|c|c|}
\hline \multirow{3}{*}{$\begin{array}{c}\text { Local de } \\
\text { disponibilização de } \\
\text { outros métodos } \\
\text { contraceptivos }\end{array}$} & \multicolumn{4}{|c|}{ Município disponibiliza DIU } & \multirow{2}{*}{\multicolumn{2}{|c|}{ Total }} \\
\hline & \multicolumn{2}{|c|}{ Sim } & \multicolumn{2}{|c|}{ Não } & & \\
\hline & $\mathbf{n}$ & $\%$ & $\mathbf{n}$ & $\%$ & $\mathbf{n}$ & $\%$ \\
\hline Farmácia central & 49 & 73,1 & 11 & 91,7 & 60 & 75,9 \\
\hline UBS/ESF & 45 & 67,2 & 09 & 75,0 & 54 & 68,4 \\
\hline $\begin{array}{l}\text { Ambulatório de } \\
\text { especialidade }\end{array}$ & 16 & 23,9 & 03 & 25,0 & 19 & 24,0 \\
\hline Secretaria de Saúde & 13 & 19,4 & 03 & 25,0 & 16 & 20,2 \\
\hline $\begin{array}{l}\text { Setor de Saúde da } \\
\text { Mulher }\end{array}$ & 10 & 14,9 & 01 & 8,3 & 11 & 13,9 \\
\hline Hospital & 04 & 6,0 & 02 & 16,7 & 06 & 7,6 \\
\hline Outro* & 05 & 7,5 & 01 & 8,3 & 06 & 7,6 \\
\hline Outro município & - & - & 02 & 16,7 & 02 & 2,5 \\
\hline
\end{tabular}

*Epidemiologia, farmácia particular ou comercial, setor DST/AIDS. 
Dessa forma, os achados mostraram que as barreiras organizacionais identificadas dizem respeito ao uso de protocolos, no que se refere à ausência ou não utilização destes, assim como a sua utilização incorreta ou, ainda, a utilização de protocolos elaborados com equívocos nas orientações. Também foram identificadas outras barreiras, que estão relacionadas à disponibilização do DIU, como a falta do método ou o excesso dos critérios estabelecidos pelos serviços de saúde para disponibilizá-lo. Ademais, foram identificadas barreiras associadas à inserção do DIU, tais como limitação da atuação do enfermeiro na inserção do DIU e agendamento prévio para realização do procedimento, assim como a adoção de determinadas condições clínicas da mulher que podem impossibilitar a inserção do DIU. Enfim, também foi observada a existência de barreiras organizacionais ligadas à organização dos grupos educativos de planejamento reprodutivo, como ausência de grupos ou o condicionamento do acesso ao DIU à participação nos grupos (Quadro 1).

Quadro 1 - Síntese das Barreiras Organizacionais para Disponibilização do DIU Identificadas nos Serviços de Atenção Básica à Saúde em Municípios da Macrorregião Sul de Minas Gerais. Macrorregião Sul de Minas Gerais, 2016.

\begin{tabular}{|c|c|c|c|}
\hline \multicolumn{4}{|c|}{ Barreiras relacionadas ao uso de Protocolos } \\
\hline $\begin{array}{c}\text { Barreiras } \\
\text { (\% observada no estudo) }\end{array}$ & Implicações & Recomendações & Evidências \\
\hline $\begin{array}{l}\text { Uso de protocolo de } \\
\text { atenção à saúde da } \\
\text { mulher sem capacitação } \\
\text { prévia dos profissionais } \\
\text { de saúde } \\
(77,8 \%) \\
\text { Ausência ou não uso de } \\
\text { protocolo específico para } \\
\text { disponibilização do DIU } \\
\text { (68,7\%) } \\
\text { Ausência ou não uso de } \\
\text { protocolo para atenção à } \\
\text { saúde da mulher } \\
\text { (44,3\%) } \\
\text { Uso de protocolo com } \\
\text { equívocos nas } \\
\text { recomendações } \\
(10,5 \%)\end{array}$ & $\begin{array}{l}\text { A falta ou não uso de } \\
\text { protocolo, o uso sem } \\
\text { capacitação, ou ainda, o uso } \\
\text { de protocolo com equívocos } \\
\text { nas orientações, podem } \\
\text { provocar: } \\
\text { Desencontro de informações } \\
\text { Variabilidade das condutas } \\
\text { clínicas } \\
\text { Processo de trabalho } \\
\text { desorganizado } \\
\text { Processo de trabalho sem } \\
\text { respaldo legal } \\
\text { Exercício profissional } \\
\text { negligente } \\
\text { Ausência de sistematização } \\
\text { da assistência } \\
\text { Descontinuidade e } \\
\text { inadequação das ações de } \\
\text { saúde } \\
\text { Danos à população }\end{array}$ & $\begin{array}{l}\text { É recomendado: } \\
\text { Adoção do uso de protocolo } \\
\text { para disponibilização do DIU } \\
\text { do Ministério da Saúde ou } \\
\text { da Organização Mundial da } \\
\text { Saúde } \\
\text { No caso da elaboração do } \\
\text { próprio protocolo, atenção } \\
\text { às recomendações de } \\
\text { construção de protocolos ou } \\
\text { aos princípios da prática } \\
\text { baseada em evidências } \\
\text { científicas } \\
\text { Realizar capacitação da } \\
\text { equipe de saúde sobre o } \\
\text { protocolo a ser utilizado } \\
\text { Divulgação do protocolo } \\
\text { utilizado para os } \\
\text { profissionais de saúde do } \\
\text { município } \\
\text { Constante atualização, } \\
\text { baseada em evidências } \\
\text { científicas, do protocolo } \\
\text { utilizado }\end{array}$ & $\begin{array}{l}\text { O uso de protocolos: } \\
\text { Subsidia a conduta dos } \\
\text { profissionais } \\
\text { Estabelece padrões de } \\
\text { condutas clínicas } \\
\text { Protege a população } \\
\text { atendida de procedimentos } \\
\text { inapropriados } \\
\text { Confere direcionalidade, } \\
\text { atualidade e adequação às } \\
\text { ações de saúde } \\
\text { Favorece o trabalho } \\
\text { interprofissional } \\
\text { Diferencia a competência } \\
\text { legal de cada membro da } \\
\text { equipe } \\
\text { Otimização do processo de } \\
\text { trabalho } \\
\text { Credibilidade dos serviços } \\
\text { de saúde pela sociedade } \\
\text { Minimiza barreiras ao } \\
\text { acesso ao DIU }\end{array}$ \\
\hline
\end{tabular}


(continuação)

\begin{tabular}{|c|c|c|c|}
\hline \multicolumn{4}{|c|}{ Barreiras relacionadas aos grupos educativos de planejamento reprodutivo } \\
\hline $\begin{array}{c}\text { Barreiras } \\
\text { (\% observada no estudo) }\end{array}$ & Implicações & Recomendações & Evidências \\
\hline $\begin{array}{l}\text { Não realização de grupos } \\
\text { educativos de } \\
\text { planejamento reprodutivo } \\
(43 \%) \\
\text { Condicionamento do } \\
\text { acesso ao DIU à } \\
\text { participação nos grupos } \\
\text { de planejamento } \\
\text { reprodutivo } \\
(25,4 \%)\end{array}$ & $\begin{array}{l}\text { A ausência de grupos } \\
\text { educativos ou o } \\
\text { condicionamento do acesso } \\
\text { ao DIU à participação nos } \\
\text { mesmos: } \\
\text { Diminui a autonomia das } \\
\text { mulheres para a escolha do } \\
\text { método } \\
\text { Contribui para que a mulher } \\
\text { não seja orientada sobre o } \\
\text { DIU e, provavelmente, não o } \\
\text { conhecerá suficientemente } \\
\text { para optar por ele } \\
\text { Exclui muitas mulheres de } \\
\text { usar o DIU, por falta de } \\
\text { disponibilidade de } \\
\text { participação nos grupos }\end{array}$ & $\begin{array}{l}\text { É recomendado: } \\
\text { Não condicionar o acesso } \\
\text { ao DIU à participação em } \\
\text { grupo de planejamento } \\
\text { reprodutivo, principalmente } \\
\text { porque as orientações sobre } \\
\text { o DIU podem ser individuais } \\
\text { Realizar grupos educativos } \\
\text { de planejamento reprodutivo } \\
\text { sistematicamente, com } \\
\text { várias opções de dias e } \\
\text { horários } \\
\text { Desmistificar crenças e } \\
\text { tabus sobre o DIU sempre } \\
\text { que houver oportunidade, } \\
\text { seja em grupo, consulta, } \\
\text { acolhimento ou visita } \\
\text { domiciliar }\end{array}$ & $\begin{array}{l}\text { A participação em grupo } \\
\text { educativo de planejamento } \\
\text { reprodutivo proporciona } \\
\text { maior autonomia e } \\
\text { segurança às mulheres, } \\
\text { homens e casais, para a } \\
\text { escolha do método } \\
\text { contraceptivo mais } \\
\text { adequado às suas } \\
\text { necessidades } \\
\text { Há evidências que } \\
\text { orientação sobre } \\
\text { planejamento reprodutivo e } \\
\text { doença sexualmente } \\
\text { transmissível fornecida } \\
\text { durante grupos educativos } \\
\text { pode aumentar a prática da } \\
\text { atividade sexual segura } \\
\text { O conhecimento inadequado } \\
\text { sobre qualquer método } \\
\text { contraceptivo pode ser um } \\
\text { fator de resistência à } \\
\text { aceitabilidade e uso do } \\
\text { contraceptivo } \\
\text { O condicionamento do } \\
\text { acesso ao DIU à } \\
\text { participação em grupos } \\
\text { pode acarretar importantes } \\
\text { perdas de mulheres que } \\
\text { desejam usá-lo, pois nem } \\
\text { todas as mulheres têm } \\
\text { disponibilidade para } \\
\text { participar nos dias e } \\
\text { horários definidos pelos } \\
\text { serviços de saúde } \\
\text { A utilização do DIU deve ser } \\
\text { incentivada e desmistificada, } \\
\text { pois representa o melhor } \\
\text { custo-benefício para o } \\
\text { planejamento familiar geral, } \\
\text { em especial no grupo de } \\
\text { vulneráveis }\end{array}$ \\
\hline \multicolumn{4}{|c|}{ Barreiras relacionadas à Disponibilização do DIU } \\
\hline $\begin{array}{c}\text { Barreiras } \\
\text { (\% observada no estudo) }\end{array}$ & Implicações & Recomendações & Evidências \\
\hline $\begin{array}{l}\text { Falta do DIU ou oferta } \\
\text { descontínua } \\
(15,2 \%)\end{array}$ & $\begin{array}{l}\text { A falta do DIU ou sua oferta } \\
\text { descontínua: } \\
\text { Limita a autonomia das } \\
\text { mulheres no controle da } \\
\text { fecundidade } \\
\text { Limita a escolha da mulher } \\
\text { pelo contraceptivo que } \\
\text { melhor se adapte a ela } \\
\text { Favorece a opção da mulher } \\
\text { por outro contraceptivo } \\
\text { Aumenta o risco de gravidez } \\
\text { não planejada }\end{array}$ & $\begin{array}{l}\text { É recomendado: } \\
\text { Ofertar o DIU continuamente }\end{array}$ & $\begin{array}{l}\text { A falta do DIU não se } \\
\text { justifica: } \\
\text { Segundo a Lei } 9.263 / 96 \text { em } \\
\text { seu art. } 9^{\circ} \text {, que dispõe sobre } \\
\text { o planejamento familiar, } \\
\text { todos os métodos } \\
\text { cientificamente aceitos } \\
\text { deverão ser oferecidos à } \\
\text { população } \\
\text { Segundo a Portaria } 1.555 \text { de } \\
\text { 30/07/2013 o financiamento, } \\
\text { aquisição e distribuição do } \\
\text { DIU cabem ao Ministério da } \\
\text { Saúde }\end{array}$ \\
\hline
\end{tabular}


(continuação)

\begin{tabular}{|c|c|c|c|}
\hline $\begin{array}{c}\text { Barreiras } \\
\text { (\% observada no estudo) }\end{array}$ & Implicações & Recomendações & Evidências \\
\hline & & & $\begin{array}{l}\text { A oferta de todos os } \\
\text { contraceptivos seguros } \\
\text { disponíveis no país garante } \\
\text { às pessoas liberdade de } \\
\text { opção para a escolha }\end{array}$ \\
\hline $\begin{array}{l}\text { Estabelecimento de } \\
\text { critérios desnecessários } \\
\text { para acesso ao DIU: } \\
\text { Necessidade de prescrição } \\
\text { médica e/ou agendamento } \\
\text { de consulta } \\
\text { (86,5\%) } \\
\text { Não disponibilização do DIU } \\
\text { nas Unidades Básicas de } \\
\text { Saúde e Estratégias Saúde } \\
\text { da Família } \\
\text { (83,7\%) } \\
\text { Necessidade de realização } \\
\text { de exames complementares } \\
\text { como de sangue, de } \\
\text { mamas, Papanicolaou, HIV } \\
\text { e ultrassonografia } \\
\text { transvaginal } \\
\text { (71,6\%) } \\
\text { Delimitação etária (mais de } \\
18 \text { anos de idade ou menos } \\
\text { de } 40 \text { anos de idade) } \\
\text { (44,8\%) }\end{array}$ & $\begin{array}{l}\text { O estabelecimento de } \\
\text { critérios desnecessários } \\
\text { para acesso ao DIU: } \\
\text { Limita o acesso das } \\
\text { mulheres ao DIU } \\
\text { Favorece a demora e } \\
\text { burocratização, que pode } \\
\text { levar a mulher a optar por } \\
\text { outro contraceptivo ou } \\
\text { enfrentar gravidez não } \\
\text { planejada, inclusive as } \\
\text { adolescentes }\end{array}$ & $\begin{array}{l}\text { É recomendado: } \\
\text { O DIU pode ser inserido } \\
\text { imediatamente durante a } \\
\text { consulta médica ou de } \\
\text { enfermagem, caso a mulher } \\
\text { se encaixe nos critérios de } \\
\text { elegibilidade e mencione } \\
\text { seu interesse por usá-lo } \\
\text { Não vincular o acesso ao } \\
\text { DIU à consulta com } \\
\text { especialista ou à realização } \\
\text { de exames complementares } \\
\text { Não é necessária realização } \\
\text { de exames, inclusive } \\
\text { ultrassonografia, como } \\
\text { rotina para inserção do DIU } \\
\text { Utilizar o teste rápido de } \\
\text { gravidez, ou a Lista de } \\
\text { Verificação de Gravidez } \\
\text { para afastar a possibilidade } \\
\text { de gravidez } \\
\text { Realizar o exame clínico } \\
\text { ginecológico para } \\
\text { determinar o tamanho e } \\
\text { posição do útero, ausência } \\
\text { de gravidez, ou sinal de } \\
\text { cervicite ou doença } \\
\text { inflamatória pélvica } \\
\text { Utilizar os procedimentos } \\
\text { preconizados na abordagem } \\
\text { sindrômica das doenças } \\
\text { sexualmente transmissíveis } \\
\text { do Manual } \\
\text { de Doenças Sexualmente } \\
\text { Transmissíveis do } \\
\text { Ministério da Saúde para } \\
\text { identificação de infecções } \\
\text { Disponibilizar o DIU para } \\
\text { adolescentes e para } \\
\text { mulheres acima de } 40 \text { anos } \\
\text { Disponibilizar e inserir o } \\
\text { DIU nas Unidades Básicas } \\
\text { de Saúde e Estratégia } \\
\text { Saúde da Família }\end{array}$ & $\begin{array}{l}\text { Dificuldades } \\
\text { organizacionais, como } \\
\text { horários para atendimento e } \\
\text { lentidão na realização de } \\
\text { exames, limitam o acesso } \\
\text { das mulheres ao DIU } \\
\text { O DIU pode ser usado com } \\
\text { segurança e eficácia pela } \\
\text { maioria das mulheres, sem } \\
\text { quaisquer exames de } \\
\text { sangue ou testes } \\
\text { preventivos para câncer } \\
\text { cervical, bastando o uso dos } \\
\text { Critérios Médicos de } \\
\text { Elegibilidade } \\
\text { O Ministério da Saúde } \\
\text { recomenda o uso dos } \\
\text { Critérios Clínicos de } \\
\text { Elegibilidade para uso de } \\
\text { DIU } \\
\text { O Ministério da Saúde } \\
\text { recomenda atenção especial } \\
\text { no exame clínico } \\
\text { ginecológico de forma a } \\
\text { determinar o tamanho e } \\
\text { posição do útero, assim } \\
\text { como ausência de gravidez } \\
\text { ou sinais de doença } \\
\text { inflamatória pélvica } \\
\text { O Ministério da Saúde não } \\
\text { recomenda a realização de } \\
\text { ultrassonografia transvaginal } \\
\text { antes e depois da inserção } \\
\text { do DIU como rotina } \\
\text { Não há qualquer } \\
\text { contraindicação da inserção } \\
\text { do DIU em adolescentes e } \\
\text { em mulheres acima de } 40 \\
\text { anos de idade }\end{array}$ \\
\hline
\end{tabular}


(continuação)

\begin{tabular}{|c|c|c|c|c|c|}
\hline \multicolumn{6}{|c|}{ Barreiras relacionadas à inserção do DIU } \\
\hline $\begin{array}{c}\text { Barreiras } \\
\text { (\% observada no estudo) }\end{array}$ & \multicolumn{2}{|c|}{ Implicações } & \multicolumn{2}{|c|}{ Recomendações } & Evidências \\
\hline $\begin{array}{l}\text { DIU é inserido apenas pelo } \\
\text { profissional médico } \\
(100 \%)\end{array}$ & \multicolumn{2}{|c|}{$\begin{array}{l}\text { A inserção do DIU como ato } \\
\text { privativo do médico pode } \\
\text { provocar: } \\
\text { Dificuldade para } \\
\text { agendamentos de consultas } \\
\text { médicas } \\
\text { Barreira no acesso ao DIU } \\
\text { pelas mulheres }\end{array}$} & \multicolumn{2}{|c|}{$\begin{array}{l}\text { É recomendado: } \\
\text { Considerar o respaldo legal } \\
\text { de que o enfermeiro } \\
\text { treinado e capacitado pode } \\
\text { inserir e retirar o DIU } \\
\text { Ampliar a atuação do } \\
\text { enfermeiro na inserção do } \\
\text { DIU } \\
\text { Realizar treinamento e } \\
\text { capacitação do enfermeiro e } \\
\text { médico para inserir e retirar } \\
\text { o DIU } \\
\text { Promover, no município, } \\
\text { discussões para resolução } \\
\text { do impasse legal da } \\
\text { prescrição, disponibilização } \\
\text { e inserão do DIU por } \\
\text { enfermeiros }\end{array}$} & $\begin{array}{l}\text { O Ministério da Saúde e a } \\
\text { Organização Mundial da } \\
\text { Saúde afirmam, de modo } \\
\text { abrangente, que } \\
\text { profissionais de saúde } \\
\text { treinados e capacitados } \\
\text { podem inserir e retirar o DIU } \\
\text { Segundo recomendações do } \\
\text { Task Shifting da } \\
\text { Organização Mundial da } \\
\text { Saúde, o enfermeiro } \\
\text { treinado e capacitado pode } \\
\text { inserir e retirar o DIU } \\
\text { A inserção do DIU por } \\
\text { enfermeiros é uma } \\
\text { intervenção eficaz que pode } \\
\text { melhorar o acesso e } \\
\text { diminuir desigualdades } \\
\text { No Brasil, o enfermeiro } \\
\text { treinado e capacitado tem } \\
\text { competência legal para } \\
\text { inserir e retirar o DIU } \\
\text { Inexiste impedimento legal } \\
\text { para que o enfermeiro } \\
\text { capacitado realize a } \\
\text { inserção do DIU }\end{array}$ \\
\hline $\begin{array}{l}\text { Agendamento prévio para } \\
\text { inserção do DIU } \\
(89,6 \%)\end{array}$ & \multicolumn{2}{|c|}{$\begin{array}{l}\text { O agendamento prévio para } \\
\text { inserção do DIU: } \\
\text { Pode ocorrer gravidez não } \\
\text { planejada no período entre } \\
\text { o desejo de usar o DIU e } \\
\text { sua efetiva inserção } \\
\text { Existe a possibilidade de o } \\
\text { agendamento prévio } \\
\text { configurar-se em } \\
\text { oportunidade perdida para } \\
\text { inserção do DIU, pois a } \\
\text { mulher pode não voltar }\end{array}$} & \multicolumn{2}{|c|}{$\begin{array}{l}\text { É recomendado: } \\
\text { Inserir o DIU no mesmo dia } \\
\text { em que a mulher mencionar } \\
\text { seu interesse por usá-lo, se } \\
\text { a mulher estiver dentro dos } \\
\text { critérios de elegibilidade } \\
\text { para o uso }\end{array}$} & $\begin{array}{l}\text { A inserção do DIU deve } \\
\text { ocorrer durante a consulta } \\
\text { médica ou de enfermagem, } \\
\text { pois o requerimento de } \\
\text { vários retornos à unidade de } \\
\text { saúde para obtenção do DIU } \\
\text { diminui o uso do mesmo } \\
\text { Existe associação entre a } \\
\text { diminuição de barreiras ao } \\
\text { acesso do DIU (como o } \\
\text { requerimento de vários } \\
\text { retornos para obtê-lo) e o } \\
\text { aumento do uso do mesmo }\end{array}$ \\
\hline \multicolumn{6}{|c|}{$\begin{array}{c}\text { Barreiras relacionadas às condições clínicas da mulher, que podem ou não impossibilitar a } \\
\text { inserção do DIU }\end{array}$} \\
\hline \multicolumn{2}{|c|}{$\begin{array}{c}\text { Barreiras } \\
\text { (\% observada no estudo) }\end{array}$} & \multicolumn{2}{|c|}{ Recomendações } & & Evidências \\
\hline \multicolumn{2}{|c|}{$\begin{array}{l}\text { Adotar a infecção vaginal como } \\
\text { condição que impossibilita a inserção } \\
\text { do DIU } \\
(80,6 \%)\end{array}$} & \multicolumn{2}{|c|}{$\begin{array}{l}\text { Não adotar a infecção vaginal como } \\
\text { condição que impossibilita a inserção } \\
\text { do DIU, a menos que a mulher tenha } \\
\text { cervicite purulenta }\end{array}$} & \multicolumn{2}{|c|}{$\begin{array}{l}\text { A maioria das mulheres pode usar o } \\
\text { DIU com segurança e eficácia, } \\
\text { incluindo-se, entre elas, mulheres que } \\
\text { tenham infecção vaginal } \\
\text { O DIU pode ser usado com restrição } \\
\text { em mulheres que tenham vaginites } \\
\text { sem cervicite purulenta }\end{array}$} \\
\hline
\end{tabular}


(continuação)

\begin{tabular}{|c|c|c|}
\hline $\begin{array}{c}\text { Barreiras } \\
\text { (\% observada no estudo) }\end{array}$ & Recomendações & Evidências \\
\hline $\begin{array}{l}\text { Adotar aborto espontâneo ou induzido } \\
\text { recente como condição que } \\
\text { impossibilita a inserção do DIU } \\
(40,3 \%)\end{array}$ & $\begin{array}{l}\text { Não adotar o aborto espontâneo ou } \\
\text { induzido recente como condição que } \\
\text { impossibilita a inserção do DIU, a } \\
\text { menos que a mulher tenha infecção } \\
\text { provocada pelo aborto }\end{array}$ & $\begin{array}{l}\text { O DIU pode ser usado sem restrição } \\
\text { no pós-abortamento primeiro trimestre } \\
\text { O DIU pode ser usado com restrição } \\
\text { no pós-abortamento que ocorre no } \\
\text { segundo trimestre, pois pode ocorrer } \\
\text { expulsão do DIU } \\
\text { Na ausência de infecção provocada } \\
\text { pelo aborto, o DIU pode ser inserido } \\
\text { imediatamente após o abortamento } \\
\text { Na presença de infecção provocada } \\
\text { pelo aborto, tratar e orientar outro } \\
\text { método de apoio. Após tratamento } \\
\text { reavaliar a possibilidade de inserção } \\
\text { do DIU }\end{array}$ \\
\hline $\begin{array}{l}\text { Adotar história anterior de doença } \\
\text { inflamatória pélvica como condição que } \\
\text { impossibilita a inserção do DIU } \\
(40,3 \%)\end{array}$ & $\begin{array}{l}\text { Não adotar história anterior de doença } \\
\text { inflamatória pélvica como condição que } \\
\text { impossibilita a inserção do DIU, a } \\
\text { menos que a mulher tenha fatores de } \\
\text { risco elevados para doença } \\
\text { sexualmente transmissível }\end{array}$ & $\begin{array}{l}\text { A maioria das mulheres pode usar o } \\
\text { DIU com segurança e eficácia, } \\
\text { incluindo-se entre elas mulheres que } \\
\text { tenham história anterior de doença } \\
\text { inflamatória pélvica } \\
\text { O DIU pode ser usado sem restrição } \\
\text { em mulheres que tenham história de } \\
\text { doença inflamatória pélvica, sem } \\
\text { fatores de risco para doenças } \\
\text { sexualmente transmissíveis, com } \\
\text { gravidez subsequente } \\
\text { O DIU pode ser usado com restrição } \\
\text { em mulheres que tenham história de } \\
\text { doença inflamatória pélvica, sem } \\
\text { fatores de risco para doenças } \\
\text { sexualmente transmissíveis, sem } \\
\text { gravidez subsequente } \\
\text { O DIU não deve ser usado por } \\
\text { mulheres que apresentam risco } \\
\text { individual muito elevado de gonorreia } \\
\text { ou clamídia no momento da inserção }\end{array}$ \\
\hline $\begin{array}{l}\text { Adotar anemia como condição que } \\
\text { impossibilita a inserção do DIU } \\
(29,8 \%)\end{array}$ & $\begin{array}{l}\text { Não adotar anemia como condição que } \\
\text { impossibilita a inserção do DIU }\end{array}$ & $\begin{array}{l}\text { A maioria das mulheres pode usar o } \\
\text { DIU com segurança e eficácia, } \\
\text { incluindo-se, entre elas, mulheres que } \\
\text { tenham anemia }\end{array}$ \\
\hline $\begin{array}{l}\text { Adotar história anterior de gravidez } \\
\text { ectópica como condição que } \\
\text { impossibilita a inserção do DIU } \\
(29,8 \%)\end{array}$ & $\begin{array}{l}\text { Não adotar história anterior de } \\
\text { gravidez ectópica como condição que } \\
\text { impossibilita a inserção do DIU }\end{array}$ & $\begin{array}{l}\text { A maioria das mulheres pode usar o } \\
\text { DIU com segurança e eficácia, } \\
\text { incluindo-se, entre elas, mulheres que } \\
\text { tenham história anterior de gravidez } \\
\text { ectópica }\end{array}$ \\
\hline $\begin{array}{l}\text { Adotar HIV como condição que } \\
\text { impossibilita a inserção do DIU } \\
(26,9 \%)\end{array}$ & $\begin{array}{l}\text { Não adotar HIV como condição que } \\
\text { impossibilita a inserção do DIU, a } \\
\text { menos que a mulher tenha AIDS e não } \\
\text { esteja em terapia antirretroviral ou } \\
\text { clinicamente bem }\end{array}$ & $\begin{array}{l}\text { Mulheres infectadas com HIV podem, } \\
\text { com segurança, colocar um DIU } \\
\text { O DIU não deve ser inserido em } \\
\text { mulheres que tenham Aids mas não } \\
\text { estejam em terapia antirretroviral ou } \\
\text { que não estejam clinicamente bem }\end{array}$ \\
\hline
\end{tabular}


(continuação)

\begin{tabular}{|c|c|c|}
\hline $\begin{array}{c}\text { Barreiras } \\
\text { (\% observada no estudo) }\end{array}$ & Recomendações & Evidências \\
\hline $\begin{array}{l}\text { Não adotar a gravidez como condição } \\
\text { que impossibilita a inserção do DIU } \\
(10,5 \%)\end{array}$ & $\begin{array}{l}\text { Adotar a gravidez como condição que } \\
\text { impossibilita a inserção do DIU }\end{array}$ & $\begin{array}{l}\text { O DIU somente pode ser inserido } \\
\text { mediante certeza de que a mulher não } \\
\text { esteja grávida }\end{array}$ \\
\hline $\begin{array}{l}\text { Adotar amamentação atual como } \\
\text { condição que impossibilita a inserção } \\
\text { do DIU } \\
(4,5 \%)\end{array}$ & $\begin{array}{l}\text { Não adotar amamentação atual como } \\
\text { condição que impossibilita a inserção } \\
\text { do DIU, caso a mulher esteja } \\
\text { menstruando } \\
\text { Atenção: caso a amamentação não } \\
\text { seja exclusiva e a menstruação não } \\
\text { tenha retornado, avaliar possibilidade } \\
\text { de gravidez }\end{array}$ & $\begin{array}{l}\text { O DIU pode ser inserido com restrição } \\
\text { até } 48 \text { horas após o parto, pois há } \\
\text { aumento do risco de expulsão do DIU } \\
\text { O DIU não deve ser inserido entre } 48 \\
\text { horas e } 4 \text { semanas após o parto, pois } \\
\text { aumenta o risco de perfuração uterina } \\
\text { A maioria das mulheres pode usar o } \\
\text { DIU com segurança e eficácia, } \\
\text { incluindo-se, entre elas, mulheres que } \\
\text { estejam amamentando e menstruando } \\
\text { Se a mulher estiver amamentando } \\
\text { exclusivamente e sua menstruação } \\
\text { não tiver retornado, ela poderá colocar } \\
\text { o DIU a qualquer momento entre } 4 \\
\text { semanas e } 6 \text { meses após o parto }\end{array}$ \\
\hline $\begin{array}{l}\text { Adotar execução de trabalho físico } \\
\text { pesado como condição que } \\
\text { impossibilita a inserção do DIU (4,5\%) }\end{array}$ & $\begin{array}{l}\text { Não adotar execução de trabalho físico } \\
\text { pesado como condição que } \\
\text { impossibilita a inserção do DIU }\end{array}$ & $\begin{array}{l}\text { A maioria das mulheres pode usar o } \\
\text { DIU com segurança e eficácia, } \\
\text { incluindo-se, entre elas, mulheres que } \\
\text { executam trabalho físico pesado }\end{array}$ \\
\hline $\begin{array}{l}\text { Adotar diabetes e/ou hipertensão como } \\
\text { condições que impossibilitam a } \\
\text { inserção do DIU } \\
(3,0 \%)\end{array}$ & $\begin{array}{l}\text { Não adotar diabetes e/ou hipertensão } \\
\text { como condições que impossibilitam a } \\
\text { inserção do DIU }\end{array}$ & $\begin{array}{l}\text { O DIU de cobre pode ser usado sem } \\
\text { restrição } \\
\text { O DIU com levonorgestrel pode ser } \\
\text { usado com restrições em mulheres } \\
\text { com história de hipertensão onde não } \\
\text { é possível aferir a pressão arterial }\end{array}$ \\
\hline
\end{tabular}

(conclusão) 




\section{DISCUSSÃO}

Este estudo permitiu identificar barreiras organizacionais para a disponibilização do DIU nos serviços de Atenção Básica à Saúde dos municípios da macrorregião Sul de Minas Gerais.

Primeiramente, foram identificadas barreiras organizacionais que dizem respeito ao uso de protocolos. A ausência ou a não utilização destes, assim como a sua utilização incorreta ou, ainda, a utilização de protocolos elaborados com equívocos nas orientações podem impor obstáculos à disponibilização do DIU. Outras barreiras organizacionais que também foram identificadas estão relacionadas à disponibilização do DIU, no que se refere à sua oferta e aos critérios adotados pelos serviços de saúde para disponibilizá-lo. A falta do DIU ou o excesso dos critérios estabelecidos pelos serviços de saúde podem se constituir como barreiras. Também foi observada a existência de barreiras organizacionais associadas à inserção do DIU. Aspectos como limitação da atuação do enfermeiro na inserção do DIU e agendamento prévio para realização do procedimento, assim como a adoção de determinadas condições clínicas da mulher que podem impossibilitar a inserção do DIU, também podem se constituir em barreiras. Por fim, igualmente, foram observadas barreiras instituídas pelos serviços de saúde para disponibilização do DIU na organização dos grupos educativos de planejamento reprodutivo. A ausência de grupos ou, ao contrário, o condicionamento do acesso ao DIU à participação em grupos pode dificultar o acesso das mulheres ao método.

Neste trabalho, para efeito didático, as barreiras organizacionais identificadas na oferta do DIU, na inserção do DIU e na organização dos grupos de planejamento reprodutivo foram tratadas separadamente da questão dos protocolos, apesar destes últimos, muitas vezes, tratarem também dos mesmos assuntos. Além disto, ainda para efeito didático, convém esclarecer as terminologias utilizadas "condição clínica" e "critério", que, por algum momento, podem causar alguma dificuldade. A "condição clínica" é aqui utilizada para se referir às condições de saúde da mulher. Já "critério" é utilizado para outras exigências que não sejam as condições de saúde, como realização de exames, prescrição médica, consultas, idade mínima para uso do DIU, participação em grupos educativos de planejamento reprodutivo e outros. 


\subsection{CARACTERIZAÇÃO DOS TRABALHADORES DE SAÚDE ENTREVISTADOS}

Quanto à caracterização dos trabalhadores respondentes, foi verificado que eles se caracterizam como adultos jovens, do sexo feminino e enfermeiros. Chama a atenção mais de um terço deles não possuir especialização e, dentre os que possuem, poucos serem especializados na área de saúde da mulher - o que seria recomendável para o exercício deste cargo. É importante considerar que o atendimento à saúde da mulher deve ir além das estruturas organizativas, sendo necessário que os trabalhadores, principalmente aqueles que estão à frente do processo de trabalho, estejam sensibilizados e capacitados para atender as necessidades da mulher.

A respeito das considerações dos trabalhadores sobre a existência de dificuldades e facilidades para mulheres obterem o DIU, o estudo mostrou que, surpreendentemente, a grande maioria reportou não haver dificuldades para as mulheres obterem o DIU. Constata-se que a opinião dos trabalhadores responsáveis pela área técnica de Saúde da Mulher não condiz com os resultados desta pesquisa. Neste ponto, a seguinte inflexão se faz necessária: se não há dificuldades para obtenção do DIU, por que é tão baixa a sua utilização? Pesquisas recentes, citadas nesta dissertação, mostram que o acesso ao DIU é permeado por barreiras organizacionais. Além disso, a aparente divergência entre os dados pode ser explicada pelas barreiras identificadas neste estudo, conforme discutidas a seguir.

\subsection{BARREIRAS ORGANIZACIONAIS QUE DIZEM RESPEITO AO USO DE PROTOCOLOS}

O atendimento em saúde estruturado na forma de protocolos organizacionais, clínicos e diretrizes terapêuticas tem sido muito utilizado, nos serviços, para auxiliar os trabalhadores de saúde na tomada de decisões. Os protocolos orientam fluxos, condutas e procedimentos, além de conferirem direcionalidade, atualidade e adequação às ações cotidianas de saúde (Araújo, 2011). Segundo Dombrowski, Pontes e Assis (2013), o protocolo é amplamente usado também no Reino Unido, na Austrália e na Nova Zelândia, além do Brasil. De acordo com o Guia para Construção 
de Protocolos Assistenciais de Enfermagem (COREN/SP, 2015), os protocolos protegem a população atendida dos procedimentos inapropriados.

As secretarias de saúde dos municípios brasileiros vêm, na última década, utilizando protocolos para a organização e a regulamentação das ações do enfermeiro no atendimento básico à saúde (Rodrigues, Nascimento, Araújo, 2011). No que se refere ao uso de protocolos para atendimento da mulher ou para a disponibilização do DIU, a normatização de procedimentos com embasamento científico pode favorecer e subsidiar a conduta dos profissionais, pois legitima e homogeneíza as ações de saúde, minimizando as barreiras que as mulheres possam encontrar no acesso aos serviços de saúde (Araújo, 2011; Peres, 2012; COREN/SP, 2015).

Os achados deste estudo possibilitam observar que quase metade dos municípios não possui um protocolo para atendimento à saúde da mulher. Tal fato provoca certa preocupação, pois a falta ou a não utilização de um protocolo com detalhes operacionais pode causar desencontro de informações e variabilidade das ações entre os profissionais, ou entre os profissionais de saúde e a mulher, provocando um processo de trabalho desorganizado e sem respaldo legal (COREN/SP, 2015). Segundo Peres (2012), a heterogeneidade das ações e a ausência de sistematização da assistência são geradas devido à falta de orientações atuais e de discussões mais aprofundadas sobre as ações e os serviços de planejamento familiar entre gestores e profissionais. Além disso, a não utilização de protocolo também favorece o exercício profissional negligente, podendo causar danos à população, problemas legais e éticos aos profissionais e falta de credibilidade dos serviços de saúde pela sociedade (COREN/SP, 2015).

No que diz respeito à utilização de protocolos específicos para disponibilização do DIU, também foi verificado que a grande maioria dos municípios não os possui. Essa situação sugere que os serviços de saúde não estão organizados para a disponibilização do DIU. Desta maneira, parece que o processo de trabalho nos municípios está sendo realizado de acordo com o que "pensa" cada profissional de saúde (Araújo, 2011). É importante considerar que a existência ou a utilização de protocolo não fere a autonomia e nem desconsidera a responsabilidade do profissional. Quando o profissional decide não usar o protocolo institucional, ele responde individualmente por sua conduta. Por outro lado, quando ele o utiliza, tem o respaldo da instituição (COREN/SP, 2005). 
Sabe-se que a simples existência de protocolo no município não garante, por si só, que os trabalhadores de saúde o apliquem adequadamente no seu dia a dia, como também não garante a qualidade no atendimento das mulheres. Porém, é de suma importância a utilização correta dos protocolos, tendo em vista seu custo-benefício.

A construção dos protocolos é onerosa e trabalhosa, pois exige recursos humanos e financeiros, além de extensas revisões dos artigos publicados e atualização constante das evidências (WHO, 2004). Araújo (2011) menciona que, para haver efetivamente uma organização do serviço de saúde, por meio de protocolos, são necessários a adesão da equipe de saúde e o treinamento sobre o protocolo, assim como sua divulgação.

Diante do exposto, depreende-se a importância do treinamento na correta aplicação das condutas preditas nos protocolos. No entanto, este estudo mostrou que grande parte dos municípios que utilizam algum tipo de protocolo, bem como daqueles que elaboraram seu próprio protocolo, não realiza qualquer treinamento dos profissionais sobre sua utilização - o que nos faz refletir que, em muitos municípios, os protocolos podem não estar sendo utilizados corretamente, haja vista que a equipe de saúde não recebeu treinamento sobre os mesmos, propiciando a constituição de barreiras.

Sobre a utilização de protocolos elaborados com equívocos nas orientações, vale mencionar que a sua aplicação é bastante preocupante, pois as orientações neles contidas podem ser vagas ou inadequadas. Geralmente, esses protocolos são concebidos sem a atenção necessária às recomendações de construção de protocolos ou aos princípios da prática baseada em evidências.

Achados deste estudo sugerem que alguns protocolos de disponibilização do DIU foram elaborados com equívocos nas orientações, tendo em vista que neles não estão contidas algumas condições clínicas relevantes que podem impossibilitar a inserção do DIU e/ou, por outro lado, foram adotadas algumas condições clínicas irrelevantes.

Neste sentido, apesar de as condições clínicas que podem impossibilitar a inserção do DIU serem discutidas mais adiante, faz-se necessário comentar aqui alguns destes achados que confirmam tal suspeita.

Foi verificado, por exemplo, que uma parcela dos protocolos específicos para disponibilização do DIU não adota a gravidez como critério e que, por outro lado, quase metade adota história anterior de gravidez ectópica como condição clínica que pode impossibilitar a inserção do DIU. Para o MS (2002) e a OMS (2007), a gravidez 
é uma condição clínica que impossibilita a inserção do DIU, ao passo que a história anterior de gravidez ectópica não exclui a mulher de usá-lo. Isso nos faz refletir que a utilização destes protocolos, além de impor barreiras às mulheres, pode ocasionar danos à população e à atuação do profissional que os utiliza, já que profissionais com capacitação deficiente, pouca experiência ou desatualizados podem se apoiar integralmente neles (COREN/SP, 2005).

\subsection{BARREIRAS ORGANIZACIONAIS RELACIONADAS DISPONIBILIZAÇÃO DO DIU}

Os achados permitiram identificar barreiras na disponibilização do DIU, no que se refere à oferta do método e aos critérios adotados pelos serviços de saúde para disponibilizá-lo, pois a falta do DIU e o excesso ou rigor dos critérios utilizados para sua disponibilização podem se constituir em barreiras para o acesso das mulheres ao dispositivo.

\subsubsection{Oferta do DIU}

De acordo com o Manual Técnico de Assistência em Planejamento Familiar do MS (2002), a assistência em contracepção prevê a oferta de todas as alternativas de métodos contraceptivos, garantindo à mulher a escolha por aquele que melhor se adapte a ela (Brasil, 2002). Segundo a Lei 9.263/96, que trata do planejamento familiar, em seu art. 9o, todos os métodos cientificamente aceitos deverão ser oferecidos, garantindo às pessoas a liberdade de opção (Brasil, 1996). Além do mais, segundo a Portaria 1.555, de 30 de julho de 2013, em seu art. 6º, cabem ao MS o cabem ao MS o financiamento, a compra e a distribuição de métodos contraceptivos. Esta mesma portaria dispõe que aos municípios com população acima de 500.000 habitantes a entrega dos contraceptivos será direta, enquanto que, aos municípios que não se enquadrarem neste critério, os contraceptivos serão entregues às secretarias estaduais de saúde para posterior distribuição aos municípios.

Diante disso, a falta do DIU, por qualquer que seja o motivo (burocrático, logístico ou por falta de decisão do município em disponibilizá-lo), não se justifica. No entanto, este estudo permitiu observar que uma pequena parcela dos municípios não 
disponibiliza o DIU. Embora não seja expressivo numericamente, a falta do insumo constitui-se em barreira, muitas vezes, intransponível às mulheres. No projeto $\mathrm{CHOICE}^{2}$, Secura et al. (2010), entenderam isto e quebraram a barreira financeira, oferecendo o DIU sem nenhum custo às mulheres norte-americanas. Como resultado, estes autores perceberam que houve aumento da taxa de uso do DIU, que passou de $3 \%$ para $56 \%$ - o que mostra que, quando se tem o DIU para ser oferecido, seu uso pode ser ampliado. Soma-se a isto que, para Heilborn et al. (2009), os constrangimentos institucionais, como, por exemplo, a falta de métodos, limitam a autonomia das mulheres no controle da fecundidade. Além disso, é preocupante o achado que ratifica outra barreira: além da não disponibilização do DIU, em alguns municípios, não há qualquer opção de referência das mulheres a outros serviços, o que confirma a inexistência de fluxo de referenciamento para colocação do DIU e evidencia falha na implementação dos direitos sexuais e reprodutivos no país.

\subsubsection{Critérios para disponibilização do DIU}

Em relação aos critérios adotados pelos serviços de saúde dos municípios para disponibilização do DIU, chama atenção que a necessidade de prescrição de médica (ginecologista ou generalista) foi o mais citado, seguido pela necessidade de realização de exames. Tais achados são relevantes, pois, em muitos municípios, o acesso a exames e consultas não é tão simples - e nem tão rápido.

Desta forma, a vinculação do acesso ao DIU à consulta com especialista e à realização de exames, muitas vezes desnecessários, implica em barreiras organizacionais. A literatura mostra que as dificuldades e os contratempos organizacionais, como horários para atendimento e lentidão nos resultados de exames, limitam sobremaneira o acesso das mulheres ao DIU (Heilborn et al., 2009). Sendo assim, a demora e a burocratização são elementos obstaculizadores, que podem levar a mulher a optar por outro método contraceptivo ou enfrentar uma gravidez não planejada ou indesejada.

\footnotetext{
${ }^{2} \mathrm{O}$ Projeto $\mathrm{CHOICE}$ de contracepção é uma coorte prospectiva desenvolvido na região de St. Louis Estados Unidos como resposta à subutilização de contraceptivo reversível de longa duração, representados pelo DIU e Implante subcutâneo, no país (3\%). Com o objetivo de promover o uso de tais contraceptivos, o CHOICE quebrou barreiras de uso como o custo, o conhecimento e as práticas e concluiu que houve significativo aumento do uso de tais contraceptivos (67\%, sendo $56 \%$ DIU e $11 \%$ implante).
} 
Dentre os tipos de exames necessários para disponibilização do DIU, os achados mostraram que o mais referido foi o exame preventivo para câncer do colo do útero, depois do teste de gravidez, seguidos pelo exame de sangue. Em menor proporção, também foi citada a necessidade de realização de ultrassonografia transvaginal (USG).

No Manual Global sobre Planejamento Familiar para Profissionais e Serviços de Saúde da OMS (2007), não há nenhuma orientação específica sobre a realização de exames para uso do DIU. O mesmo manual orienta que o DIU pode ser usado com segurança e eficácia pela maioria das mulheres, sem quaisquer exames de sangue ou testes preventivos para câncer cervical, bastando o uso dos Critérios Médicos de Elegibilidade (OMS, 2007) (Anexo 3). Esses critérios constituem-se em um conjunto de perguntas que são feitas às mulheres para identificar problemas clínicos que podem excluí-las de usar o DIU. Em alguns casos, mesmo com a identificação de problemas, o DIU poderá ser inserido.

O Manual do MS (2002) também não faz nenhuma orientação específica sobre a realização de exames para colocação do DIU. Este manual orienta o uso dos Critérios Clínicos de Elegibilidade para o uso de DIU, cujas condições clínicas, que podem impossibilitar a inserção do mesmo, são apresentadas por categorias (Anexo 2). Ele aconselha atenção especial no exame ginecológico, de forma a identificar infecções vaginais, cervicais e pélvicas. Para isso, é sugerido o uso do Manual de DST do Ministério da Saúde, $3^{a}$ edição (1999), e o uso dos procedimentos preconizados na Abordagem Sindrômica das DST. Além disso, também orienta que, antes da inserção do DIU, o profissional de saúde deve fazer toque vaginal para determinar o tamanho (histerometria) e posição do útero, assim como ausência de gravidez ou sinais de DIP, não sendo necessária a realização de USG, antes e após a inserção do DIU como rotina, e que a mulher deve ser orientada sobre a maneira de verificar se o DIU está no lugar correto (Brasil, 2002).

No tocante ao teste de gravidez, este estudo mostrou que um terço dos municípios não considera necessária sua realização. Todavia, este estudo não observou quais os critérios utilizados para afastar a possibilidade de gravidez, tendo em vista que a inserção do DIU somente é realizada em mulheres que não estejam grávidas. Portanto, para estes municípios, ou para aqueles que desejarem, deve ser recomendado a utilização do teste rápido de gravidez, disponível em todo o país ou, 
na ausência deste, a utilização da Lista de Verificação de Gravidez proposta pela OMS (2007) (Anexo 4).

Outro critério também referido em alguns municípios foi a idade mínima de 18 anos. Os achados mostraram que metade dos municípios adota este critério para disponibilizar o DIU. Isso nos faz concluir que muitas adolescentes dessa macrorregião não têm acesso ao DIU, o que se constitui em uma barreira organizacional. Situação semelhante foi observada no estudo realizado por Figueiredo, Castro Filho e Kalckmann (2014), no qual consta que apenas um terço das UBS de São Paulo referiu colocação de DIU em adolescentes. Para Sorpreso, Soares Júnior e Baracat (2015), as adolescentes são vulneráveis à gravidez não planejada e/ou indesejada, com repercussões negativas para sua saúde. Estes mesmos autores mencionaram que o emprego de um método contraceptivo de alta eficácia, como o DIU, deve ser considerado, inclusive, como política de saúde pública. Penna e Brito (2015) relataram que as gravidezes indesejadas são mais frequentes em mulheres adolescentes, com baixa escolaridade e baixo nível socioeconômico para as quais o acesso aos métodos contraceptivos continua a ser uma grande preocupação para corrigir as desigualdades. Ademais, a Sociedade Americana de Pediatria também recomenda o emprego do DIU como opção para reduzir a taxa de gestações não planejadas na adolescência (American Academy of Pediatrics, 2014).

Em relação ao local de disponibilização do DIU, este estudo mostrou que a grande maioria dos municípios referiu não disponibilizar o DIU nas UBS/ESF, sendo geralmente centralizada a sua disponibilização. Além disso, em alguns municípios, a disponibilização acontece na atenção secundária, como ambulatório de especialidade e hospital. Peres (2012) menciona que a organização da atenção em contracepção deve se dar, inicialmente, pela UBS e que a colocação do DIU é um procedimento totalmente praticável no nível primário da atenção. Além disso, um dos fundamentos da Política Nacional de Atenção Básica, de 2006, é "possibilitar o acesso universal e contínuo a serviços de saúde de qualidade e resolutivos, caracterizados como a porta de entrada preferencial do sistema de saúde, com território adscrito permitindo o planejamento e a programação descentralizada" (Brasil, 2006). É preciso reconhecer que a disponibilização do DIU, quando suceder em qualquer outro lugar que não seja o mais próximo possível das residências das mulheres, pode representar uma barreira ao acesso, pois distância e burocracia podem se constituir como elementos obstaculizadores. No estudo de Bergin (2012), cuja amostra se constituiu de mulheres 
urbanas com alto risco de gravidez indesejada e baixa renda, foi demonstrado que a distância da clínica pode representar uma barreira adicional para cuidados contraceptivos.

Embora o estudo tenha captado inúmeras barreiras organizacionais na disponibilização do DIU, há também aspectos positivos que merecem ser evidenciados. A grande maioria dos municípios realiza o agendamento das consultas de diversas maneiras, não apenas por iniciativa da mulher, mas também por encaminhamento do agente comunitário de saúde ou de outro profissional. Acreditase que essa forma de agendamento melhora a captação e o encaminhamento de mulheres pelos serviços de saúde e pode favorecer seu acesso ao DIU.

\subsection{BARREIRAS ORGANIZACIONAIS ASSOCIADAS À INSERÇÃO DO DIU}

Os aspectos relevantes quanto à inserção do DIU referem-se à limitação da atuação do enfermeiro na inserção do DIU, à necessidade de agendamento prévio para realização do procedimento e à adoção de determinadas condições clínicas da mulher que podem impossibilitar a inserção do DIU.

Os achados confirmaram que tal procedimento tem sido tarefa exclusiva do médico. Destaca-se que, na pesquisa, o enfermeiro não foi referido por nenhum município como profissional que insere o DIU, mesmo tendo competência legal para execução de tal prática (PARECER 17/2010/COFEN/CTLN; COREN/SP, 2016). Segundo recomendações do Task Shifting (WHO, 2012), o enfermeiro treinado e capacitado pode inserir e retirar o DIU, pois é uma intervenção eficaz que pode melhorar o acesso e diminuir desigualdades. Peres (2012) menciona que a difusão do DIU no Brasil é limitada, devido sua inserção ser considerada ato privativo do médico, e sugere uma necessária discussão sobre a atuação do enfermeiro nos programas de saúde pública. Soma-se a isto o estudo de Dombrowski, Pontes, Assis (2013), que sustenta que a resolução do impasse legal quanto à prescrição de contraceptivos merece uma tomada de decisão urgente, pois configura barreira de acesso aos métodos contraceptivos, além de gerar transtorno legal e ético ao profissional.

Apesar de a inserção do DIU no Brasil ser considerada tarefa exclusiva do médico em muitos serviços (Peres, 2012), em São Paulo, por exemplo, estes profissionais nem sempre inserem o DIU, como relatado por Figueiredo, Castro Filho, Kalckmann (2014). Para estes autores, a inserção do DIU tem sua oferta ainda mais restrita na 
ESF, pois médicos generalistas não realizam tal procedimento, que o associam à ginecologia.

Segundo o MS (2002) e a OMS (2007), a inserção do DIU não é ato privativo do médico, tampouco do médico ginecologista. Essas instituições afirmam, de modo abrangente, que profissionais de saúde treinados e capacitados podem realizar tal procedimento. Além disso, Polus et al. (2015) relatam evidências sobre a eficácia e a segurança da disponibilização de contraceptivos por meio de Task Shifting, pois os resultados de estudos sobre a inserção do DIU por enfermeiros e obstetrizes sugerem haver pouca ou nenhuma diferença em comparação com o desempenho de médicos.

Constata-se, assim, que a ampliação da atuação do enfermeiro na disponibilização/inserção do DIU pode representar uma ação eficaz e segura para diminuir barreiras ao DIU e aumentar o acesso das mulheres ao método.

O estudo também mostrou que quase todos os municípios têm, como rotina, o agendamento prévio para inserção do DIU. O trabalho organizado dessa maneira nos faz refletir sobre alguns riscos, como, por exemplo, de gravidez não planejada ou indesejada e de oportunidade perdida para colocação do DIU. É importante ressaltar que, até a data da consulta subsequente para colocação do DIU, a mulher pode engravidar ou encontrar diversas dificuldades que a impossibilite de voltar. A literatura mostra que a inserção do DIU deveria ocorrer durante a consulta médica ou de enfermagem, pois o requerimento de vários retornos das mulheres para obtenção do DIU diminui as possibilidades de adesão ao método (Bergin, 2012). Segundo Secura et al. (2010), existe associação entre a diminuição de barreiras e o aumento do uso do DIU. Nesse sentido, o projeto CHOICE melhorou o acesso ao método, por meio da inserção imediata do DIU, quebrando a barreira do tempo de espera (Secura et al., 2010), e verificou aumento do uso do método. Tal processo de trabalho é considerado factível no Brasil, tendo em vista a cobertura da população pela ESF (64,6\%) (DAB, 2016) e o contingente de profissionais de saúde espalhados pelo país.

No tocante à adoção de condições que podem impossibilitar a inserção do DIU, o estudo mostrou que alguns municípios têm adotado restrições em demasia, o que pode ser justificado pelo excesso de zelo para com a mulher ou por insegurança da equipe de saúde. É importante destacar que as condições clínicas estabelecidas pelos serviços de saúde, que podem impossibilitar a inserção do DIU, não devem ser utilizadas simplesmente como barreiras, mas como referência de avaliação da mulher. 
Os achados mostram que condições clínicas relevantes, como a gravidez, deixaram de ser citadas por uma pequena parcela de municípios. Tal situação é preocupante, pois, nesses municípios, corre-se o risco de inserir o DIU em mulheres grávidas. É relevante mencionar que o DIU pode ser inserido na maioria das mulheres, desde que se tenha certeza de que a mulher não esteja grávida (Brasil, 2002; OMS, 2007; Poli et al., 2009).

Ainda sobre as condições que podem impossibilitar a inserção do DIU, a infecção vaginal foi a segunda mais referida, depois da gravidez. Porém, é preciso destacar que, segundo o MS (2002), o DIU pode ser inserido em mulheres com vaginites sem cervicite purulenta. Soma-se a isso que, para OMS (2007), a condição infecção vaginal, por si só, não se constitui como impossibilitante para inserção do DIU, sendo necessária uma avaliação da mulher antes de impedi-la de usar o DIU. Este mesmo órgão cita que as infecções que merecem maior atenção, quando da colocação do DIU, são a gonorreia e a clamídia, pois podem aumentar o risco de DIP. Se a mulher não apresentar sinais e sintomas destas infecções, recomenda-se o uso da avaliação de mulheres quanto ao risco de doenças sexualmente transmissíveis, sendo impossibilitado o uso do DIU somente no caso de risco individual muito elevado (OMS, 2007).

Sobre a condição "estar amamentando", a mulher deve ser avaliada com cuidado antes de impossibilitar a mulher que amamenta de usar o DIU. Estar amamentando, por si só, não é uma condição que impossibilita a inserção do dispositivo (OMS, 2007), mas sim a possibilidade de gravidez, tendo em vista que a mulher que amamenta pode ter ausência de menstruação. No entanto, alguns municípios que participaram da pesquisa referiram adotar "estar amamentando" como condição que impossibilita a inserção do DIU. Isso nos faz refletir que, a mulher que amamenta, mas não de maneira exclusiva, pode estar menstruando e tem indicação para uso do DIU, caso ela tenha interesse no método.

\subsection{BARREIRAS ORGANIZACIONAIS RELATIVAS AOS GRUPOS DE PLANEJAMENTO REPRODUTIVO}

Os serviços de saúde organizam grupos de planejamento reprodutivo como estratégia que proporciona orientação e informação às mulheres, aos homens e aos 
casais, para maior autonomia e segurança na escolha do método contraceptivo mais adequado às suas necessidades (Brasil, 2002). A literatura reforça os resultados positivos dos grupos educativos de planejamento reprodutivo. Casarin e Siqueira (2010), por exemplo, mencionaram que, nas publicações analisadas sobre enfermagem e educação em saúde no planejamento reprodutivo, o trabalho em grupo foi considerado um método eficiente para orientação sobre planejamento reprodutivo e DST, pois pode trazer como impacto, a mudança no comportamento frente à prática da atividade sexual segura. Desse modo, a realização dos grupos tem suma importância para instrumentalizar as pessoas na escolha do método. Dombrowski, Pontes e Assis (2013) acrescentaram que o conhecimento inadequado sobre qualquer método contraceptivo pode ser um aspecto de resistência à aceitabilidade e uso do método, o que pode ser minimizado com a realização regular de grupos educativos.

No entanto, na organização dos grupos de planejamento reprodutivo, barreiras ao DIU também podem ser estabelecidas. Na direção oposta ao que é preconizado, este estudo observou que quase metade dos municípios não realiza grupos de planejamento reprodutivo e, dentre os que realizam, metade o faz apenas esporadicamente. Foi verificado, também, que, em alguns municípios, as reuniões acontecem somente no período da manhã, ao passo que, em outros, somente no período da tarde, o que pode impedir a participação das mulheres que trabalham durante o dia. Soma-se a isso o fato que um quarto dos municípios adota como critério a exigência de participação nos grupos educativos para disponibilização do DIU. Esse contexto nos permite concluir que a organização dos grupos de planejamento reprodutivo nesses municípios é falha, o que se constitui em barreiras para acesso das mulheres ao DIU.

Segundo Heilborn et al. (2010), o condicionamento do acesso ao DIU à participação em grupos educativos pode acarretar importantes perdas de mulheres que desejam usar o método, tendo em vista que nem todas as mulheres têm disponibilidade para participar dos grupos nos dias e horários definidos pelos serviços. Ademais, se o município não realiza o grupo, ou realiza de maneira esporádica, entende-se que as pessoas não estão sendo orientadas sobre contracepção e saúde sexual ou reprodutiva, a menos que a orientação esteja sendo feita individualmente, o que não foi mensurado neste estudo.

É importante mencionar que a operacionalização de grupos educativos como imposição de barreiras não é uma exclusividade da macrorregião Sul de Minas Gerais. 
Peres (2012) também identificou problemas similares no Distrito Federal, mostrando que as UBS não estão preparadas para organizar os grupos educativos e continuam agindo da maneira mais prática e conveniente.

Apesar da vontade expressa da mulher em usar o DIU, é muito importante que ela tenha a oportunidade de conhecer e escolher a opção contraceptiva que melhor atenda às suas necessidades. Neste sentido, no caso da impossibilidade do uso de DIU ou da escolha por outro método, considerou-se relevante questionar aos municípios, independentemente se eles disponibilizam ou não o DIU, sobre a oferta de outros métodos contraceptivos à população. Verificou-se que a pílula oral e o preservativo masculino são os contraceptivos mais disponibilizados, sugerindo que outros métodos contraceptivos, como o DIU, não têm sido incentivados ou desmistificados. Outra consideração diz respeito à contracepção de emergência. Observou-se que é disponibilizada por apenas um quarto dos municípios, independentemente da sua situação quanto à disponibilização do DIU. Este dado mostra que, além do DIU, a contracepção de emergência também enfrenta barreiras organizacionais - o que pode corroborar a pesquisa de Santos (2014), que buscou identificar as razões para o seu não uso quando indicada e concluiu que são as barreiras impostas pelas UBS.

\subsection{LIMITAÇÕES E POTENCIALIDADES DO ESTUDO}

Como se trata de um estudo exploratório, uma das limitações do estudo é que não foi possível responder perguntas como:

- Quanto à elaboração dos protocolos: o que seria ideal? Cada município elaborar seu próprio protocolo ou seguir um modelo do MS/OMS? Qual material foi utilizado como referência na elaboração do protocolo? As evidências são fortes? O protocolo foi validado?

- Quanto ao uso do protocolo: em que medida o treinamento contribui para o uso de protocolos; os profissionais de saúde destes municípios estariam realmente utilizando os protocolos no seu cotidiano? Eles têm conhecimento da existência dos protocolos? Estariam aplicando adequadamente as condutas previstas nos protocolos? 
Neste sentido, considera-se que as respostas a estas questões podem contribuir significativamente para o desenvolvimento de ações de atenção em contracepção com qualidade.

Convém sobrelevar que a proporção de municípios participantes foi ao redor de $50 \%$ do total de municípios da macrorregião Sul de Minas Gerais, portanto, a amostra não é representativa e não é possível generalizar os achados. Contudo, os resultados obtidos poderiam ser utilizados para reflexão e avaliação dos serviços prestados, a fim de melhorar e ampliar a atenção à saúde da mulher em quaisquer outros municípios brasileiros.

Este estudo tem grande potencial para influenciar positivamente os serviços e as políticas públicas de saúde a oferecerem atendimento de qualidade às mulheres, garantindo-Ihes o exercício pleno dos seus direitos sexuais e reprodutivos. 
6 CONCLUSÃO 



\section{CONCLUSÃo}

A identificação de barreiras organizacionais para disponibilização do DIU nos serviços de Atenção Básica à Saúde é fundamental para a ampliação do acesso ao dispositivo e para os avanços na atenção à saúde da mulher.

Este estudo atingiu plenamente seus objetivos, pois identificou barreiras organizacionais para disponibilização do DIU nos serviços de Atenção Básica à Saúde da macrorregião Sul de Minas Gerais. Além disso, foi elaborada uma síntese de tais barreiras, destinada aos gestores de saúde, com as devidas recomendações. Este estudo também corroborou os achados de outros estudos que investigaram as barreiras que as mulheres encontram no acesso ao DIU ou outros contraceptivos, em outras localidades do país.

As barreiras identificadas dizem respeito ao uso de protocolos, considerando que a sua ausência ou a sua não utilização, assim como sua utilização incorreta ou, ainda, a utilização de protocolos elaborados com equívocos nas orientações, determinam obstáculos à disponibilização do DIU.

Também foram identificadas barreiras que estão relacionadas à disponibilização do DIU, que se referem à oferta do dispositivo e aos critérios estabelecidos pelos serviços de saúde para disponibilizá-lo. Certamente, a indisponibilidade do DIU e/ou o excesso dos critérios adotados instauram barreiras.

Do mesmo modo, foi observada a existência de barreiras organizacionais associadas à inserção do DIU. Aspectos como limitação da atuação do enfermeiro na inserção do DIU e agendamento prévio para realização do procedimento, assim como a adoção de determinadas condições clínicas da mulher como impossibilitantes do uso de DIU, dificultam o acesso ao método pelas mulheres.

$\mathrm{Na}$ organização dos grupos de planejamento reprodutivo, barreiras são igualmente instituídas, no que se relaciona à ausência de grupos ou ao condicionamento do acesso ao DIU à participação nesses grupos, pois nem todas as mulheres têm disponibilidade para participar dos grupos nos dias e horários definidos pelos serviços.

Destaca-se que o Ministério da Saúde tem interesse em difundir e viabilizar o uso do DIU, promovendo uma escolha contraceptiva não hormonal e, com isto, desestimulando as laqueaduras precoces (Peres, 2012). A utilização do DIU deve ser 
incentivada e desmistificada, pois representa o melhor custo-benefício para 0 planejamento familiar geral, em especial no grupo de vulneráveis (Penna, Brito, 2015).

As barreiras organizacionais são um dos muitos motivos para o não uso do DIU. As barreiras individuais e a preferência dos profissionais de saúde que atuam nesta área por certos métodos contraceptivos em detrimento dos demais podem ser outros motivos. Porém, sugere-se, com urgência, investimento em capacitação dos trabalhadores de saúde sobre o DIU e assuntos correlatos, além do ensino durante a graduação, e discussões para reafirmação da competência legal do enfermeiro, a fim de que mais mulheres e a população possam usufruir dos benefícios deste método. 
REFERÊNCIAS 



\section{REFERÊNCIAS}

American Academy of Pediatrics. Policy statement: contraception for Adolescents. Illinois; 2014.

Araújo JM. Construção, composição e implantação de protocolos clínicos nas ações de atenção primária [monografia]. Belo Horizonte: Faculdade de Medicina, Universidade Federal de Minas Gerais; 2011.

Andrade EC, Silva LR. Planejamento familiar: uma questão de escolha. Rev Eletr Enf [Internet]. 2009 [citado 2015 abr. 22];11(1). Disponível em: https://www.fen.ufg.br/fen revista/v11/n1/pdf/v11n1a11.pdf.

Bahamondes L, Bottura BF, Bahamondes MV, Gonçalves MP, Correia VM, EspejoArce $X$ et al. Estimated disability-adjusted life years averted by long-term provision of long acting contraceptive methods in a brazilian clinic. Hum Reprod. 2014;29(10):2163-70.

Bergin A, Tristan S, Terplan M, Gilliam ML, Whitaker AK. A missed opportunity for care: two-visit IUD insertion protocols inhibit placement. Contraception. 2012;86(6):694-7.

Brasil. Lei n. 9.263, de 12 de janeiro de 1996. Trata do planejamento familiar, estabelece penalidades e dá outras providências. Diário Oficial da União, Brasília, 15 jan. 1996. Seção 1.

Brasil. Ministério da Saúde, Centro Brasileiro de Análise e Planejamento. Pesquisa Nacional de Demografia e Saúde da Criança e da Mulher - PNDS 2006. Brasília; 2006.

Brasil. Ministério da Saúde. Portaria GM n.1.555, de 30 de julho de 2013. Dispõe sobre as normas de financiamento e de execução do Componente Básico de Assistência Farmacêutica no âmbito do Sistema Único de Saúde. Brasília; 2013. 
Brasil. Ministério da Saúde. Secretaria de Atenção à Saúde. Departamento de Atenção Básica. Avaliação para melhoria da qualidade da estratégia saúde da família. Brasília; 2005.

Brasil. Ministério da Saúde. Secretaria de Atenção à Saúde. Departamento de Atenção Básica. Política Nacional de Atenção Básica. Brasília; 2006.

Brasil. Ministério da Saúde, Secretaria de Atenção à Saúde, Departamento de Ações Programáticas Estratégicas. Direitos sexuais, direitos reprodutivos e métodos anticoncepcionais. Brasília; 2009.

Brasil. Ministério da Saúde, Secretaria de Atenção à Saúde, Departamento de Atenção Básica. Saúde sexual e saúde reprodutiva. Brasília; 2010.

Brasil. Ministério da Saúde, Secretaria de Atenção à Saúde, Departamento de Ações Programáticas Estratégicas. Atenção humanizada ao abortamento: norma técnica. $2^{\underline{a}}$ ed. Brasília; 2011.

Brasil. Ministério da Saúde, Secretaria de Políticas de Saúde, Área Técnica de Saúde da Mulher. Assistência em Planejamento Familiar: manual técnico. $4^{\underline{a}}$ ed. Brasília; 2002.

Caetano AJ. Acesso à contracepção segura. In: Brasil. Ministério da Saúde, Secretaria Especial de Políticas para as Mulheres da Presidência da República. Rumos para Cairo +20: compromissos do governo brasileiro com a plataforma da Conferência Internacional sobre População e Desenvolvimento. Brasília; 2010. p. 59-80.

Conselho Regional de Enfermagem de São Paulo. Orientação fundamentada 060/2016. São Paulo: Câmara Técnica; 2016.

Carvalho JO, Lemos AL, Cerqueira JC. Produção Bibliográfica acerca dos Direitos Humanos Sexuais e Reprodutivos na Atenção à Saúde e sua relação com a Enfermagem. Rev Pesq Cuid Fundam. 2010;2(3):1154-1164. 
Carvalho MLO, Schor N. Motivos de rejeição aos métodos contraceptivos reversíveis em mulheres esterilizadas. Rev Saude Publica. 2005;39 (5):788-94.

Casarin ST, Siqueira HCH. Planejamento familiar e os direitos reprodutivos: a produção científica da enfermagem. Rev Enferm UFPE. 2010;4(1):348-56.

Chein MBC, Brito LMO, Brito HO. Dispositivo intra-uterino. Cad Pesqui. 2000; 11(2):21-8.

Cleland J, Conde-Agudelo A, Peterson H, Ross J, Tsui A. Contraception and health. Lancet. 2012;380(9837):149-56.

Coelho EAC, Lucena MFG, Silva ATM. O Planejamento familiar no Brasil no contexto das políticas públicas de saúde: determinantes históricos. Rev Esc Enferm USP. 2000:34(1):37-44.

Conselho Federal de Enfermagem. Resolução COFEN - 17/2010. Trata-se de encaminhamento dos documentos em epígrafe pela Secretaria do COFEN para análise de Parecer sobre "viabilidade dos enfermeiros realizarem procedimentos com medicamentos e insumos para planejamento familiar reprodutivo. Brasília; 2010. p. $59-62$.

Corrêa S, Alves JED, Jannuzzi PM. Direitos e saúde sexual e reprodutiva: marco teórico-conceitual e sistema de indicadores. In: Cavenaghi S. Indicadores Municipais de Saúde Sexual e Reprodutiva. Rio de Janeiro: ABEP; 2006. p. 27-62.

Costa AM. Participação social na conquista das políticas de saúde para mulheres no Brasil. Cienc Saude Coletiva. 2009;14(4):1073-83.

Curitiba (Município). Secretaria Municipal de Saúde. Planejamento familiar: programa Mãe Curitibana. Curitiba; 2005. 
DATASUS [Internet]. Brasília: Departamento de Informática do SUS; 2012. [citado 2015 jun. 17]. Disponível em: http://tabnet.datasus.gov.br/cgi/tabcgi.exe?ibge/cnv/popMG.def

Demarqui DL, Gouvêa LAVN. Trajetória histórica das políticas de saúde para a mulher na fase do climatério. In: Anais da 3를 Mostra de Trabalhos em Saúde Pública; 2009 nov. 5-6; Cascavel. Cascavel: UNIOESTE; 2009. p. 1-12.

Dias CN, Spindola T. Conhecimento e prática das gestantes acerca dos métodos contraceptivos. Rev Enferm UERJ. 2007;15(1):59-63.

Dombrowski JG, Pontes JA, Assis ALM. Atuação do enfermeiro na prescrição de contraceptivos hormonais na rede de atenção primária em saúde. Rev Bras Enferm. 2013; 66(6): 827-32.

Figueiredo R, Castro Filho JM, Kalckmann S. Planejamento Familiar e Reprodutivo na Atenção Básica do Município de São Paulo: direito constitucional respeitado? Bol Inst Saude. 2014;15(2):81-93.

Gil AC. Métodos e técnicas da pesquisa social. São Paulo: Atlas; 2008.

Hayashi AML, Nogueira VO. Escolha dos métodos contraceptivos de um grupo de planejamento familiar em uma UBS de Guarulhos. Saude Coletiva. 2007; 4(16):1203.

Heilborn ML, Portella AP, Brandão ER, Cabral CS, Grupo CONPRuSUS. Assistência em contracepção e planejamento reprodutivo na perspectiva de usuárias de três unidades do Sistema único de Saúde no Estado do Rio de Janeiro, Brasil. Cad Saude Publica. 2009;25(Sup 2):s269-s278.

Holanda AAR, Barreto CFB, Holanda JCP, Mota KB, Medeiros RD, Maranhão TMO. Controvérsias acerca do dispositivo intrauterino: uma revisão. Femina. 2013;41(3):141-6. 
Kaneshiro B, Aeby T. Long-term safety, efficacy, and patient acceptability of the intrauterine Copper T-380A contraceptive device. Inst J Womens Health. 2010:2 211220.

Kittur ND, Secura GM, Peipert JF, Madden T, Finer LB, Allsworth JE. Comparison of contraceptive use between the Contraceptive CHOICE Project and state and national data. 2011;83(5):479-85.

Minas Gerais (Estado). Secretaria de Estado da Saúde. Adscrição e população dos municípios por macrorregião e microrregião de saúde: estimativa IBGE/TCU 2014. Belo Horizonte; 2014.

Minas Gerais (Estado). Caderno Regional do Sul de Minas Gerais. [S.I.]; 2014.

Morse MA, Fonseca SC, Barbosa MD, Calil MB, Eyer FPC. Mortalidade materna no Brasil: o que mostra a produção científica nos últimos 30 anos? Cad Saude Publica. $2011 ; 27(4): 623-38$.

Moura ERF, Silva RM. Informação e planejamento familiar como medidas de promoção da saúde. Cienc Saude Coletiva. 2004;9(4):1023-32.

Muller ALL. Estudo comparativo do uso do dispositivo intrauterino inserido no pósparto/ pós-cesárea imediatos [dissertação]. Porto Alegre: Faculdade de Medicina, Universidade Federal do Rio Grande do Sul; 2004.

Nicolau AIO, Moraes MLC, Lima DJM, Aquino OS, Pinheiro AKB. Laqueadura tubária: caracterização de usuárias laqueadas de um serviço público. Rev Esc Enferm USP. $2011 ; 45(1): 55-61$.

Nivia MAA. Los dispositivos intrauterinos: evolución a través de los tiempos, método de inserción, beneficios y riesgos. Med Uis. 2007;20:121-9. 
Organização das Nações Unidas. Declaração e Plataforma de Ação da IV Conferência Mundial sobre a Mulher [Internet]. Pequim; 1995. [citado em 2015 mar. 16]. Disponível em: http://www.sepm.gov.br/articulação/articulação-internacional/relatorio-pequim.pdf

Organização das Nações Unidas. Relatório da Conferência Internacional sobre População e Desenvolvimento: plataforma Cairo [Internet]. Cairo; 1994. [citado em 2015 mar. 16]. Disponível em: http://www.unfpa.org.br/Arquivos/relatorio-cairo.pdf

Organização Mundial da Saúde. Departamento de Saúde Reprodutiva e Pesquisa; Universidade Johns Hopkins. Escola Bloomberg de Saúde Pública, Centro de Programas de Comunicação, Projeto INFO. Planejamento familiar: um manual global para prestadores de serviços de saúde. Baltimore; 2007.

Osis MJMD. Paism: um marco na abordagem da saúde reprodutiva no Brasil. Cad Saude Publica. 1998;14(Supl. 1):25-32.

Painel de Monitoramento da Mortalidade Materna [Internet]. Brasília: Coordenação Geral de Informações e Análises Epidemiológicas; 2015. [citado 2015 mai. 17]. Disponível em: http://svs.aids.gov.br/dashboard/mortalidade/materna.show.mtw

Penna IAA, Brito MB. A importância da contracepção de longo prazo reversível. Femina. 2015;43(Supl.1):1-6.

Peres VBF. Descrição das ações e serviços do planejamento familiar em Unidades Básicas de Saúde com equipes de Saúde da Família no Distrito Federal, Brasil [dissertação]. Rio de Janeiro: Escola Nacional de Saúde Pública Sérgio Arouca; 2012.

Pimenta CAM, Pastana ICASS, Sichieri K, Solha RKT, Souza W. Guia para construção de protocolos assistenciais de enfermagem. São Paulo: COREN-SP; 2015.

Poli MEH, Mello CR, Machado RB, Pinho Neto JS, Spinola PG, Tomas G et al. Manual de anticoncepção da FEBRASGO. Femina. 2009;37(9):459-92. 
Polus S, Lewin S, Glenton C, Lerger PM, Rehfuess E, Gülmezoglu AM. Optimizing the delivery of contraceptives in low- and middle-income countries through task shifting: a systematic review of effectiveness and safety.

Reprod Health.2015; 12:27. DOI:10.1186/s12978-015-0002-2

Population Reference Bureau. The World's women and girls: 2011 data sheet. Washington; 2011.

Portal da Saúde. Histórico de cobertura da Saúde da Família [Internet]. Brasília; 2016. [citado 2016 out. 02]. Disponível em: http://dab.saude.gov.br/portaldab/historico cobertura sf.php

Rodrigues EM, Nascimento RG, Araújo A. Protocolo na assistência pré-natal: ações, facilidades e dificuldades dos enfermeiros da Estratégia de Saúde da Família. Rev Esc Enferm USP. 2011;45(5):1041-1047.

Santos AO. Razões do não uso da anticoncepção de emergência quando indicada [dissertação]. São Paulo: Escola de Enfermagem, Universidade de São Paulo; 2014.

Secura GM, Allsworth JE, Madden T, Mullermann JL, Peipert JF. The Contraceptive CHOICE Project: reducing barriers to long-acting reversible contraception. Am J Obstet Gynecol. 2010;203(2):115 e 1-7.

Silva CB. Regionalização da saúde em Minas Gerais: algumas reflexões críticas. Hygeia. 2010; 6(11):60-79.

Sorpreso ICE, Soares-Júnior JM, Baracat EC. Mulheres com vulnerabilidade sexual: anticoncepção reversível de longa duração pode ser a solução? Rev Bras Ginecol Obstet. 2015;37(9):395-6.

Wartchow E. Segunda mesa: acesso à contracepção segura. In: Brasil. Secretaria Especial de Políticas para as Mulheres da Presidência da República, Ministério da Saúde. Rumos para Cairo +20: compromissos do governo brasileiro com a plataforma 
da Conferência Internacional sobre População e Desenvolvimento. Brasília; 2010. p. 81.

World Health Organization. Drug and Therapeutics Committees: a practical guide. Geneva; 2004.

World Health Organization. Recommendations: optimizing health worker roles to improve access to key maternal and newborn health interventions through task shifting [Internet]. Geneve; 2012 [cited 2015 mai. 05]. Available from: http://apps.who.int/iris/bitstream/10665/77764/1/9789241504843 eng.pdf

World Health Organization. Selected practice recommendations for contraceptive use. $2^{\mathrm{a}}$ ed. Geneva; 2004.

Wu JP, Pickle S. Extended use of the intrauterine device: a literature review and recommendations for clinical practice. Contraception. 2014;89(6):495-503. 
APÊNDICES 



\section{APÊNDICES}

\section{Apêndice A - DISPOSITIVO INTRAUTERINO}

Existem vários modelos de DIU, sendo que alguns deles já foram abandonados, como é o caso da alça de Lippes, dando lugar aos mais modernos, com qualidade superior e com menores riscos associados. No Brasil, estão disponíveis dois tipos: aqueles que contêm cobre, podendo-se citar o TCu 380A e o Multiload 375 (MLCu375), e aqueles que contêm hormônio (progesterona ou levonorgestrel - LNG). Em outros países, existem outras variedades, chamadas de frame less, de inserção na musculatura uterina (Nivia, 2007; OMS, 2007; Poli et al., 2009).

O método de colocação de um dispositivo no útero, a fim de evitar a gravidez, é antigo, tendo seu início há dois milênios (Chein, Brito L, Brito H, 2000). Naquela época, durante as longas travessias nos desertos, eram colocadas pedras nos úteros de camelas para prevenção da prenhez. O primeiro DIU fabricado exclusivamente como anticoncepcional humano foi desenvolvido por Richard Richter, ginecologista alemão, em 1909. Ele elaborou um anel flexível, de $27 \mathrm{~mm}$ de diâmetro, feito do intestino do bicho de seda, enrolado com fio de alumínio e bronze. Posteriormente, em 1931, surgiu o anel de prata desenvolvido pelo pesquisador alemão Ernest Grafenberg, que, porém, apresentou grandes taxas de expulsão. Tal problema foi resolvido por Ota, no Japão, em 1934, que adicionou um suporte chapeado em ouro ou prata ao centro de seu anel. Inicialmente, se acreditava que o dispositivo era abortivo, porém, em 1969, Zipper demonstrou que a prata alemã continha mais de $30 \%$ de cobre, cuja ação é espermicida (Chein, Brito L, Brito H, 2000; Muller, 2004).

A partir da década de 1960, foram empregados os plásticos biologicamente ativos e seguros na produção dos DIU, surgindo os modelos flexíveis, que diminuíram as dores e os sangramentos, aumentando a sua aceitabilidade e a sua popularidade. Além disso, começou também a se empregar, nos DIU de plástico, sulfato de bário para promover a sua visibilidade aos raios X (Nivia, 2007). Em 1962, Jack Lippes, professor da Universidade de Nova York, desenvolveu o dispositivo conhecido como Alça de Lippes. Este dispositivo foi considerado padrão-ouro para avaliar outros DIU nos 30 anos seguintes e foi amplamente aceito por sua eficácia e seu conforto, tanto para a paciente quanto para seu parceiro sexual. Em 1968, Howard J. Tatum 
desenvolveu o DIU em forma de T e, no mesmo ano, o professor Jaime Zipper Abragan, da Universidade do Chile, criou dispositivos com liberação de íons de cobre no interior da cavidade uterina, aumentando a eficiência do dispositivo anticoncepcional. Nessa época, surgiu o primeiro DIU impregnado com progesterona, cujo objetivo era diminuir o sangramento menstrual (Nivia, 2007).

O mecanismo de ação do DIU não está completamente esclarecido, mas evita a gravidez por meio de alterações químicas, que interferem na migração dos espermatozoides, impedindo a fertilização do óvulo. Ele tem taxas de falhas extremamente baixas, de 1 por 100 mulheres no primeiro ano de uso, semelhante à taxa observada na esterilização cirúrgica feminina. Quanto às indicações e contraindicações, devem-se observar os Critérios Médicos de Elegibilidade para uso de DIU da OMS (2007), que estabeleceu um conjunto de perguntas que ajuda a verificar se há sinais de problemas que podem excluir a colocação de DIU, e os Critérios Clínicos de Elegibilidade para uso de DIU do MS (Brasil, 2002) que estabeleceu as seguintes categorias: categoria 1, o DIU pode ser usado sem restrições; categoria 2, o DIU pode ser usado com restrições; categoria 3, o DIU é o método de última escolha. Os riscos possíveis e comprovados superam os benefícios do método, sendo necessário acompanhamento rigoroso; categoria 4, o DIU não pode ser usado (OMS, 2007; Poli et al., 2009; Holanda et al., 2013; Bahamondes, 2014).

A inserção do DIU pode ocorrer a qualquer momento durante o ciclo menstrual, desde que se tenha certeza de que a mulher não esteja grávida, ou em até 12 dias após o início da menstruação, desde que não existam sinais de infecção ou de malformação uterina. O dispositivo deve ser inserido, de preferência, durante a menstruação, pois afasta a possibilidade de gravidez. Soma-se a isto que, neste período, o orifício cervical fica dilatado, facilitando a inserção e provocando menos dor, além do fato de qualquer sangramento causado pela inserção não incomodar tanto a mulher. Após o parto, ele pode ser inserido, porém, o momento mais indicado é logo após a expulsão da placenta ou até 48 horas após o parto; caso contrário, devem-se esperar quatro semanas para a sua colocação. Depois de aborto espontâneo ou provocado, têm-se demonstrado que o DIU é mais eficiente, por não haver o risco de esquecimento do uso, e sua inserção deve ocorrer imediatamente, no fim do esvaziamento uterino, se não houver infecção, ou dentro dos primeiros 15 dias pós-abortamento ou logo depois da primeira menstruação, após o esvaziamento 
(Brasil, 2002; OMS, 2007; Brasil, 2011). Como rotina, não é necessário realizar ultrassonografia após a inserção (Brasil, 2002, Poli et al., 2009).

Quanto à remoção do DIU, se a mulher manifestar o desejo de retirá-lo, seja qual for o motivo, não se deve recusar ou adiar sem necessidade. Porém, se a mulher não solicitar, o mesmo deve ser removido de acordo com o período de validade. Se for o TCu 380A, deve ser removido após 10 anos da sua inserção, enquanto o MLCu375 após 5 anos e o LNG após 5 a 7 anos. A remoção antes do período de validade deve ocorrer nos casos de DIP, gravidez, sangramento vaginal anormal, perfuração do útero e expulsão parcial do DIU. O retorno da fertilidade após a remoção do DIU é imediato. Quanto à proteção contra o contágio de doenças sexualmente transmissíveis (DST), a eficácia é nula (Brasil, 2002; OMS, 2007). 


\section{APÊNDICE B - CARACTERIZAÇÃO DA MACRORREGIÃO SUL DE MINAS GERAIS}

Para a realização da caracterização da macrorregião Sul de Minas Gerais, apresentada a seguir, se utilizou do Caderno Regional do Sul de Minas (Minas Gerais, 2014).

Segundo o Caderno, a maioria da área do Sul de Minas localiza-se na bacia hidrográfica do rio Grande, que nasce na Serra da Mantiqueira. Esta macrorregião apresenta oito circuitos turísticos: Águas, Caminhos do Sul de Minas, Caminhos Gerais, Malhas do Sul de Minas, Nascentes das Gerais, Serras Verdes do Sul de Minas, Terras Altas da Mantiqueira e Vale Verde Quedas D'água.

Dentre as atividades econômicas desenvolvidas na macrorregião Sul de Minas, destacam-se pecuária leiteira, metalurgia-alumínio, mineração, agroindústria, eletroeletrônicos, helicópteros, autopeças, bebidas, têxteis e turismo. Segundo o IBGE (2010), esta macrorregião é responsável por 12,7\% do Produto Interno Bruto de Minas Gerais.

A média de moradores por domicílio foi de 3,3, valor inferior ao registrado para Minas Gerais em 2010. Além disto, a grande maioria dos municípios usufrui de um bom serviço de saneamento, possuindo os melhores índices do estado.

Em 2011, a macrorregião Sul de Minas, em comparação com a população do Estado, apresenta uma estrutura etária mais envelhecida. Ainda em comparação ao Estado, o atendimento pela ESF, o acompanhamento da gestante, os exames preventivos e de mamografia são superiores. Já a educação apresenta uma escolaridade média da população de 15 anos ou mais, semelhante à do Estado (7 anos completos). Vale salientar que esta macrorregião possui 55 instituições de ensino superior (IES), sendo que 51 (92,7\%) são privadas e 4 (7,3\%) são públicas federais. Não há IES pública estadual ou municipal. No que se refere à criminalidade, o nível é inferior ao observado para o Estado, assim como a renda per capita da população. 


\section{APÊNDICE C- SUPERINTENDÊNCIAS REGIONAIS DE SAÚDE (SRS) DA MACRORREGIÃO SUL DE MINAS GERAIS E RESPECTIVOS MUNICÍPIOS}

\begin{tabular}{|c|c|c|c|c|c|c|c|}
\hline \multicolumn{2}{|c|}{ SRS Alfenas } & \multicolumn{2}{|c|}{ SRS Passos } & \multicolumn{2}{|c|}{ SRS Pouso Alegre } & \multicolumn{2}{|c|}{ SRS Varginha } \\
\hline Município & Pop. & Município & Pop. & Município & Pop. & Município & Pop. \\
\hline 1. Alfenas & 74.804 & 1. Alpinópolis & 18.709 & 1. Albertina & 2.924 & 1. Aiuruoca & 6.116 \\
\hline 2. Alterosa & 13.829 & $\begin{array}{l}\text { 2. Bom Jesus da } \\
\text { Penha }\end{array}$ & 3.942 & 2. Andradas & 37.920 & 2. Alagoa & 2.696 \\
\hline 3. Arceburgo & 9.732 & 3. Capetinga & 7.039 & 3. Bom Repouso & 10.449 & 3. Baependi & 18.426 \\
\hline 4. Areado & 13.958 & 4. Capitólio & 8.251 & 4. Borda da Mata & 17.523 & 4. Boa Esperança & 38.734 \\
\hline $\begin{array}{l}\text { 5. Bandeira do } \\
\text { Sul }\end{array}$ & 5.405 & 5. Cássia & 17.433 & 5. Brasópolis & 14.585 & 5. Cambuquira & 12.612 \\
\hline 6. Botelhos & 14.893 & 6. Claraval & 4.588 & 6. Bueno Brandão & 10.886 & 6. Campanha & 15.635 \\
\hline 7. Cabo Verde & 13.838 & 7. Delfinópolis & 6.869 & $\begin{array}{l}\text { 7. Cachoeira de } \\
\text { Minas }\end{array}$ & 11.107 & $\begin{array}{l}\text { 7. Carmo da } \\
\text { Cachoeira }\end{array}$ & 11.872 \\
\hline 8. Campestre & 20.707 & 8. Doresópolis & 1.454 & 8. Caldas & 13.764 & $\begin{array}{l}\text { 8. Carmo de } \\
\text { Minas }\end{array}$ & 13.932 \\
\hline $\begin{array}{l}\text { 9. Campo do } \\
\text { Meio }\end{array}$ & 11.483 & $\begin{array}{l}\text { 9. Fortaleza de } \\
\text { Minas }\end{array}$ & 4.150 & 9. Camanducaia & 21.162 & 9. Carrancas & 3.958 \\
\hline $\begin{array}{l}\text { 10. Campos } \\
\text { Gerais }\end{array}$ & 27.760 & 10. Guapé & 13.911 & 10. Cambuí & 27.020 & 10. Carvalhos & 4.530 \\
\hline $\begin{array}{l}\text { 11. Carmo do Rio } \\
\text { Claro }\end{array}$ & 20.531 & 11. Ibiraci & 12.470 & 11. Careaçu & 6.372 & 11. Caxambu & 21.641 \\
\hline 12. Carvalhópolis & 3.380 & 12. Itamogi & 11.293 & $\begin{array}{l}\text { 12. Conceição das } \\
\text { Pedras }\end{array}$ & 2.755 & $\begin{array}{l}\text { 12. Conceição do } \\
\text { Rio Verde }\end{array}$ & 13.052 \\
\hline $\begin{array}{l}\text { 13. Conceição da } \\
\text { Aparecida }\end{array}$ & 9.888 & $\begin{array}{l}\text { 13. Itaú de } \\
\text { Minas }\end{array}$ & 15.135 & $\begin{array}{l}\text { 13. Conceição dos } \\
\text { Ouros }\end{array}$ & 10.609 & 13. Coqueiral & 9.241 \\
\hline 14. Divisa Nova & 5.797 & 14. Jacuí & 7.429 & 14. Congonhal & 10.732 & 14. Cordislândia & 3.447 \\
\hline 15. Fama & 2.350 & $\begin{array}{l}\text { 15. Monte Santo } \\
\text { de Minas }\end{array}$ & 21.238 & 15. Consolação & 1.732 & 15. Cristina & 10191 \\
\hline 16. Guaranésia & 18.727 & 16. Passos & 107.661 & $\begin{array}{l}\text { 16. Córrego do } \\
\text { Bom Jesus }\end{array}$ & 3.716 & 16. Cruzília & 14.716 \\
\hline 17. Guaxupé & 49.792 & 17. Piumhi & 32.352 & 17. Delfim Moreira & 7.962 & 17. Dom Viçoso & 2.988 \\
\hline 18. Juruaia & 9.474 & 18. Pratápolis & 8.746 & $\begin{array}{l}\text { 18. Espírito Santo } \\
\text { do Dourado }\end{array}$ & 4.470 & 18. Elói Mendes & 25.715 \\
\hline 19. Machado & 39.264 & $\begin{array}{l}\text { 19. São João } \\
\text { Batista do Glória }\end{array}$ & 6.981 & 19. Estiva & 10.918 & 19. Ijaci & 5.980 \\
\hline 20. Monte Belo & 13.049 & $\begin{array}{l}\text { 20. São José da } \\
\text { Barra }\end{array}$ & 6.888 & 20. Extrema & 30.016 & 20. Ilicínea & 11.633 \\
\hline 21. Muzambinho & 20.406 & $\begin{array}{l}\text { 21. São Roque } \\
\text { de Minas } \\
\text { 22. São }\end{array}$ & 6.741 & 21. Gonçalves & 4.235 & 21. Ingaí & 2.650 \\
\hline $\begin{array}{l}\text { 22. Nova } \\
\text { Resende }\end{array}$ & 15.599 & $\begin{array}{l}\text { Sebastião do } \\
\text { Paraíso }\end{array}$ & 65.984 & 22. Heliodora & 6.192 & 22. Itamonte & 14.276 \\
\hline 23. Paraguaçu & 20.442 & $\begin{array}{l}\text { 23. São Tomás } \\
\text { de Aquino }\end{array}$ & 7.062 & $\begin{array}{l}\text { 23. Ibitiúra de } \\
\text { Minas }\end{array}$ & 3.395 & 23. Itanhandu & 14.366 \\
\hline 24. Poço Fundo & 16.082 & $\begin{array}{l}\text { 24. Vargem } \\
\text { Bonita }\end{array}$ & 2.156 & 24. Inconfidentes & 6.973 & 24. Itumirim & 6.101 \\
\hline $\begin{array}{l}\text { 25. São Pedro da } \\
\text { União }\end{array}$ & 4.953 & & & 25. Ipuiúna & 9.607 & 25. Itutinga & 3.879 \\
\hline \multirow[t]{7}{*}{ 26. Serrania } & 7.548 & & & 26. Itajubá & 91.643 & 26. Jesuânia & 4.760 \\
\hline & & & & 27. Itapeva & 8.861 & 27. Lambari & 19.752 \\
\hline & & & & 28. Jacutinga & 23.341 & 28. Lavras & 94.228 \\
\hline & & & & 29. Maria da Fé & 14.157 & 29. Luminárias & 5.413 \\
\hline & & & & 30. Marmelópolis & 2.919 & 30. Minduri & 3.841 \\
\hline & & & & 31. Monte Sião & 21.658 & $\begin{array}{l}\text { 31. Monsenhor } \\
\text { Paulo }\end{array}$ & 8.244 \\
\hline & & & & 32. Munhoz & 6.197 & 32. Nepomuceno & 25.871 \\
\hline
\end{tabular}


(continuação)

\begin{tabular}{|c|c|c|c|c|c|c|c|}
\hline \multicolumn{2}{|c|}{ SRS Alfenas } & \multicolumn{2}{|c|}{ SRS Passos } & \multicolumn{2}{|c|}{ SRS Pouso Alegre } & \multicolumn{2}{|c|}{ SRS Varginha } \\
\hline Município & Pop. & Município & Pop. & Município & Pop. & Município & Pop. \\
\hline & & & & $\begin{array}{l}\text { 33. Natércia } \\
\text { 34. Ouro Fino } \\
\text { 35. Paraisópolis } \\
\text { 36. Pedralva } \\
\text { 37. Piranguçu } \\
\text { 38. Piranguinho } \\
\text { 39. Poços de } \\
\text { Caldas } \\
\text { 40. Pouso Alegre } \\
\text { 41. Santa Rita de } \\
\text { Caldas } \\
\text { 42. Santa Rita do } \\
\text { Sapucaí } \\
\text { 43. São João da } \\
\text { Mata } \\
\text { 44. São José do } \\
\text { Alegre } \\
\text { 45. São Sebastião } \\
\text { da Bela Vista } \\
\text { 46. Sapucaí-Mirim } \\
\text { 47. Senador } \\
\text { Amaral } \\
\text { 48. Senador José } \\
\text { Bento } \\
\text { 49. Silvianópolis } \\
\text { 50. Tocos do Moji } \\
\text { 51. Toledo } \\
\text { 52. Turvolândia } \\
\text { 53. Wenceslau } \\
\text { Braz } \\
\end{array}$ & $\begin{array}{l}4.661 \\
31.893 \\
19.664 \\
11.386 \\
5.254 \\
8.110 \\
154.974 \\
134.215 \\
8.990 \\
38.734 \\
2.728 \\
4.026 \\
5.045 \\
6.360 \\
5.233 \\
1.793 \\
6.053 \\
3.970 \\
5.846 \\
4.721 \\
2.547\end{array}$ & $\begin{array}{l}\text { 33. Olímpio } \\
\text { Noronha } \\
\text { 34. Passa Quatro } \\
\text { 35. Perdões } \\
\text { 36. Pouso Alto } \\
\text { 37. Ribeirão } \\
\text { Vermelho } \\
\text { 38. Santana da } \\
\text { Vargem } \\
\text { 39. São Bento } \\
\text { Abade } \\
\text { 40. São Gonçalo } \\
\text { do Sapucaí } \\
\text { 41. São Lourenço } \\
\text { 42. São Sebastião } \\
\text { do Rio Verde } \\
\text { 43. São Tomé das } \\
\text { Letras } \\
\text { 44. Seritinga } \\
\text { 45. Serranos } \\
\text { 46. Soledade de } \\
\text { Minas } \\
\text { 47. Três Corações } \\
\text { 48. Três Pontas } \\
\text { 49. Varginha } \\
\text { 50. Virgínia }\end{array}$ & $\begin{array}{l}2.577 \\
15.692 \\
20.292 \\
6.145 \\
3.857 \\
7.188 \\
4.704 \\
24.148 \\
42.372 \\
2.131 \\
6.724 \\
1.797 \\
1.984 \\
5.755 \\
73.894 \\
54.289 \\
125.208 \\
8.612\end{array}$ \\
\hline Total & 463.691 & Total & 397.573 & Total & 922.003 & Total & 857.865 \\
\hline
\end{tabular}

Fonte: http://tabnet.datasus.gov.br/cgi/tabcgi.exe?ibge/cnv/popMG.def 


\section{APÊNDICE D - ROTEIRO PARA ENTREVISTA SEMIESTRUTURADA}

\section{UNIVERSIDADE DE SÃO PAULO}

\section{ESCOLA DE ENFERMAGEM}

Projeto de Pesquisa: Barreiras organizacionais para disponibilização do Dispositivo Intrauterino nos serviços de Atenção Básica à Saúde (macrorregião Sul de Minas Gerais) Pesquisadora: Vanderléa Aparecida Silva Gonzaga

\section{Identificação do Município}

Nome do Município:

Superintendência Regional de Saúde (SRS) a que pertence:

$\square$ SRS Alfenas $\square$ SRS Passos $\square$ SRS Pouso Alegre $\square$ Varginha

Quantas unidades de saúde há no município (UBS, ESF e Centro de Especialidades)?

\section{Perfil do profissional responsável pela área técnica de saúde da mulher}

Profissão: $\square$ Médico $\square$ Enfermeiro $\square$ Psicólogo $\square$ Assistente Social $\square$ Odontólogo $\square$ Outro

Sexo: $\square$ Masculino $\square$ Feminino

Idade (anos completos):

Grau de escolaridade:

$\square$ Ensino Médio $\square$ Ensino Superior $\square$ Especialização $\square$ Mestrado $\square$ Doutorado

Possui especialização na área de Saúde da Mulher? $\square$ Não $\square \operatorname{Sim}$

Se sim, qual?

Tempo de atuação no cargo:

$\square$ menos de 1 ano $\square$ de 1 a 5 anos $\square$ de 6 a 10 anos $\square$ mais de 10 anos

\section{Atenção à Saúde da Mulher}

No município existe protocolo específico para atendimento à saúde da mulher? $\square$ Não $\square \operatorname{Sim}$

Se sim, ele foi elaborado pelo próprio município? $\square$ Não $\square \operatorname{Sim}$ 


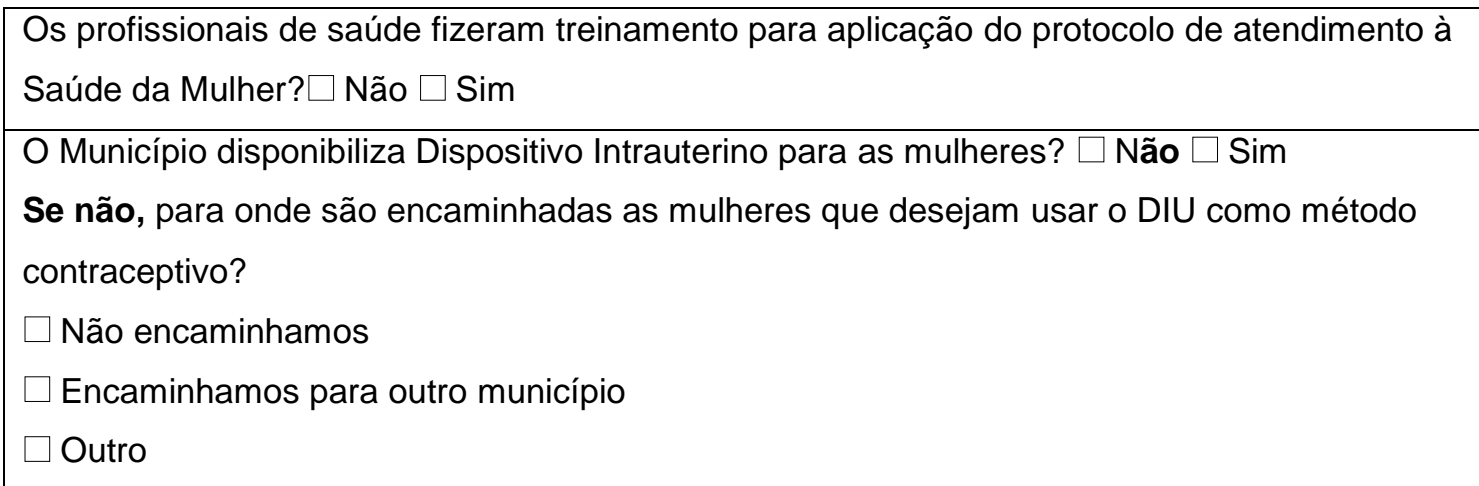

Existe protocolo específico para a disponibilização do DIU? $\square$ Não $\square \operatorname{Sim}$

Segundo o Protocolo de disponibilização do DIU ou segundo a rotina do município, quais das situações podem impossibilitar a inserção do DIU?

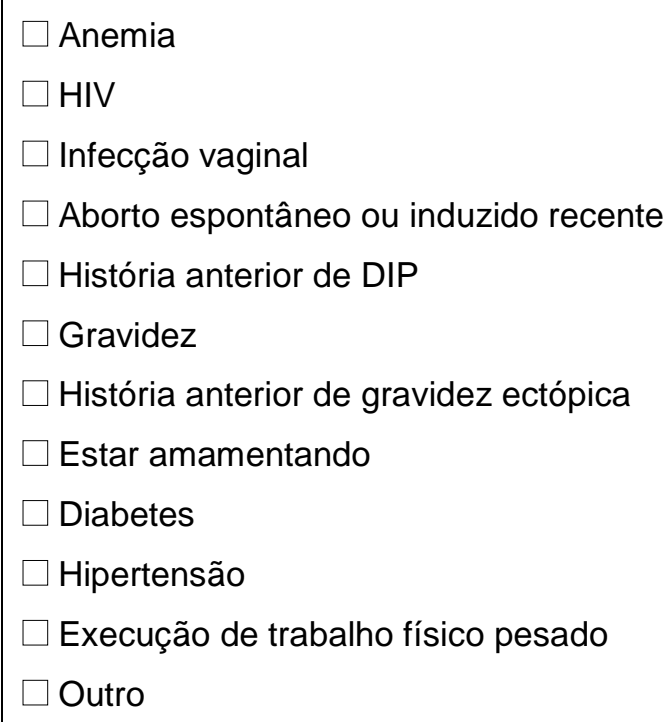

Segundo o Protocolo de disponibilização do DIU ou segundo a rotina do município, qual ou quais profissionais de saúde inserem o DIU?

$\square$ Médico ginecologista/ obstetra

$\square$ Médico generalista

$\square$ Enfermeiro obstetra

$\square$ Enfermeiro generalista

$\square$ Outro

Segundo o Protocolo de disponibilização do DIU ou segundo a rotina do município, precisa de agendamento para a inserção do DIU?

$\square$ Não

$\square \operatorname{Sim}$

Qual o tempo médio esperado pela mulher entre o dia da consulta ou o dia que ela comunica seu interesse em usar o DIU até a sua inserção?

$\square$ Menos de 1 semana

$\square$ Entre 1 e 4 semanas

$\square$ Mais de 1 mês 


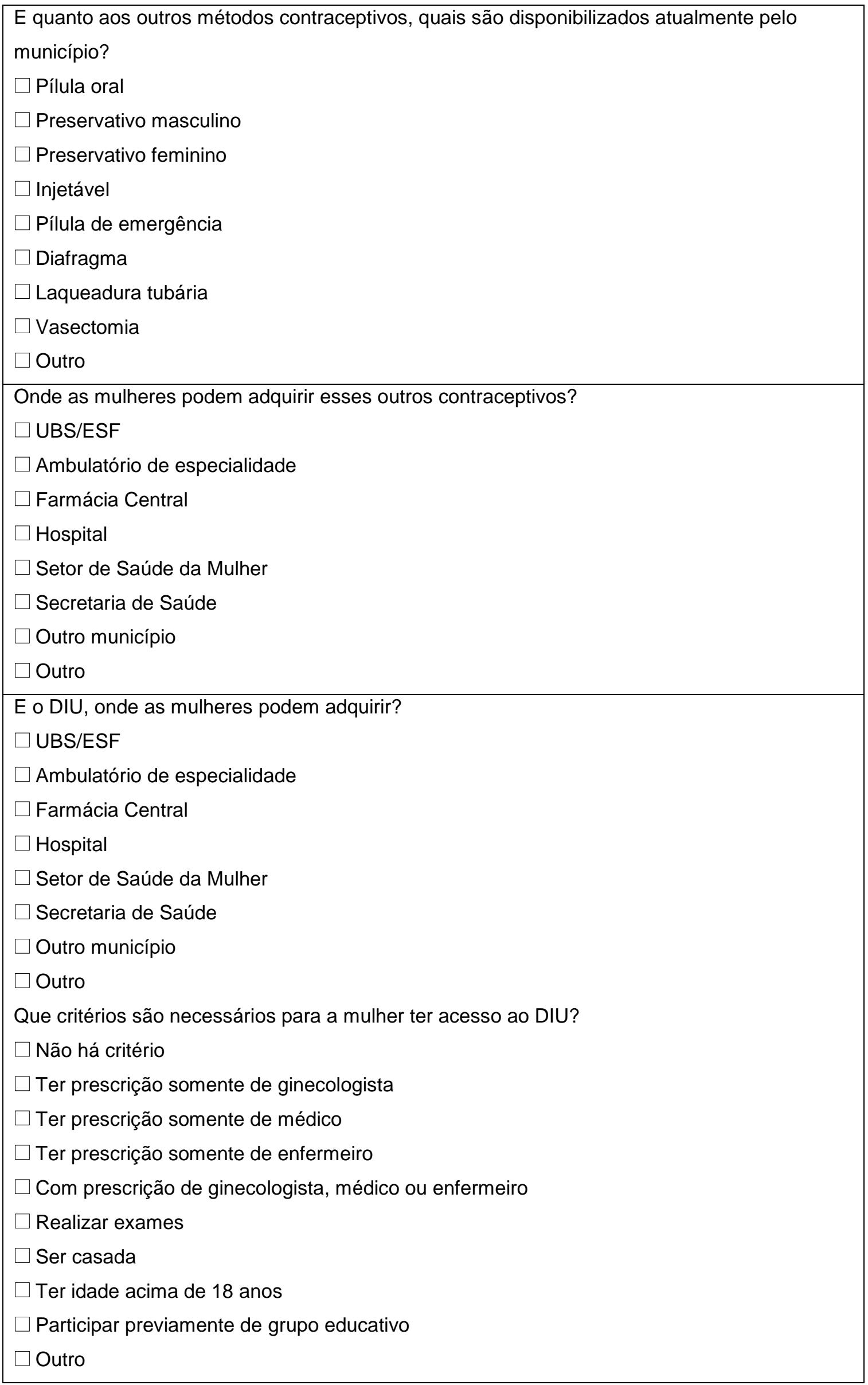




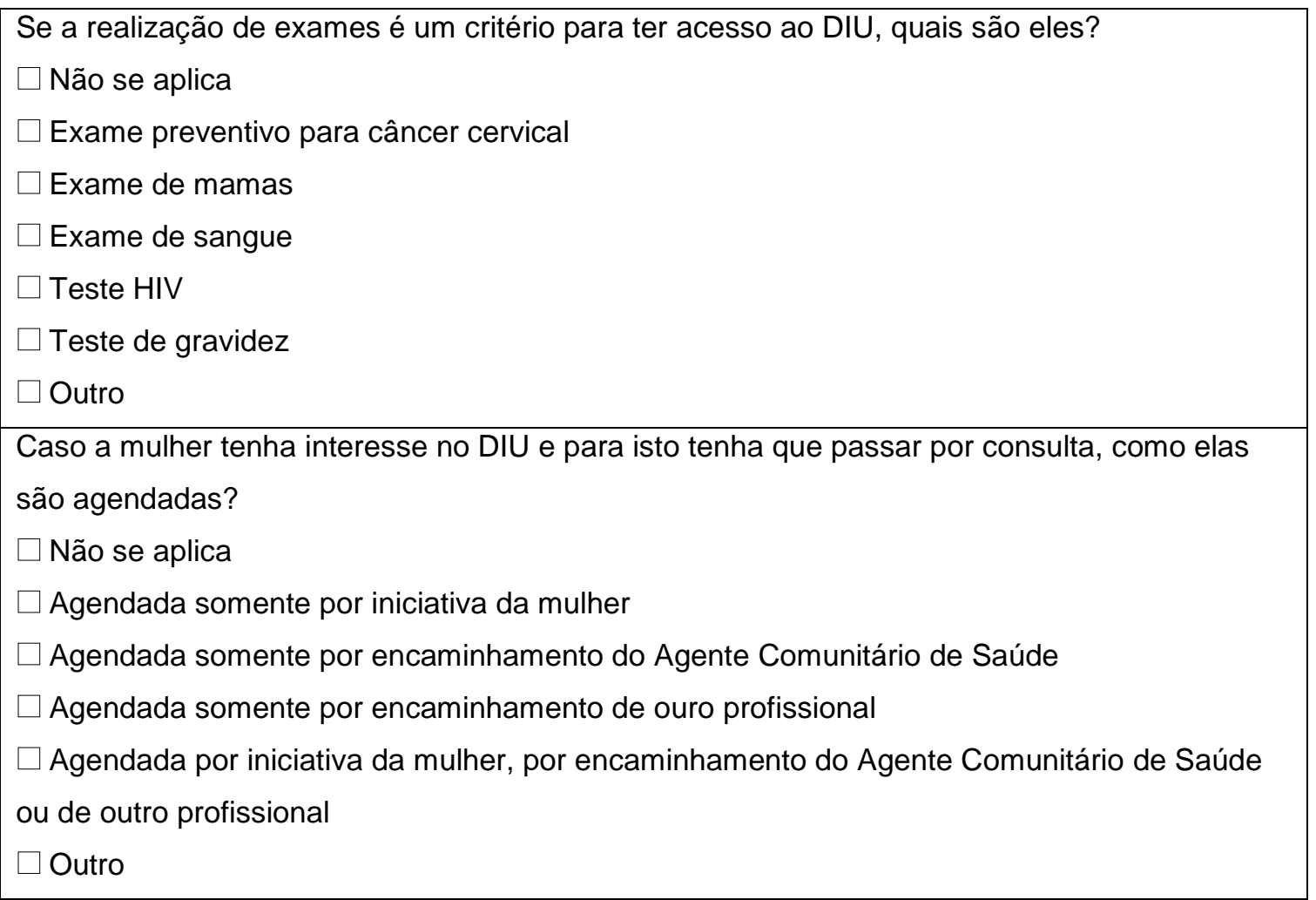

\section{Atividades educativas}

As Unidades de Saúde do município realizam grupos de planejamento familiar?

$\square$ Sim, algumas Unidades

$\square$ Sim, todas as Unidades

$\square$ Não

Em geral, quem coordena os grupos de planejamento familiar?

$\square$ Médico

$\square$ Enfermeiro

$\square$ Auxiliar de Enfermagem

$\square$ Agente Comunitário de Saúde

$\square$ Assistente Social

$\square$ Odontólogo

$\square$ Psicólogo

$\square$ Outro

Em geral, quem participa dos grupos?

$\square$ Mulheres e homens em geral, de todas as idades

$\square$ Apenas mulheres, de todas as idades

$\square$ Apenas mulheres, exceto as adolescentes

$\square$ Apenas adolescentes

$\square$ Outro

Em geral, como as pessoas são inscritas no grupo de planejamento familiar? 


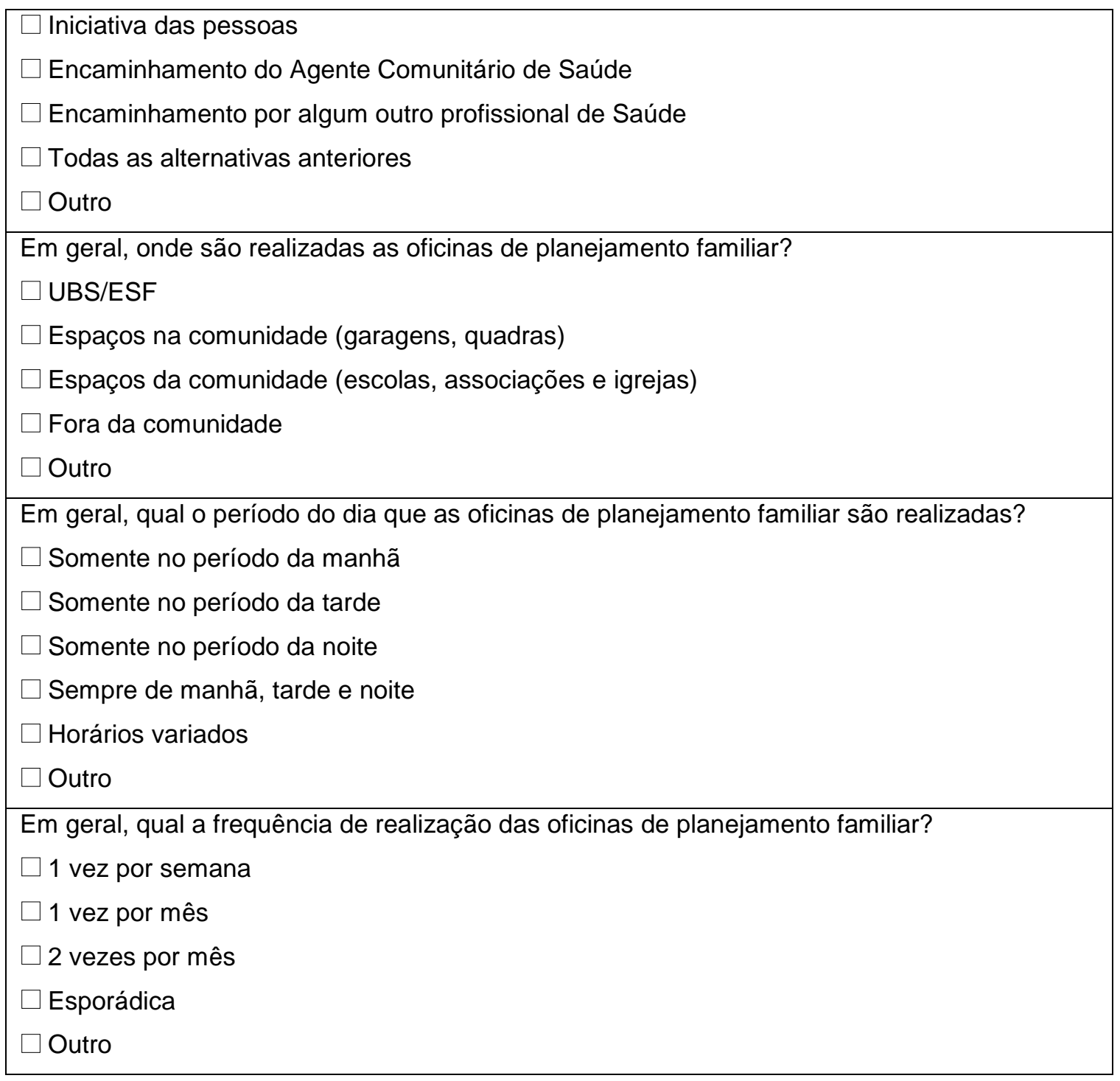

\section{Considerações dos respondentes}

\section{Você considera que as mulheres enfrentam dificuldades para obterem o DIU?}

$\square$ Não

$\square \operatorname{Sim}$

\section{Quais dificuldades?}

Você considera que as mulheres enfrentam facilidades para obterem o DIU?

$\square$ Não

$\square \operatorname{Sim}$

Quais facilidades? 


\section{APÊNDICE E - CARTA DE SOLICITAÇÃO DE AUTORIZAÇÃO ENVIADA ÀS SUPERINTENDÊNCIAS REGIONAIS DE SAÚDE DA MACRORREGIÃO SUL DE MINAS GERAIS}

São Paulo, junho de 2015.

IImo. Sr. Diretor da Superintendência Regional de Saúde (Nome)

Prezado Senhor,

Eu, Vanderléa Aparecida Silva Gonzaga, enfermeira, aluna do curso de Mestrado Profissional em Enfermagem na Atenção Primária em Saúde, no Sistema Único de Saúde, da Escola de Enfermagem da Universidade de São Paulo (USP), solicito sua autorização para realizar coleta de dados nos municípios dessa Superintendência Regional de Saúde, para a pesquisa intitulada "Barreiras Organizacionais para disponibilização do dispositivo intrauterino nos serviços de Atenção Básica à Saúde (macrorregião Sul de Minas Gerais)", que tem por objetivo geral identificar as barreiras para disponibilização do DIU nos serviços de atenção básica à saúde.

A pesquisa pretende ser realizada, por meio de entrevista online, com os coordenadores da área técnica de saúde da mulher ou com o trabalhador que saiba responder pelas práticas de disponibilização do dispositivo intrauterino nos municípios sob sua jurisdição. Esclareço que os trabalhadores serão convidados a participar da pesquisa por meio do Termo de Consentimento Livre e Esclarecido. Esclareço ainda que os dados somente serão coletados após sua autorização e que o Projeto de Pesquisa foi aprovado pelo Comitê de Ética em Pesquisa da Escola de Enfermagem da Universidade de São Paulo.

As informações obtidas somente serão utilizadas para fins de pesquisa e me comprometo a compartilhar os resultados em reunião aberta com convite para todos os trabalhadores participantes da pesquisa e outros interessados.

Aguardo sua resposta e estou disponível para maiores esclarecimentos ou sugestões que V. S. ${ }^{\text {a }}$ queira encaminhar.

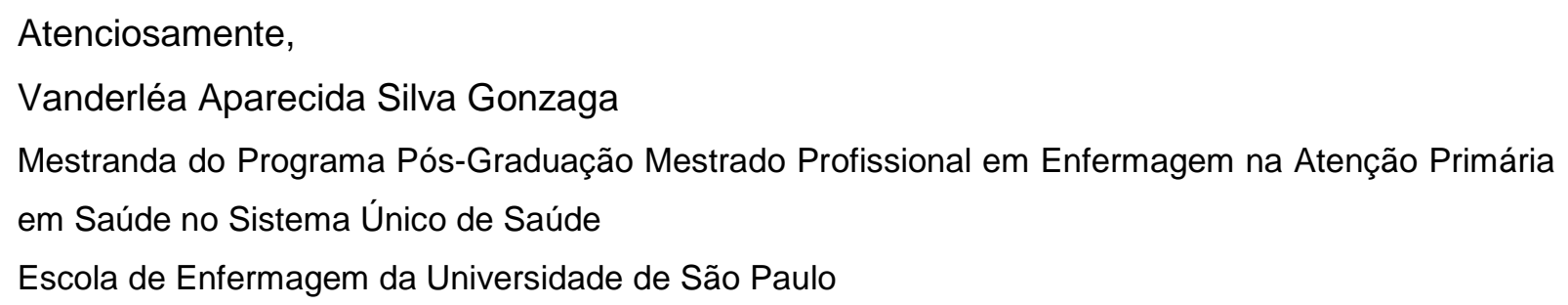




\section{APÊNDICE F - CARTA DE SOLICITAÇÃO DE AUTORIZAÇÃO ENVIADA AOS GESTORES DE SAÚDE DOS MUNICÍPIOS DA MACRORREGIÃO SUL DE MINAS GERAIS}

São Paulo, junho de 2015.

Ilmo. Sr. Secretário de Saúde (Nome)

Prezado Senhor,

Eu, Vanderléa Aparecida Silva Gonzaga, enfermeira, aluna do curso de Mestrado Profissional em Enfermagem na Atenção Primária em Saúde, no Sistema Único de Saúde, da Escola de Enfermagem da Universidade de São Paulo (USP), solicito sua autorização para realizar coleta de dados nesse município para a pesquisa intitulada "Barreiras Organizacionais para disponibilização do dispositivo intrauterino nos serviços de Atenção Básica à Saúde (macrorregião Sul de Minas Gerais)", que tem por objetivo geral identificar as barreiras para disponibilização do DIU nos serviços de atenção básica à saúde.

A pesquisa pretende ser realizada, por meio de entrevista online, com os coordenadores da área técnica de saúde da mulher ou com o trabalhador que saiba responder pelas práticas de disponibilização do dispositivo intrauterino nesse município. Esclareço que os trabalhadores serão convidados a participar da pesquisa por meio do Termo de Consentimento Livre e Esclarecido. Esclareço ainda que os dados somente serão coletados após sua autorização e que o Projeto de Pesquisa foi aprovado pelo Comitê de Ética em Pesquisa da Escola de Enfermagem da Universidade de São Paulo.

As informações obtidas somente serão utilizadas para fins de pesquisa e me comprometo a compartilhar os resultados em reunião aberta com convite para todos os trabalhadores participantes da pesquisa e outros interessados.

Aguardo sua resposta e estou disponível para maiores esclarecimentos ou sugestões que

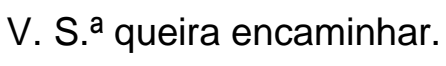

Atenciosamente,

Vanderléa Aparecida Silva Gonzaga

Mestranda do Programa Pós-Graduação Mestrado Profissional em Enfermagem na Atenção Primária em Saúde no Sistema Único de Saúde

Escola de Enfermagem da Universidade de São Paulo 


\section{APÊNDICE G - TERMO DE CONSENTIMENTO LIVRE E ESCLARECIDO}

Eu, Vanderléa Aparecida Silva Gonzaga, aluna do curso de Mestrado Profissional em Enfermagem na Atenção Primária em Saúde no Sistema Único de Saúde, da Escola de Enfermagem da Universidade de São Paulo, venho, por meio deste documento, convidá-lo(a) a participar do estudo intitulado "Barreiras Organizacionais para disponibilização do Dispositivo Intrauterino nos serviços de Atenção Básica à Saúde (macrorregião Sul de Minas Gerais)", que tem por objetivo geral identificar as barreiras para disponibilização do DIU nos serviços de Atenção Básica à Saúde.

Se consentir em participar, você será entrevistado(a) por meio de um instrumento (questionário) específico, elaborado pela pesquisadora, e enviado por e-mail. $\mathrm{O}$ preenchimento do instrumento se dará de forma online e deve durar cerca de quinze minutos. As informações obtidas estarão sob sigilo e serão utilizadas somente para fins desta pesquisa. Sua participação é voluntária e você pode recusar-se a participar do estudo ou abandoná-lo quando desejar. A participação não incorrerá em nenhum tipo de ônus para você ou qualquer prejuízo em relação ao seu trabalho, assim como não haverá nenhuma remuneração financeira caso participe. Os resultados da pesquisa serão divulgados em eventos de caráter científico e por meio de publicação e também serão apresentados em reunião - quando serão convidados todos os participantes do estudo.

Informações a respeito do estudo poderão ser solicitadas a qualquer momento. $O(a)$ senhor(a) poderá entrar em contato comigo pelo telefone (12) 98859-0943 ou por e-mail vanderlea@usp.br.

Atenciosamente,

Vanderléa

Aparecida Silva Gonzaga

Favor, clicar na opção desejada: $0 \square$ Não aceito

$1 \square$ Aceito

São Paulo, de 2015.

Para maiores informações sobre este estudo, entre em contato com: Comitê de Ética em Pesquisa da Escola de Enfermagem da USP. E-mail: edipesq@usp.br. Telefone: (11) 3061-7548. Endereço: Av. Dr. Enéas de Carvalho Aguiar, 419 - 05403-000 - São Paulo - SP. 
ANEXOS 



\section{ANEXOS}

\section{ANEXO 1- PARECER CONSUBSTANCIADO DO COMITÊ DE ÉTICA EM PESQUISA DA ESCOLA DE ENFERMAGEM DA UNIVERSIDADE DE SÃO PAULO}

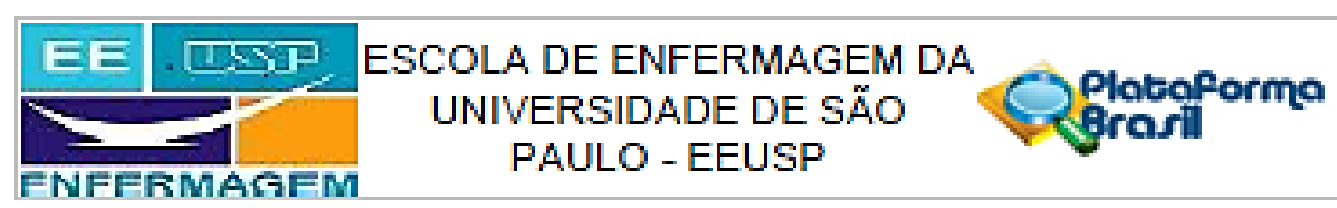

\section{PARECER CONSUBSTANCIADO DO CEP}

DADOS DO PROJETO DE PESQUISA

TItulo da Pøgqulsa: BARREIRAS ESTRUTURAIS PARA DISPONIBILIZACRO DO DISPOSITIVO INTRAUTERINO NOS SERVICOS DE ATENCAÓ BASICA A SAUDE (MACRORREGIAO SUL DE NINAS GERAIS).

Peequisador: Vanderlea Apareclda Silva Gorzaga

Area Tematica:

Versac: 1

CAAE: 43172015.3 .0000 .5392

Institulçso Proponente: Escoia de Enfermagem da USP

Patrocinador Principal: Financlamento Proprio

DADOS DO PARECER

Nümero do Parecer: 1.212 .779

Apresentaça do Projeto:

O cojeto de estudo trata da dsponibilizaç5o do DIU nos serviços de Atençáo Basica a Saúde dos munic|plos da macrorreglâs sul de Minas Gerals (4 cldades), na perspectva do quadro teorco da saude Sexual e Reproduttva. Para tanto utilza metodologla claselficada como quantititiva, de natureza descittiva. A amostra total de acesso e de 152 trabahadores responsavels pela area tecnlca de saode da mulher ou que salbam responder pelas praticas de dlsponibilizaç5o do DIU.

Objetivo da Pasqulsa:

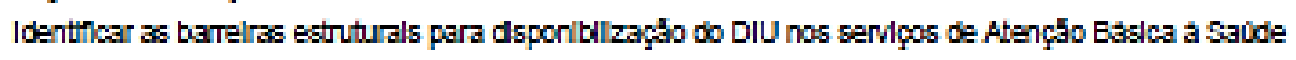

Avallaçaso dos Flscos $\theta$ Bentinclos:

Somente inscos inerentes ao modo de coleta de dados (questionario seml-estruturado, onilne, portanto, sem a presença do pesqulsador). Os dados a serem coletados năo incluem Informaçdes pessoals apenas de ordem de attvidade profssional. o estudo apresenta beneflclos no sentido de permitir reconhecer as

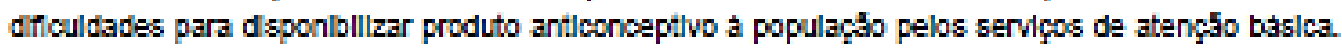

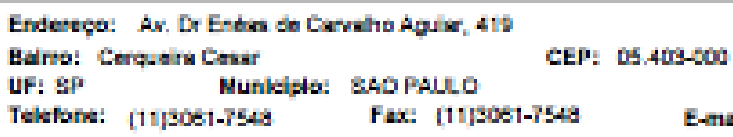




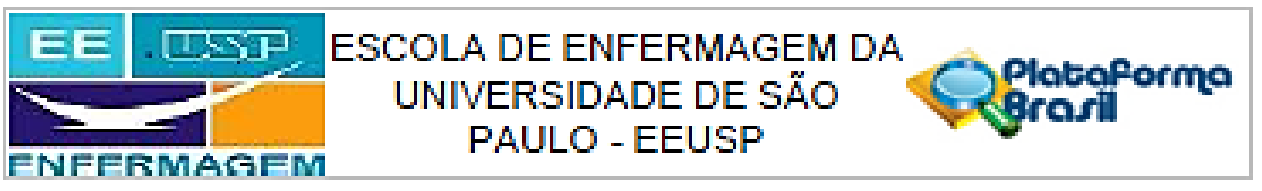

Corthackla to Pancer: $1212 \pi \%$

Comentarices $\theta$ Consideraç0s scbre a Pesqulsa:

Apresenta descriçato adequada dos procedmentos de coleta de dados (entrevist3s semlestuturad3s, por e mal, para preenchimento online). O Instrumento, elaborado pela propria pesquisadora consta de 5 biocos ((1. caracteristicas do questionario; 2 . caracteristicas do municiplo e unidades de saude; 3 . pernl do pronssional respondente; 4. Experiencia, capacitaçăo e trelnamento em contracepç5̆o, existencla de protocolo na atenç5̆o a saude da mulher e trelnamento e capacitaçấ dos profissionals de saude para utllizaçăso desse protocolo; 5 . attvidades de atençấ a saude da mulher, como a oferta de metodos contraceptlvos, especialmente o DIU, consultas e attvidades educativas)

Consideraços sobre os Termos de apresentaçăo obrigatorla:

Antes da coleta de dados propriamente dita, o projeto sera apresentado as SRS, para autortzaçăo da pesquisa e para aquisiçăo dos e-mals dos participantes. A explcaçấ sotre a pesquisa ocorrera por melo das SRS para todos 06 municiplos. Em relaç5o a TCLE, o projeto esciarece que tambem sera enviado por emal. O termo do TCLE Informa que a partcipaça dos profissionals sera de llvre iniclativa, e tara parte dos dados somente apos envio do mesmo com assinatura de acelte. Consta tambem que as Informaçbes estarâo sob siglo e serâo ưllizadas somente para fins de pesqulsa, a participaçăo e voluntarla, sendo possivel recusar a particlpar ou abandonar quando desejar. A participaç5̆o n55o incorrera em nenhum tipo de onus para voce ou qualquer prejulzo em relaçâo a seu trabalho, assim como nấo havera nenhuma remuneraça financelra caso participe. 06 resultados da pesquisa serdo divulgados em eventos de carater clentinco e por melo de publicaç5̆o e tambem serdేo apresentados em reurlaేo - quando serăo convidados todos 05 particlpartes do estudo.

Recomendaços:

N55o ha.

Conclusbes ou Pendenclas $\theta$ Llata de Inadequsçoes:

Aprovado

Consideraçses Flnals a criterio do CEP:

Este CEP Informa a necessidade de reglstro dos resultados parcials e tnals na Platafomna Brasil.

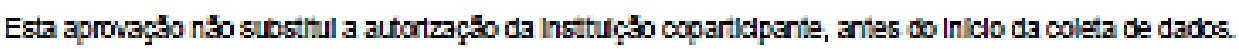

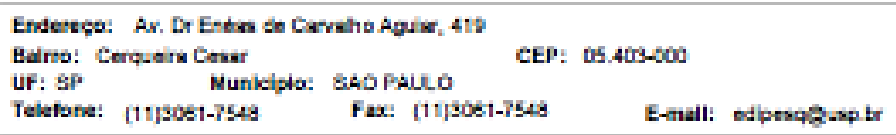




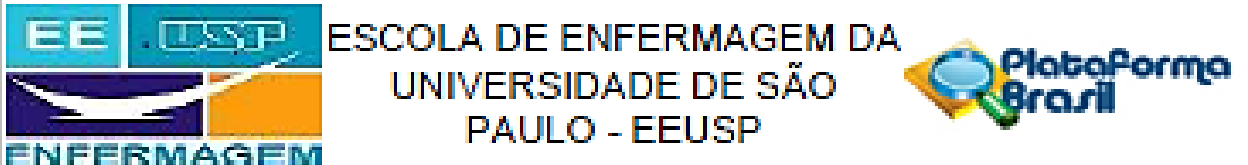

Corthachla to Pancer: $1212 \pi$

Este parecer fol elaborado bsesado nos documentos abslxo relacionados:

\begin{tabular}{|c|c|c|c|c|}
\hline Tlpo Documento & Arquivo & Postagem & Alfor & Situaç50 \\
\hline $\begin{array}{l}\text { TCLE/ Termos de } \\
\text { Assentimento / } \\
\text { Justulicativa de } \\
\text { ALLEencla }\end{array}$ & $\begin{array}{l}\text { Temo de Consentimento Lve e } \\
\text { Esclarecido.docx }\end{array}$ & $\begin{array}{l}0906 / 2015 \\
11: 03: 35\end{array}$ & & Acerio \\
\hline $\begin{array}{l}\text { Fojeto Detalhado } / \\
\text { Erochura } \\
\text { Investloador }\end{array}$ & $\begin{array}{l}\text { PFOJETO OFICIAL WESTRADO } \\
\text { WORD. DळX }\end{array}$ & $\begin{array}{l}09062015 \\
11: 07: 59\end{array}$ & & ACR \\
\hline Fotha de Fosto & Folha rosto Platiaforma Brasl.pdf & $\begin{array}{c}0908 / 2015 \\
10: 59: 12 \\
\end{array}$ & & Acelto \\
\hline $\begin{array}{l}\text { Informaçes Basicas } \\
\text { do Proleto }\end{array}$ & $\begin{array}{l}\text { PB INFOFMACOES BASICAS_DO_P } \\
\text { RODETO } 507104 \text {.pf }\end{array}$ & $\begin{array}{l}0908 / 2015 \\
11: 09: 10\end{array}$ & & Acelto \\
\hline
\end{tabular}

stuaçaso do Parecer:

Aprovado

Necosalta Apreciaço da CONEP:

Nă

SAO PAULO, 02 de Setembro de 2015

Assinado por:

Marcolo Jose dos Santos

(Coordenador)

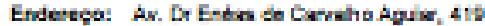

Burno: Cerquarm Conar $\quad$ CEP: 05.4063-500

UF: SP Nunicipla: BAD Pallo

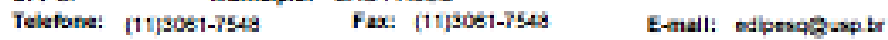




\section{ANEXO 2 - CRITÉRIOS CLÍNICOS DE ELEGIBILIDADE PARA USO DE DISPOSITIVO INTRAUTERINO COM COBRE (BRASIL, 2002)}

\section{Categoria 1 - 0 método pode ser usado sem restrições}

- 4 semanas ou mais após o parto.

- Pós-aborto (primeiro trimestre).

- Idade de 20 anos ou mais.

- Fumante (qualquer idade).

- História de hipertensão se não for possível avaliar a pressão arterial.

- Hipertensão arterial.

- História de pré-eclâmpsia.

- História de diabetes gestacional.

- Diabetes insulinodependente ou não.

- Diabetes com lesão vascular ou duração maior que 20 anos.

- Trombose venosa profunda ou embolia pulmonar atual ou no passado.

- Cirurgia de grande porte com ou sem imobilização prolongada.

- Cirurgia de pequeno porte sem imobilização.

- Varizes.

- Tromboflebite superficial.

- Doença cardíaca isquêmica atual ou passada.

- AVC.

- Hiperlipidemias.

- Doença cardíaca valvular complicada ou não.

- Cefaleia leve.

- Cefaleia grave, recorrente, incluindo enxaqueca, com ou sem sintomas neurológicos focais.

- Nódulo mamário sem diagnóstico.

- Doença mamária benigna.

- Câncer de mama atual ou no passado.

- História familiar de câncer de mama.

- Ectopia cervical.

- Neoplasia intraepitelial cervical.

- Sangramento vaginal irregular não volumoso.

- Doença inflamatória pélvica no passado, sem fatores de risco para DST, com gravidez subsequente. 
- Doença biliar sintomática ou assintomática.

- História de colestase relacionada à gravidez ou ao uso de anticoncepcional oral combinado.

- Hepatite viral aguda.

- Portador assintomático de hepatite viral.

- Cirrose hepática compensada ou descompensada.

- Tumor hepático benigno ou maligno.

- Antecedente de gravidez ectópica.

- Obesidade.

- Tireoidopatias (bócio simples, hipertireoidismo, hipotireoidismo).

- Epilepsia.

- Esquistossomose não complicada ou com fibrose hepática.

- Malária.

- Uso de rifampicina, griseofulvina e anticonvulsivantes (fenitoína, carbamazepina, barbituratos, primidona).

- Outros antibióticos.

- Multiparidade.

- Tuberculose não pélvica.

- Tumores ovarianos benignos (inclusive cistos).

- Cirurgia pélvica no passado.

\section{Categoria 2 - O método pode ser usado com restrições}

As vantagens geralmente superam riscos possíveis ou comprovados. Se a mulher escolhe esse método, um acompanhamento mais rigoroso pode ser necessário:

- Menos de 48 horas pós-parto (lactante ou não) - Há aumento do risco para expulsão do DIU.

- Pós-aborto no segundo trimestre - Há alguma preocupação sobre o risco de expulsão após aborto no segundo trimestre.

- Menarca, até os 20 anos - Há aumento do risco de expulsão em mulheres jovens devido à nuliparidade.

- Doença cardíaca valvular complicada (hipertensão pulmonar, risco de fibrilação atrial, história de endocardite bacteriana subaguda, uso de anticoagulação) - É aconselhável o uso de antibioticoprofilaxia antes da inserção, se a mulher não está usando antibióticos regularmente. 
- Sangramento vaginal inexplicado (para continuação do uso) - Não é necessário remover o DIU antes da avaliação.

- Câncer de colo uterino (aguardando tratamento, para continuação de uso).

- Câncer de ovário ou de endométrio.

- Passado de doença inflamatória pélvica, sem fatores de risco atuais para DST e sem gravidez subsequente - Risco atual para as DST e o desejo de gravidez são fatores que indicam a remoção do método.

- Vaginite sem cervicite purulenta

- Mioma uterino - Miomas uterinos pré-existentes podem distorcer a cavidade uterina e dificultar o correto posicionamento do DIU.

- Talassemia - O DIU pode aumentar a perda sanguínea

- Nuliparidade - Nuliparidade está associada com aumento do risco para expulsão.

- Alterações anatômicas que não distorcem a cavidade uterina ou não interferem com a inserção do DIU (incluindo estenose ou lacerações de colo).

- Dismenorreia grave - Pode haver aumento da dismenorreia.

- Endometriose.

\section{Categoria 3 - É o método de última escolha}

Os riscos possíveis e comprovados superam os benefícios do método. Caso seja escolhido, um acompanhamento rigoroso se faz necessário:

- 48 horas a 4 semanas após o parto - Existe aumento do risco de perfuração uterina.

- Risco aumentado para DST - Existe aumento do risco para doença inflamatória pélvica. HIV positivo ou AIDS - Existe aumento do risco para DST e doença inflamatória pélvica devido à supressão da resposta imunológica; além disso, o DIU de cobre aumenta a perda sanguínea.

- Doença trofoblástica gestacional benigna.

- Sangramento volumoso prolongado.

- Anemia ferropriva - O DIU pode aumentar perda sanguínea.

- Anemia falciforme - O DIU pode aumentar perda sanguínea.

\section{Categoria 4 - 0 método não deve ser usado}

- Gravidez.

- Sepsis puerperal.

- Após aborto séptico. 
- Sangramento vaginal inexplicado (para iniciar o uso) - Se há suspeita de gravidez ou alguma condição médica subjacente, deve-se investigar e reavaliar a indicação do método.

- Câncer de colo uterino (aguardando tratamento) - Pode aumentar o risco para infecção e sangramento durante a inserção; o DIU deve ser removido por ocasião do tratamento.

- Câncer de ovário ou de endométrio - Pode aumentar o risco para infecção, perfuração e sangramento durante a inserção; o DIU deve ser removido por ocasião do tratamento.

- Doença inflamatória pélvica atual ou nos últimos 3 meses (para iniciar o uso) - O DIU aumenta muito o risco de doença inflamatória pélvica para essas mulheres.

- Doença sexualmente transmissível atual ou nos últimos 3 meses, incluindo cervicite purulenta - O DIU aumenta muito o risco de doença inflamatória pélvica para essas mulheres.

- Doença trofoblástica gestacional maligna - Pode aumentar o risco de perfuração uterina; não há dados que associam o DIU à recorrência de malignidade da doença.

- Alterações anatômicas que distorcem a cavidade uterina - O correto posicionamento do DIU na cavidade uterina pode ser impossível.

- Tuberculose pélvica - Existe aumento do risco para infecção secundária e sangramento. 


\section{ANEXO 3 - CRITÉRIOS CLÍNICOS DE ELEGIBILIDADE PARA USO DE DISPOSITIVO INTRAUTERINO COM LEVONORGESTREL (BRASIL, 2002)}

\section{Categoria 1 - 0 método pode ser usado sem restrições}

- 4 semanas ou mais após o parto.

- Pós-aborto (primeiro trimestre).

- Idade de 20 anos ou mais.

- Fumante (qualquer idade).

- Hipertensão arterial leve ou moderada: PA 140-159/90-99 e PA 160-179/100-109.

- História de pré-eclâmpsia.

- História de diabetes gestacional.

- Trombose venosa profunda ou embolia pulmonar atual ou no passado.

- Cirurgia de grande porte com ou sem imobilização prolongada.

- Cirurgia de pequeno porte sem imobilização.

- Varizes.

- Tromboflebite superficial.

- Doença cardíaca valvular não complicada.

- Cefaleia leve.

- Sangramento irregular não volumoso.

- Sangramento irregular volumoso e prolongado (para iniciar o uso).

- Doença mamária benigna.

- História familiar de câncer de mama.

- Ectopia cervical.

- Doença inflamatória pélvica no passado, sem fatores de risco para DST, com gravidez subsequente.

- Doença biliar sintomática ou assintomática.

- História de colestase relacionada à gravidez.

- Portador assintomático de hepatite viral.

- Antecedente de gravidez ectópica.

- Obesidade.

- Tireoidopatias (bócio simples, hipertireoidismo, hipotireoidismo).

- Talassemia.

- Anemia falciforme.

- Anemia ferropriva. 
- Epilepsia.

- Esquistossomose não complicada ou com fibrose hepática.

- Malária.

- Uso de rifampicina, griseofulvina e anticonvulsivantes (fenitoína, carbamazepina, barbituratos, primidona).

- Outros antibióticos.

- Multiparidade.

- Dismenorreia grave.

- Endometriose.

- Tuberculose não pélvica.

- Tumores ovarianos benignos (inclusive cistos).

- Cirurgia pélvica no passado.

\section{Categoria 2 - O método pode ser usado com restrições}

As vantagens geralmente superam riscos possíveis ou comprovados. Se a mulher escolhe esse método, um acompanhamento mais rigoroso pode ser necessário:

- Pós-aborto no segundo trimestre - Há alguma preocupação sobre o risco de expulsão após aborto no segundo trimestre.

- Menarca até 20 anos - Há aumento do risco de expulsão em mulheres jovens devido à nuliparidade.

- História de hipertensão onde não é possível aferir a pressão arterial.

- Hipertensão arterial grave: 180+/110+ ou com doença vascular - Existe preocupação com o risco potencial do efeito hipoestrogênico e a diminuição do HDL-colesterol com o uso do DIU-LING.

- Diabetes insulinodependente ou não.

- Diabetes com lesão vascular, neuropatia, retinopatia, nefropatia ou duração maior que 20 anos - O DIU-LING pode alterar o metabolismo lipídico e de carboidratos.

- Doença cardíaca isquêmica atual ou passada (para iniciar o uso) - Existe preocupação com o risco potencial do efeito hipoestrogênico e a diminuição do HDL-colesterol com o uso do DIU-LING.

- $\quad$ AVC - Existe preocupação com o risco potencial do efeito hipoestrogênico e a diminuição do HDL-colesterol com o uso do DIU-LING.

- Hiperlipidemias.

- Doença cardíaca valvular complicada (hipertensão pulmonar, risco de fibrilação atrial, história de endocardite bacteriana subaguda, uso de anticoagulação) - É aconselhável o 
uso de antibioticoprofilaxia antes da inserção, se a mulher não está usando antibióticos regularmente.

- Cefaleia grave, recorrente, incluindo enxaqueca, com ou sem sintomas neurológicos focais - Pode haver piora da cefaleia.

- Sangramento volumoso e prolongado - O DIU-LING pode provocar sangramento irregular, principalmente nos 3-6 primeiros meses de uso; a quantidade da perda sanguínea é reduzida.

- Sangramento vaginal inexplicado (para continuação do uso) - Não é necessário remover o DIU antes da avaliação.

- Nódulo mamário sem diagnóstico.

- Neoplasia intraepitelial cervical - Existe alguma preocupação sobre a possibilidade de progressão do NIC com o uso do DIU-LING.

- Câncer de colo uterino (aguardando tratamento, para continuação de uso).

- Câncer de ovário ou de endométrio.

- Passado de doença inflamatória pélvica, sem fatores de risco atuais e sem gravidez subsequente - O risco atual de DST e o desejo de gravidez são fatores relevantes na escolha do método.

- Vaginite sem cervicite purulenta.

- HIV positivo.

- História de colestase relacionada ao uso de anticoncepcional oral combinado.

- Cirrose leve (compensada).

- Mioma uterino - Miomas uterinos pré-existentes podem distorcer a cavidade uterina e dificultar o correto posicionamento do DIU.

- Nuliparidade - Nuliparidade está associada com aumento do risco para expulsão.

- Alterações anatômicas que não distorcem a cavidade uterina ou não interferem com a inserção do DIU (incluindo estenose ou lacerações de colo).

\section{Categoria 3 - Método de última escolha}

Os riscos possíveis e comprovados superam os benefícios do método. Caso seja escolhido, um acompanhamento rigoroso se faz necessário:

- Menos de 48 horas pós-parto (lactante ou não) - Não existem dados sobre os efeitos locais desse tipo de DIU sobre a involução uterina; além disso, pode haver risco de exposição do recém-nascido aos hormônios esteróides. 
- 48 horas a 4 semanas após o parto - Não existem dados sobre os efeitos locais desse tipo de DIU sobre a involução uterina; além disso, pode haver risco de exposição do recém-nascido aos hormônios esteróides.

- Doença cardíaca isquêmica atual ou passada (para continuação de uso) - Pode ocorrer redução do HDL-colesterol devido à ação hipoestrogênica.

- Câncer de mama atual ou no passado e sem evidência de doença nos últimos 5 anos.

- Risco aumentado para DST - Existe aumento do risco para doença inflamatória pélvica.

- Doença inflamatória pélvica atual ou nos últimos 3 meses (para continuação do uso) categoria $3 / 4$ - Existe aumento do risco para doença inflamatória pélvica.

- AIDS - Existe aumento do risco para DST e doença inflamatória pélvica devido à supressão da resposta imunológica.

- Hepatite viral aguda - O LING é metabolizado pelo fígado e seu uso pode agravar uma condição pré-existente; além disso, existem dúvidas se o uso de progestogênio aumenta o risco para hepatoma.

- Cirrose grave (descompensada) - O LING é metabolizado pelo fígado e seu uso pode agravar uma condição pré-existente; além disso, existem dúvidas se o uso de progestogênio aumenta o risco para hepatoma.

- Tumores hepáticos benignos e malignos - O LING é metabolizado pelo fígado e seu uso pode agravar uma condição pré-existente; além disso, existem dúvidas se o uso de progestogênio aumenta o risco para hepatoma.

- Doença trofoblástica gestacional benigna.

- Tuberculose pélvica (para continuação de uso) - Existe aumento do risco para infecção secundária e sangramento.

\section{Categoria 4 - O método não deve ser usado}

- Gravidez - Nenhum método é indicado; qualquer risco potencial é considerado inaceitável. O uso de DIU durante a gravidez aumenta bastante o risco para abortamento espontâneo e aborto séptico.

- Sepsis puerperal.

- Após aborto séptico.

- Sangramento vaginal inexplicado (para iniciar o uso) - Se há suspeita de gravidez ou alguma condição médica subjacente, deve-se investigar e reavaliar a indicação do método. 
- Câncer de mama atual (para continuação do uso) - O câncer de mama é um tumor sensível aos hormônios; é provável que o risco de progressão da doença seja menor do que com os anticoncepcionais orais combinados ou injetáveis.

- Câncer de colo uterino (aguardando tratamento) - para iniciar o uso - Pode aumentar o risco para infecção e sangramento durante a inserção; o DIU deve ser removido por ocasião do tratamento.

- Câncer de ovário ou de endométrio - Pode aumentar o risco para infecção, perfuração e sangramento durante a inserção; o DIU deve ser removido por ocasião do tratamento.

- Doença inflamatória pélvica atual ou nos últimos 3 meses (para iniciar o uso) - O DIU aumenta muito o risco de doença inflamatória pélvica para essas mulheres.

- Doença sexualmente transmissível atual ou nos últimos 3 meses, incluindo cervicite purulenta - O DIU aumenta muito o risco de doença inflamatória pélvica para essas mulheres.

- Doença trofoblástica gestacional maligna - Pode aumentar o risco de perfuração uterina; não há dados que associam o DIU à recorrência de malignidade da doença.

- Alterações anatômicas que distorcem a cavidade uterina - $O$ correto posicionamento do DIU na cavidade uterina pode ser impossível.

- Tuberculose pélvica (para iniciar o uso). 


\section{ANEXO 4 - CRITÉRIOS MÉDICOS DE ELEGIBILIDADE PARA USO DE DIU COM COBRE DA ORGANIZAÇÃO MUNDIAL DA SAÚDE (OMS, 2007)}

\section{Critérios Médicos de Elegibilidade para Uso dos DIUs com Cobre}

Faça à cliente as perguntas abaixo quanto a problemas médicos que sejam do seu conhecimento. Caso ela responda "não" para todas as perguntas, significa que ela pode colocar um DIU se assim desejar. Caso ela responda "sim" a alguma questão, siga as instruções indicadas. Em alguns casos mesmo assim ela poderá colocar um DIU. Estas perguntas também se aplicam ao DIU de levonorgestrel (ver p. 160).

I. Você deu à luz há mais de $\mathbf{4 8}$ horas e há menos de 4 semanas?

- NÃO SIM Retarde a colocação de um DIU até atingir 4 ou mais semanas depois do parto (ver Logo após o parto, p. 140).

2. Você teve uma infecção que se seguiu ao parto ou aborto?

$\square$ NÃO SIM Se ela apresentar, no momento, uma infecção dos órgãos reprodutivos durante as primeiras 6 semanas após o parto (sepsia puerperal) ou ela acaba de ter uma infecção no útero provocada por um aborto (aborto séptico), não insira o DIU. Trate ou encaminhe caso ela não tenha recebido o atendimento necessário. Ajude-a a escolher outro método ou ofereça um método de apoio.*Após o tratamento, reavalie a possibilidade de utilizar o DIU.

3. Você tem sangramento vaginal que é incomum para você?

NÃO SIM Se ela tiver sangramento vaginal inexplicável que sugira gravidez ou um problema médico subjacente, o uso de um DIU poderia dificultar o diagnóstico e o monitoramento de qualquer tratamento. Ajude-a a escolher um método a ser usado enquanto o problema estiver sendo avaliado e tratado (mas não um DIU hormonal, injetáveis só de progestógeno ou implantes). Após o tratamento, reavalie a possibilidade de utilizar o DIU.

4. Você tem alguma condição ou problema ginecológico ou obstétrico, tais como câncer genital ou tuberculose pélvica? Em caso afirmativo, quais problemas?

] NÃO I SIM Se houver conhecimento de câncer cervical, endometrial ou ovariano; doença trofoblástica gestacional; tuberculose pélvica: Não insira um DIU.Trate ou encaminhe para atendimento caso isto ainda não tenha sido feito. Ajude-a a escolher outro método. No caso de tuberculose pélvica, reavalie a possibilidade de utilizar - DIU após o tratamento.

(Continua na próxima página)

Entre os métodos de apoio estão a abstinência, preservativos masculinos e femininos, espermicidas e "coito interrompido" (retirada do pênis antes de ejacular). Diga a ela que os espermicidas e o coito interrompido são os métodos contraceptivos menos eficazes. Se possivel, forneça-lhe preservativos. 
Critérios Médicos de Elegibilidade Para Uso de DIUs com Cobre (continuação)

\section{Você tem Aids?}

$\square$ NÃO SIM Não insira um DIU se ela tiver Aids a menos que ela esteja clinicamente bem e em terapia anti-retroviral. Caso ela esteja infectada com HIV mas não tenha Aids, ela poderá usar o DIU. Se uma mulher que tem um DIU colocado desenvolver Aids, ela poderá manter o DIU (ver DIUs para Mulheres com HIV, p. 138).

\section{Avalie se ela tem risco individual muito alto de gonorréia ou clamídia.}

Mulheres que apresentam uma probabilidade individual muito alta de exposição a gonorréia ou clamídia não devem colocar um DIU (ver Avaliação de Mulheres quanto ao Risco de Doenças Sexualmente Transmissíveis, p. 138).

\section{Avalie se a cliente pode estar grávida.}

Faça à cliente as perguntas constantes na lista de verificação de gravidez (ver p. 372). Se ela responder "sim" a alguma das questões, ela poderá colocar um DIU (ver também Quando Começar, p. 140).

Para obter as classificações completas, ver Critérios Médicos de Elegibilidade para Uso de Anticoncepcionais, p. 324. Não deixe de explicar os benefícios e riscos à saúde bem como os efeitos colaterais do método que a cliente utilizará. Além disso, destaque quaisquer situações que possam tornar o método desaconselhável, quando relevante para a cliente.

\section{Uso de Critério Clínico em Casos Especiais}

Geralmente, uma mulher que apresente qualquer um dos fatores relacionados abaixo não deveria colocar um DIU. Em circunstâncias especiais, entretanto, quando outros métodos, mais apropriados, não estiverem disponíveis ou sejam aceitáveis para ela, um profissional de saúde qualificado que tenha condições de avaliar cuidadosamente a situação e as condições específicas de uma mulher poderá decidir quanto ao uso de um DIU. O profissional de saúde precisa levar em consideração a gravidade de sua condição e, na maioria das situações, se ela terá acesso a acompanhamento.

- Entre 48 horas e 4 semanas após o parto

- Doença trofoblástica gestacional não cancerígena (benigna)

- Cãncer ovariano no momento

- Apresenta risco individual muito elevado de gonorréia ou clamídia no momento da inserção

- Tem Aids, não está em terapia anti-retroviral e está clinicamente bem 


\section{Perguntas de Triagem para Exame Pélvico antes da Inserção de DIU}

Ao realizar o exame pélvico, responder às perguntas abaixo ajuda a verificar se há sinais de problemas que poderiam excluir a colocação de um DIU. Se a resposta a todas as questões for "não," então a cliente poderá colocar um DIU. Se a resposta a alguma questão for "sim," não faça a inserção do DIU.

Para as perguntas de I a 5, se a resposta for "sim," encaminhe-a para diagnóstico e tratamento conforme apropriado.Ajude-a a escolher outro método e aconselhe-a sobre o uso de preservativos caso ela enfrente risco de doenças sexualmente transmissiveis (DSTs). Forneça-lhe preservativos, se possivel. Se for confirmada uma DST ou doença inflamatória pélvica (DIP) e ela ainda queira um DIU, o mesmo poderá ser colocado assim que ela tiver alta do tratamento, caso ela não ofereça risco de reinfecção antes da inserção.

\section{Há algum tipo de úlcera na vulva, vagina ou cérvix?}

- NÃO I SIM Possibilidade de DST.

2. A cliente sente dor na parte inferior do abdômen quando move o cérvix?

] NÃO I SIM Possibilidade de DIP.

3. Há sensibilidade no útero, ovários ou nas trompas (sensibilidade nos anexos)?

\NÃO 」 SIM Possibilidade de DIP.

4. Há descarga cervical purulenta?

$\checkmark N A ̃ O$ SIM Possibilidade de DST ou DIP.

5. O cérvix sangra com facilidade quando se toca nele?

¿ NÃO SIM Possibilidade de DST ou câncer cervical.

6. Há alguma anormalidade anatômica da cavidade uterina que impeça a correta inserção do DIU?

- NÃO SIM Se houver uma anormalidade anatômica que distorça a cavidade uterina, talvez não seja possível realizar a colocação adequada do DIU.Ajude-a a escolher outro método.

7. Você não conseguiu determinar o tamanho e/ou a posição do útero?

J NÃO I SIM Determinar o tamanho e a posição do útero antes da inserção do DIU é fundamental para assegurar uma boa colocação do mesmo e minimizar o risco de perfuração. Caso o tamanho e a posição não possam ser determinados, não insira um DIU.Ajude-a a escolher outro método. 


\section{Dispositivos Intrauterinos para Mulheres com HIV}

- Mulheres que tenha risco de contrair ou estejam infectadas com o HIV podem, com segurança, colocar um DIU.

- Mulheres que tenham Aids, estejam em terapia anti-retroviral (ARV) e estejam clinicamente bem pode, com segurança, colocar um DIU.

- Mulheres quem tenham Aids mas não estejam em terapia ARV ou que não estejam clinicamente bem não devem colocar o DIU.

- Caso uma mulher desenvolva Aids durante o tempo em que esteja utilizando um DIU, o mesmo não precisa ser removido.

- As usuárias de DIU com Aids devem ser monitoradas quanto a doença inflamatória pélvica.

- Incentive as mulheres a utilizarem preservativos juntamente com o DIU. Quando usados de maneira consistente e correta, os preservativos ajudam a prevenir a transmissão do HIV e de outras DSTs.

\section{Avaliação de Mulheres quanto ao Risco de Doenças Sexualmente Transmissíveis}

Uma mulher que tenha gonorréia ou clamídia no momento não deve colocar um DIU. O fato de ela ter doenças sexualmente transmissíveis (DSTs) quando da colocação do DIU poderá aumentar o risco de doença inflamatória pélvica. Contudo, estas doenças podem ser de difícil diagnóstico clínico, e os testes laboratoriais confiáveis levam muito tempo, são caros e, freqüentemente, não estão disponíveis. Não havendo sinais clínicos ou sintomas e sem os testes laboratoriais, o único indício de que uma mulher possa ter uma DST é verificar se seu comportamento ou situação de vida a coloca em risco individual muito elevado de contrair uma infecção. Se o risco indiividual da cliente é muito alto, de modo geral não se deve colocar um DIU nela. $\neq$ (As taxas locais de prevalência de DSTs não são base para se avaliar o risco individual.)

Não há um conjunto universal de perguntas que possam determinar se uma mulher apresenta risco individual muito elevado de contrair gonorréia e clamídia. Ao invés de fazer perguntas, os profissionais de saúde pode conversar com a cliente sobre comportamentos pessoais e situações na comunidade que levam, com maior probabilidade, a expor as mulheres às DSTs.

\section{Medidas a tomar:}

1. Diga à cliente que uma mulher que enfrenta risco individual muito alto de contrair algumas DSTs, de modo geral, não deve colocar um DIU.

₹ Por sua vez, se a situação de uma usuária atual de DIU se alterar e ela se encontrar em risco individual muito elevado de pegar gonorréia ou clamídia, ela pode continuar utilizando seu DIU. 
2. Peça a mulher para avaliar seu próprio risco e considerar se ela deve colocar um DIU.A própria mulher é, freqüentemente, o melhor juiz de seu próprio risco.§ Ela não precisa falar ao profissional de saúde sobre seu comportamento ou o de seu parceiro. Os profissionais podem explicar as possiveis situações de risco que possam colocar uma mulher em risco individual muito elevado.A cliente pode refletir se tais situações ocorreram recentemente (mais ou menos nos últimos 3 meses). Sendo assim, ela pode ter uma DST no momento e talvez ela queira escolher um método diferente do DIU. Dentre as possiveis situações de risco estão:

- Um parceiro sexual tem sintomas de DST tais como pus saindo do pênis, dor ou ardência ao urinar ou uma ferida aberta na área genital

- Ela ou um parceiro sexual foi diagnosticado com DST recentemente

- Ela teve mais de um parceiro sexual recentemente

- Ela tem um parceiro sexual que teve relação com outras pessoas recentemente

Além disso, o profissional de saúde pode mencionar outras situações de alto risco que existam naquela localidade.

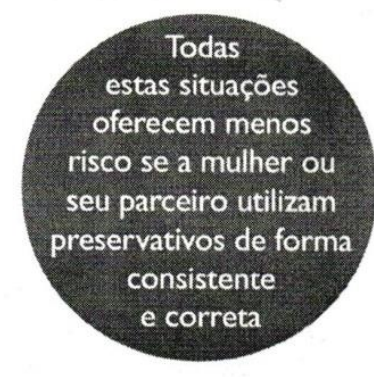

3. Pergunte se ela acha que cumpre os requisitos para colocar DIU ou se gostaria de considerar a possibilidade de usar outros métodos anticoncepcionais. Se, após refletir sobre seu risco individual, ela achar que atende aos requisitos e estiver apta, forneça a ela um DIU. Se ela quiser considerar outros métodos ou caso se tenha fortes motivos que levem a crer que ela apresenta risco individual muito elevado de contrair uma infecção, ajude-a a escolher outro método.

Observação: Se ela ainda assim quiser colocar o DIU mesmo tendo risco individual muito alto de contrair gonorréia e clamídia e houver testes confiáveis à disposição, pode-se colocar o DIU numa mulher cujos testes sejam negativos. Uma mulher com resultado positivo pode colocar um DIU assim que tiver alta do tratamento, se não tiver risco de reinfecção no momento da inserção.

Em circunstâncias especiais, se não houver outros métodos, mais apropriados, ou se eles não forem aceitáveis, o profissional de saúde em condições de avaliar cuidadosamente as condições e a situaçăo especifica de uma mulher poderá decidir que uma mulher em risco individual muito alto possa colocar o DIU mesmo se não houver testes de DST disponiveis. (Dependendo das circunstâncias, o profissional poderá considerar presuntivamente tratá-la com uma dose integral curativa de antibióticos eficazes tanto contra gonorréia quanto contra clamidia e colocar o DIU depois que ela terminar o tratamento.)

Independente dela receber ou não tratamento presuntivo, o profissional de saúde deverá assegurar-se que a cliente possa retornar para a consulta de acompanhamento, que ela será cuidadosamente examinada para verificar se há infecção e que a mesma será tratada imediatamente, se necessário. Deve-se solicitar que ela retorne imediatamente caso desenvolva uma febre e/ou dor na parte inferior do abdômen ou descarga vaginal anormal, ou ambas.

${ }^{5}$ Qualquer mulher que ache que possa ter uma DST deve procurar atendimento imediatamente 


\section{ANEXO 5 - CRITÉRIOS MÉDICOS DE ELEGIBILIDADE PARA USO DE DIU COM LEVONORGESTREL DA ORGANIZAÇÃO MUNDIAL DA SAÚDE (OMS, 2007)}

\section{Só os capítulo 10 pontos: Essenciais \\ Dispositivo Intrauterino com Levonorgestrel}

\section{Pontos Básicos para Profissionais de Saúde e} Clientes

- Proteção de longo prazo contra gravidez. Muito eficaz por 5 anos, sendo imediatamente reversível.

- É colocado no útero por um profissional especificamente treinado para tal.

- Pouca ação requerida da cliente uma vez que o DIU.LNG tenha sido colocado.

- Mudanças na menstruação são comuns. Tipicamente, sangramento de menor intensidade e menos dias de menstruação, menstruação ocasional ou irregular.

\section{O Que É o Dispositivo Intrauterino com}

\section{Levonorgestrel?}

- O dispositivo intrauterino com levonorgestrel (DIU- LNG) é um dispositivo plástico em forma de $T$ que libera constante e regularmente pequenas quantidades de levonorgestrel por dia. (O levonorgestrel é um progestógeno largamente utilizado em implantes e pílulas anticoncepcionais orais.)

- Um profissional de saúde especificamente treinado para tal insere o DIU-LNG no útero de uma mulher através de sua vagina e cérvix.

- É também conhecido como sistema intrauterine de liberação de levonorgestrel, LNG-IUS, ou DIU hormonal.

- Comercializado sob a marca de Mirena.

- Funciona basicamente pela supressão do crescimento da membrana que recobre a parede da cavidade uterina (endométrio). 


\section{Quem Pode e Quem Não Pode Usar DIU com Levonorgestrel}

\section{Seguro e Adequado para Quase Todas as Mulheres}

Praticamente todas as mulheres podem usar o DIU-LNG com segurança e eficácia.

\section{Critérios Médicos de Elegibilidade para uso dos DIUs com Levonorgestrel}

Faça à cliente as perguntas de Critérios Médicos de Elegibilidade para o DIU com Cobre (ver p. 135). Também faça as perguntas quanto a problemas médicos que sejam de seu conhecimento. Se ela responder "nâo" a todas as perguntas desta seção e a todas do DIU com cobre, então ela poderá colocar um DIU-LNG se assim desejar. Caso ela responda "sim" a alguma questão, siga as instruções indicadas. Em alguns casos mesmo assim ela poderá colocar um DIU-LNG.

1. Você deu à luz há menos de $\mathbf{4}$ semanas?

$\square$ NÃO $\square$ SIM Ela poderá colocar o DIU-LNG passadas 4 semanas após - parto (ver Quando Começar, na próxima página).

2. Você tem no momento um coágulo sangüíneo em veias profundas das pernas ou pulmões?

\NÃO SIM Caso ela relate existência atual de coágulo sangüíneo (exceto coágulos superficiais), ajude-a a escolher um método sem hormônios.

3. Você tem cirrose no fígado, alguma infecção ou tumor hepático? (Os olhos ou a pele dela têm aspecto amarelo incomum?[sinais de icterícia])

- NÃO $\square$ SIM Caso ela relate doença hepática ativa grave (icterícia, hepatite ativa, cirrose aguda, tumor no fígado), não forneça o DIU-LNG.Ajude-a a escolher um método sem hormônios.

4. Você tem ou já teve câncer de mama?

$\square$ NÃO $\square$ SIM Não coloque o DIU-LNG.Ajude-a a escolher um método sem hormônios.

Para obter as classificações completas, ver Critérios Médicos de Elegibilidade para Uso de Anticoncepcionais, p. 324. Não deixe de explicar os benefícios e riscos à saúde bem como os efeitos colaterais do método que a cliente utilizará.Além disso, destaque quaisquer situações que possam tornar o método desaconselhável, quando relevante para a cliente. 


\section{Uso de Critério Clínico em Casos Especiais}

Geralmente, uma mulher que apresente qualquer um dos fatores relacionados abaixo não deveria colocar um DIU-LNG. Em circunstâncias especiais, entretanto, quando outros métodos, mais apropriados, não estiverem disponiveis ou sejam aceitáveis para ela, um profissional de saúde qualificado que tenha condições de avaliar cuidadosamente a situação e as condições específicas de uma mulher poderá decidir quanto ao uso de um DIU-LNG. O profissional de saúde precisa levar em consideração a gravidade de sua condição e, na maioria das situações, se ela terá acesso a acompanhamento.

- Menos de 4 semanas desde o parto

- Existência atual de coágulo sangüíneo em veias profundas das pernas ou dos pulmões

- Teve câncer de mama há mais de 5 anos e o mesmo não retornou

- Tumor, infecção ou doença aguda no fígado

Ver também DIU com Cobre, Uso de Critério Clínico em Casos Especiais, p. 136. 


\section{ANEXO 6 - LISTA DE VERIFICAÇÃO DE GRAVIDEZ DA ORGANIZAÇÃO MUNDIAL DA SAÚDE (OMS, 2007)}

\section{Lista de Verificação de Gravidez}

Faça à cliente as perguntas de I a 6. Tão logo a cliente responda "sim" a qualquer uma das questões, pare e siga as instruções abaixo.

\begin{tabular}{|c|c|c|c|}
\hline \multirow[t]{2}{*}{ NÃo } & & & Sim \\
\hline & \multicolumn{2}{|c|}{$\begin{array}{l}\text { (1) Você teve um bebê há menos de } 6 \text { meses, } \\
\text { você está amamentando de forma exclusive } \\
\text { ou quase e não teve nenhuma menstruação } \\
\text { desde então? }\end{array}$} & \\
\hline & \multicolumn{2}{|c|}{$\begin{array}{l}\text { (2) Você se absteve de ter relações sexuais desde } \\
\text { sua última menstruação ou parto? }\end{array}$} & \\
\hline & \multicolumn{2}{|c|}{ (3) Você teve um bebê nas últimas 4 semanas? } & \\
\hline & \multicolumn{2}{|c|}{$\begin{array}{l}\text { (4) Sua última menstruação começou nos últimos } \\
7 \text { dias (ou nos últimos } 12 \text { dias caso a cliente } \\
\text { esteja planejando utilizar um DIU)? }\end{array}$} & \\
\hline & \multicolumn{2}{|c|}{$\begin{array}{l}\text { (5) Você teve um aborto natural ou induzido nos } \\
\text { últimos } 7 \text { dias (ou nos últimos } 12 \text { dias caso a } \\
\text { cliente esteja planejando utilizar um DIU)? }\end{array}$} & \\
\hline & \multicolumn{2}{|c|}{$\begin{array}{l}\text { 6. Você tem utilizado um método } \\
\text { anticoncepcional confiável de maneira } \\
\text { consistente e correta? }\end{array}$} & \\
\hline \multicolumn{2}{|c|}{$\begin{array}{l}\text { Se a cliente respondeu } \\
\text { "não" a todas as } \\
\text { perguntas, não é possível } \\
\text { excluir a possibilidade } \\
\text { de gravidez.A cliente } \\
\text { deve esperar até sua } \\
\text { próxima menstruação } \\
\text { ou utilizar um teste de }\end{array}$} & \multicolumn{2}{|c|}{$\begin{array}{l}\text { Se a cliente respondeu } \\
\text { "sim" a pelo menos } \\
\text { uma das perguntas e } \\
\text { não apresenta sinais ou } \\
\text { sintomas de gravidez, } \\
\text { pode-se fornecer a ela o } \\
\text { método de sua escolha. }\end{array}$} \\
\hline
\end{tabular}

gravidez. 